\title{
HEIDEGGER, HOUELLEBECQ AND THE PRESENT AGE OF DISENCHANTMENT: A PHILOSOPHICAL ANALYSIS OF THE RISE OF THE FRONTE NATIONALE
}

\author{
Marcus Charlesworth
}

A thesis submitted to the Faculty of Graduate and Postdoctoral Affairs in partial fulfillment of the requirements of the degree of

\author{
Master of Arts
}

In

Political Science- Political Theory

CARLETON UNIVERSITY

OTTAWA, ONTARIO

(C)2017

Marcus Charlesworth 


\section{Table of Contents}

Acknowledgements

Introduction

Literature Review

Methodology

Division One: Science, Technology and Heideggerian Thought in Modern France Introduction: Modernity and its Malcontents

Chapter One: Man, Technology and Nature

Chapter Two: Globalisation, Equality and the Age of the World Picture

Chapter Three: Extension of the Scientific Domain

Division Two: Progressivism, Universalism and the Rejection of the Post-War Order

Introduction: The Question of Being

Chapter One: Care, Rootedness and the Critique of Universalism

Chapter Two: History, Time and the Critique of Progress

Chapter Three: Departures

Conclusions

Recapitulation

Final Reflections

Works Cited 


\section{Acknowledgements}

My greatest debt in this enterprise is, of course, to Dr. Tom Darby. Beyond his obvious contribution to the cultivation of this project; from a vague and over-ambitious global survey of all anti-liberal movements of both left and right the world over to the far more plausible, modest study that I present to you in these pages; it is also only right, at this point, to mention that it was Dr. Darby who gave me my first taste of philosophy, and opened my mind to the possibility of an understanding of the political world that transcends the bickering of partisan politics and the drudgery of federal bureaucracy. For this I must be forever grateful, as the unconcealing of the possibility of political philosophy to a person for whom such a thing was genuinely uncanny cannot be any small thing. However, as Dr. Darby enters into what we all hope will be a happy, fruitful and productive retirement, it is timely to reflect that the above story is but one of hundreds, if not thousands, of stories wherein young men and women came into Dr. Darby's orbit and had their intellectual lives irreversible, and positively, recalibrated by an encounter with a wonderful teacher and man. Thank you Tom!

Naturally I am also grateful to Dr. Waller Newell and Dr. Robert Sibley, both of whom take places on my committee and have taught me over the course of my studies but particular mention is owed to Dr. Geoffrey Kellow, who stepped in at the last moment to ensure that my defence went forward. Alongside Dr. Darby these men have provided, between them, almost the entirety of my philosophical education and as a result my debt to them cannot be satisfactorily conveyed beyond the obvious significance of the acknowledgement of this fact, and it is no small thing in itself. In addition, of course, I must thank friends and family; particularly my editors par excellence, Florence Guillot and Chris Charlesworth; who have been ever reliable for diversion and philosophical conversation throughout this process. Most of all though, I would like to end these acknowledgements by thanking my wonderful partner, Natalia Pochtaruk, who has kept me healthy in body and sound in mind throughout this project. Her kindness, compassion and decency has been an invaluable source of comfort and support, as well as a reminder of the possibility of human goodness, something that one needs reminding of when one's life becomes so deeply entangled in the worlds of Heidegger, Le Pen, Zemmour and Houellebecq. 


\section{Introduction}

In the aftermath of the collapse of the Soviet Union scholars in a multitude of disciplines engaged seriously with the possibility that this seemingly seminal event represented the end of history, the final resolution of the final great dispute over the way in which the affairs of man were to be governed. While there was not uniform agreement that history, so understood, had indeed come to its conclusion, the fact that the end of the long journey of man as a political animal from the Ancient Greek city states to this apparent homecoming in a universal "republic" of scientific reason, could so seriously be considered as having come to an end suggested at the time that the spirit of this new age may well be post-historical, post-political, post-national, post, indeed, any of those questions that had underpinned and driven the canon of Western political philosophy until that point. How strange, then, to reflect upon this belief at a time when there exists the real possibility that, at the time of writing, the UN general assembly could conceivably have hosted Presidents Trump, Le Pen and Putin alongside Prime Minister's Wilders, Orban and Dahl 1. Significantly, these figures are not mere recalcitrant malcontents from peripheral civilizations or the "bloody borders" of Islam, as Huntington expected, but come, with the possible exception of Putin, from some of the very countries that shaped modernity and the liberal project against which these figures present themselves as a radical antithesis. The emergence of such hostile enemies of post-cold war liberalism, as they variously understand it, as credible leaders of powerful, developed countries suggests that history may not be so ready to give up the ghost as was once thought; but rather that we merely find ourselves at yet another intersection in the epic journey of man, politics and the city. Down one path lies the perilous uncertainty of the chaotic rebirth of the genuinely political, down the other, depending on one's perspective, either a gentle return to the 
peace of home or a full speed collision with a finality to which we cannot be consoled. Leo Strauss, in "What is Political Philosophy?", claimed that "political philosophy is the attempt to replace opinions about political fundamentals by knowledge about them"2. In this spirit, it must fall upon political philosophy to attempt to shed light upon the truth of this contemporary phenomenon; for philosophy is directly concerned with truth and unbound from the methodological limitations of the social sciences and economics which, it will later be shown, have shaped much of the questioning of this political development. It will, simply stated, be the goal of this essay to attempt to provide a philosophical account of the rise of those movements that have come to be known as "far-right", and to show the way in which they have emerged from the very post-cold war liberalism once thought so unassailable, to renew a tradition of anti-liberalism that is, arguably, as old as the enlightenment itself.

While such movements exist in a multitude of countries both in the West and elsewhere, this paper will focus on the iteration of the "far-right" that has emerged in France. There are a number of reasons why France provides such an illuminating and illustrative case study for the study of this phenomenon. Partly, as hinted at in the preceding paragraph, because France is a crucible of the ideas that animate modern liberalism; the rationalist, liberal individualism that emerged from the French Enlightenment has certainly been accorded great importance by critics of the Enlightenment project; and it is, therefore, interesting that France should be the home of such a strong "far-right" movement. This is particularly interesting in light of Heidegger's concept of "saving power", which will be discussed later. France is also the country with the longest surviving far-right political party; the National Front [Fronte Nationale] can trace its roots at least to the Algerian War of Independence, although there are competing claims from opponents and 
supporters that its genesis lies in either the Vichy regime or the early resistance to the German occupation of France in the Second World War. It has therefore been the subject of many decades of scholarship and research, making it a rich source of information pertaining to the subject under consideration. Finally, France is a country with a deep tradition of philosophical anti-liberalism and a surprisingly direct connection between philosophical thought and political action. French philosophers are frequently present on prime-time television programmes, write books aimed at non-academic audiences, are studied by high-school children, and in some cases are directly involved with political parties and in policy-making; Bernard Henri-Levy's involvement in the Libyan intervention being the most obvious example. As a result, philosophy in France is a public exercise, and the ideas of philosophy cannot be ignored as a factor in that nations politics. This gives greater salience to a philosophical account of this phenomenon than might be possible should, for example, Hungary or the United States be made the subject of the case study. For these reasons, and for the more prosaic reason of brevity, this paper will approach it's subject by way of an engagement with the following, narrower question: What are the underlying philosophical currents that underpin the contemporary resistance to liberalism in French political thought, usually defined as the "far-right", and why are they appealing to so many?

To this end, this paper aims to explore the parallels between contemporary French antiliberal thought and the Heideggerian critique of liberal, technological modernity in order to establish that what can be observed in France is, in many but not all respects, a manifestation of the concerns and anxieties of thinkers like Martin Heidegger in a contemporary French context. While, as stated before, France has a tradition of anti-liberal philosophy as old as the enlightenment itself, it will be the contention of this paper that it's definitive influence comes from the antiglobalist particularism that is evident in Heidegger rather than the more straightforwardly Catholic 
reactionary conservatism of, to give one example from many, De Maistre. This connection will be demonstrated by highlighting the parallels and connections between Heidegger and the contemporary French novelist Michel Houellebecq. One might reasonably ask why a novelist, particularly a satirical novelist like Houellebecq, should be the subject of a questioning of a philosophical matter such as the subject of this paper. This can be answered in a number of ways. While it may seem unconventional as an approach, it is fairly intuitive that the writing of a dystopian novelist, such as Houellebecq, would reflect the concerns and anxieties that are abroad in a society at any particular time. Given that the "far-right" makes such an explicit appeal to anxieties about the status-quo, it is fairly reasonable to pursue an exploration of the philosophical and cultural factors contributing to this rise by analysing the writings of a dystopian novelist. This paper will not contend, though, that Houellebecq is a driving force behind the rise of the "farright"; a charge that is frequently and erroneously levelled against him in the French media. Rather, it will argue that the stance he adopts towards his world and the actions and thoughts of his protagonists convey the underlying concern of contemporary French anti-liberalism. Houellebecq is thus being used as a demonstrative rather than causal agent in this analysis of French antiliberalism. Much as one might reasonably look to Shakespeare to understand the mindset of the Renaissance Englishman, one can equally look to a novelist like Houellebecq to understand the disillusionment of so many contemporary Frenchmen.

This being established, this paper will undertake its task in the following way. It will begin with a review of literature that will be shown primarily to divide into two separate explanatory lenses, sociological and economic, which have dominated scholarship on this phenomenon. While the claims made by these studies will not need to be discredited, it will be shown that such approaches fail to answer fundamental questions that arise when one considers this phenomenon 
to the full extent. This will show that economic and sociological explanations, simply stated, cannot explain why the "far-right" has traction in a multitude of countries that often share little in terms of economic or sociological characteristics. It must, of course, be noted that some excellent philosophical work has been done on this subject, work that provides the foundations upon which this analysis rests, and some examples of this will be explored. This being done, the focus will then turn to the argument proper. There will be two levels upon which this analysis will be done. Division One will concern the critique of "liberal" politics against which the "far-right" is in reaction. In order to explore the connection between this critique and Heideggerian philosophy it will be necessary to engage in a close reading of some of Heidegger's more overtly polemical writings. This will focus, in the first chapter, upon Heidegger's essay on "The Question Concerning Technology". This essay will be analysed exegetically and it will be shown that Heidegger presents an interesting perspective on the relationship between technology and nature. This will be compared with the depiction of contemporary France that can be found throughout Houellebecq's oeuvre; particularly his direct critique of technology in "The Possibility of an Island" and "Extension of the Domain of Struggle" (occasionally translated as "Whatever") as well as his more esoteric critique of the setting upon of human nature in "Platform". This will show that many of Heidegger's concerns regarding technology and the way in which it mediates man's relation to the world are replicated in Houellebecq's works, suggesting that such concerns remain prominent in contemporary France. The second chapter will engage in a similar analysis of Heidegger's argument in "The Age of the World Picture" which will be compared with Houellebecq's criticisms of the leveling out of cultural particularism in the name of universal civilization, as well as his critique of the technological intellect (a critique that can also be linked directly to Heidegger's essay). Both of these will be shown to be central parts of the ideological 
shift of the National Front resulting from the transfer of power to Marine Le Pen. The third and final chapter of this part will analyse the elaboration of the concept of "entrapping-securing" and the critique of science provided in "Science and Reflection", which will be compared with Houellebecq's critique of the encroachment of scientific logos upon the world of art and will be shown to be comparable to the "far-right's" aggressive rejection of an "elitist intelligentsia" that they perceive to dominate French society as a whole. In Division Two, attention will be turned to the more fundamental critique of the foundational philosophical assumptions of modernity provided by Heidegger in "Being and Time". This will also consist of three chapters. The first will concern Heidegger's conception of "being-as-care" and his general account of the spatial rootedness of being, which will be compared to the relationship between cultural rootedness and authenticity that can be observed in "Submission". It will then be shown that a similar relationship is posited by the "far-right" in their distinction between the "Français de souche" and the "Français de papier". Secondly, Heidegger's critique of the concept of ideal forms and of historicism will be shown to represent a rejection of the "progressive" view of history, and therefore "progressivism" itself. This will be compared with the anti-progressivism of Houellebecq and contrasted with the more vulgar reactionary traditionalism of the "far-right". Finally, this part will conclude with two important departures from Heideggerian thought that can be observed when one compares "Being and Time" with contemporary French anti-liberalism. Firstly, the ambiguity surrounding the relationship between the "they" and the Dasein will be shown to be entirely nonexistent in Houellebecq's radical misanthropy nor in the nationalism of the "far-right". And secondly, the project of authentic Dasein will be shown to have no relation to the romantic communitarianism of the "far-right". Altogether, this can be said to represent the underlying concern motivating contemporary anti-liberalism, but not the political substance of the "far-right" 
reaction. This paper will demonstrate that the case of Michel Houellebecq shows that the contemporary French "far-right", and by extension probably "far-right" politics in general, is far more than a mere reaction to immigration and economic depression, but is a continuation of a longstanding philosophical scepticism about the project of modernity; particularly technology, globalization and the "cult of progress"; and its impact on the modern world. This movement is clearly a product of a spiritual crisis in the Western world and therefore must be seen as a genuine and profound, though perhaps not productively actionable, philosophical critique of modernity and liberalism. 


\section{Literature Review}

With the rise of the French National Front being a relatively recent phenomenon, it goes without saying that there is a relatively limited amount of scholarship that has been dedicated to this subject. However, there is no doubt that academic and media actors across Europe and North America have been alarmed by the rise of "far-right' politics more generally and, as a result, an enormous amount of ink has been spilled discussing the possible reasons for this return on the part of a style of politics that was long thought to be a thing of the past. The following section of this paper will engage in a comprehensive, but not exhaustive, overview of some of this literature in order to ascertain the explanations given by both academic and popular writers for this surprising political occurrence. It will be shown that there are two dominant frames of analysis through which the rise of the "far-right", both in France and more generally, has come to be studied. The first and most prevalent of these is an economistic frame. This consists of attempting to understand the National Front as a political phenomenon that is linked directly to growing economic inequality, unemployment and wage stagnation. The second prevalent frame is a more sociologically oriented approach. This consists of the attempt to understand the "far-right" as a movement primarily rooted in racism, xenophobia and cultural protectionism. As will be shown, a lot of academic literature has explored the link between mass immigration, fear of socio-cultural change and the dislike of the foreign "other". While these frames of analysis are popular, the academic literature remains highly inconclusive with regards to the actual explanatory value of such approaches to this question. While the importance of these economic and sociological explanations is not nothing, academic literature that attempts to understand this subject through these frames tends to leave us with a confused and inconclusive picture. It appears that these factors have some influence on the rise of the "far-right" but cannot, in themselves, offer a satisfactory explanation as to why this phenomenon exists, or why it seems to be growing in significance today. As a result, this paper 
will turn towards a philosophical frame of analysis and will briefly outline some of the philosophically grounded explanations that exist in the literature. It is upon these studies that this paper will attempt to build in order to contribute to the filling of the gap that exists in the literature outside of the flawed economistic and sociological frames that dominate the literature on the subject of the National Front and its rise.

\section{Part One: National Front as Economic Phenomenon}

\section{$\underline{\text { Popular Literature }}$}

Much of the popular discussion surrounding the emergence of the National Front as a serious contender in French electoral politics is presented in economic terms. A significant part of the popular understanding of the "far-right" and the generally prevalent explanation for its rise center around the proposition that the "far-right" gains its support from those who have lost out as a result of globalization and have been left behind, in a state of economic hopelessness, while those around them have grown ever richer and more successful. Thus the support base of the "far-right" is understood as being motivated by resentment of those to whom greater benefits have been granted by "neoliberalism" or globalization3 and a desire to create a fairer distribution of the market share between "ordinary people" and a transnational elite that is increasingly detached from the concerns of ordinary people4. As the Washington Post's Whitte, Rauhala et al. put it, "far-right support is driven by anxiety over economic gains that accrue to the few and leave the rest stagnant or sinking. Unease with the cultural implications of an increasingly interconnected world. And alienation from

3 Delamaide, Darell. "French Election Shaping up to Be Another Disaster for Establishment Parties; Le Pen Bolstered by Trump and Brexit, Not to Mention Her Weak and Corrupt Opponents." Editorial. Market Watch. N.p., 18 Nov. 2016. Web. 4 Ockrent, Christine. "Trumpism, the French Way." Washington Post Online. The Washington Post, 19 Nov. 2016. Web. 
a self-serving political class that aligns with the wealthy at the expense of the working class." 5

Thus the phenomenon in question is generally understood in primarily economic terms, in terms of inequality and the distribution of the wealth generated by the expansion of free trade and economic liberalisation.

The perception that increases in inequality are the result of the liberalisation of international trade are often seen to feed into a conspiratorial narrative. Those who benefit most are considered to be part of an "establishment" or an "elite" who have rigged the economy in their favour and who set the parameters of competition in such a way as to benefit themselves to the greatest extent possible. Thus, ironically, the "far-right" is often seen as presenting itself in the traditionally leftist terms of a defence of the marginalized worker against a conspiracy of the capitalist classes and their acolytes in the institutions of power. In Der Spiegel in November 2016, Sauer, Reierman et al. present this narrative of an increasingly unequal capitalism driven by the cronyism of elites and argue that "the consequence has been a widespread feeling that the system isn't fair and that globalization primarily helps the elite and large corporations, which keep growing in size and wealth." 6 This, it is assumed, leads to an environment of resentment and anti-establishment sentiment that provides fertile ground for the movements of the "far-right". Or as Owen Jones of the Guardian puts it, "who is waiting, preparing and consolidating? Europe's far right, already feeding off the despair of economic crisis and a backlash against refugees fleeing violence from the Middle East. ... Marine Le Pen's far-right Fronte Nationale - combining anti-immigration

\footnotetext{
5 Whitte, Griff, Emily Rauhala, and Dom Phillips. "Trump's Win May Be Just the Beginning of a Global Populist Wave." Editorial. Washinton Post Online. The Washington Post, 18 Nov. 2016. Web.

6 Sauga, Michael, Christian Reierman, Alexander Jung, Christoph Pauly, Martin Hesse, Sven Boll, and Armin M-W Wagner. "Inequality, Market Chaos and Angry Voters." Der Spiegel Online International. Der Spiegel, 17 Nov. 2016. Web.
} 
politics with an audacious raid on the economic rhetoric of the left - won nearly $7 \mathrm{~m}$ votes in France ['s regional elections]."7

\section{Academic Literature}

Academic literature, however, appears to be far less conclusive in its judgments on the importance of this perception of the "far-right" as the representatives of the resentment of the economically marginalized. It is, though, undoubtedly the case that such economistic arguments are supported as partially explanatory by the literature. There are, though, a number of shortcomings that undermine this explanation. Firstly, this attitude towards "far-right" groups appears to be a little dated, "most research in the 1990s on the radical right has focused on social characteristics of voters for such parties. These voters were depicted as the losers of modernity who supported radical right parties to express resentment against immigrants and/or the political elite (e.g., Betz 1996)." 8 While this may have held true for supporters in the 1990's it is without doubt that the support base of such parties has grown in the previous two decades. Similarly, we see, in the findings of Jean Pierre Le Goff, the claim that in the wake of globalization, whole categories of the population thus found themselves in a position of precarity and disinheritance that damages their self-esteem and creates a favourable terrain for demagogy and extremism of all stripes.9 Again, while he certainly sees precarity and inequality as contributing to the rise of the "far-right", we will see later that he can only grant these factors partial causal responsibility.

Le Goff's position seems to be corroborated by the expectations of Lubbers and Scheepers going into their micro and macro level analyses of FN Voting. They hypothesised that "extreme

\footnotetext{
7 Jones, Owen. "If There Is Another Economic Crash, Europe's Far Right Is Ready for It." Editorial. The Guardian. The Guardian, 11 Feb. 2016. Web.

8 Van der Brug, Wouter, and Meindert Fennema. "Causes of voting for the radical right." International Journal of Public Opinion Research 19.4 (2007): 474-487.

9 Le Goff Jean-Pierre, « Le syndrome du Front national. Genèse d'une ascension», Le Débat 4/2011 ( $\left.n^{\circ} 166\right)$, p. 53 -

62 URL : www.cairn.info/revue-le-debat-2011-4-page-53.htm.
} 
right-wing parties emphasize this division between out-groups and in-group, and might therefore be attractive in regions where competition over scarce resources is more severe." 10 This theme is taken up by Hans-Georg Betz, according to whom, "the recent success of far right parties result from an aggregation of the post-industrial protest of parts of the working class and the new middle class. The scapegoating of immigrants appeals to a marginalized segment of the working class that suffers from unemployment, inadequate training, and poor housing conditions." 11 It is, therefore clearly the case that a significant part of the academic literature begins the questioning of this phenomenon with the expectation of finding a strong link between the economic suffering of segments of society, and the power and popularity of the "far-right". This is seen to reflect "a steady deterioration of their socio-economic position as a result of the growth of manufacturing unemployment and consequent erosion of workers' living standards over the past quartercentury."12

However, even these parts of the literature which Heidegger might accuse of begging technological, or economistic, answers by asking technological, or economistic, questions tend to report relatively unpredictable results. In the aforementioned study by Lubbers and Scheepers, where the expectation of a strong correlation was expected, they found "no direct effect of unemployment, which coincides with findings in Flanders, The Netherlands, and Germany. But, we did find a small indirect effect such that higher unemployment levels evoke a more unfavourable attitude towards ethnic outgroups, a stronger identification with France and a stronger authoritarian attitude, which in turn increase the likelihood of a vote for the Fronte

10 Lubbers, Marcel, and Peer Scheepers. "French Front National voting: a micro and macro perspective." Ethnic and Racial Studies 25.1 (2002): 120-149.

11 Veugelers, John. "Social Cleavage and the Revival of Far Right Parties: The Case of France's National Front." Acta Sociologica 40.1 (1997): 31-49. Web.

12 Goodliffe, Gabriel. (06/01/2012). The Price of Disengagement: Radical Populism in France and Germany. Journal of contemporary European studies. (20)2. p.137 - 160. 
Nationale." 13 In other words, a fairly weak and indirect relationship between economic hardship and support for "far-right" parties. These results are particularly interesting when one considers the extent to which "far-right" parties trade upon the discourse of socio-economic resentment. For example at the National Front's 2005 convention “[Jean-Marie] Le Pen's speech focused on unemployment and the failure of the present French government to ameliorate its effects. Le Pen attacked the Socialists for "30 years of disaster"-making ironic reference to the trente glorieuses - the label for the thirty years of post-war prosperity that began to decline in the 1980s. According to Le Pen, France's only hope lay in a break with the past that would lead to a "French renaissance and a new defence of workers and the French people." 14 Several years later his daughter would go on to claim that "she would renationalise agricultural policy and implement a protectionist agenda of 'economic patriotism', essentially building new factories for made-inFrance goods and imposing a 'Buy French' obligation in public procurement. She would also prioritise aid to small business and, in a clear pitch for the rural vote, she promised to halt the closure of post offices and defend the French countryside against 'the contempt of a little Parisian elite who think themselves superior" 15 This seeming contradiction leads Cochrane to the conclusion that "far-right anti-immigration political parties... play a pivotal role in forging the connection between economic misery and anti-immigrant sentiment." This leaves us with a relatively confused picture of a movement that uses economic misery to advance its anti-immigrant appeal but one that cannot allow us to claim with any authority that economic inequality and pauperization are the engines of "far-right" growth.

\footnotetext{
13 Lubbers, Marcel, and Peer Scheepers. "French Front National voting: a micro and macro perspective." Ethnic and Racial Studies 25.1 (2002): 120-149. 14 Berezin, Mabel. "Revisiting the French National Front: The Ontology of a Political Mood." Journal of Contemporary Ethnography 36.2 (2007): 129-46. Web. 15 Shields, James. "Marine Le Pen and the 'New' FN: A Change of Style Or of Substance?" Parliamentary Affairs 66.1, 2013. 179-96. Web.
} 


\section{Part Two: National Front as Sociological Phenomenon}

With the economic explanation having fallen short of achieving genuine explanatory value, it falls upon us then to turn to the second most common explanation found in popular and academic literature for the re-emergence of "far-right" politics. This is essentially a sociological claim that suggests that Western societies are increasingly threatened by the demographic and cultural change that has occurred since the fall of the Berlin wall.

\section{Popular Literature}

This is a position that was proposed by John Judis in the Guardian Newspaper in the aftermath of the surprise victory of Donald Trump in the American election of 2016. He claimed that "leaders have favoured increased immigration, only to find that American voters were up in arms about illegal immigration, and European voters were up in arms about immigrant communities they regarded as seedbeds of crime and, later, terrorism."16 In fact, analysis of the discourse of the National Front in its present incarnation, under Marine Le Pen, shows an even greater focus on this juxtaposition between cosmopolitan, post-national urban areas and the marginalized, ethnically homogenous rural periphery. Francois Hourmant made the following observation about the mood surrounding the National Front in recent years, "it's the feeling of abandonment of the rural world and the way Marine le Pen has seen her way to making herself a spokeswoman for rurality, of the forgotten. She surfs a wave of rural malaise, of exaltation for the terroir, of patriotism, of rootedness. She plays on stylised representations of the grand metropolis as a symbol of globalisation, which is stigmatised in the discourse of the National Front.17 So prevalent is this conception in political circles that former French Republican Party contender, Alain Juppe, spoke

16 Judis, John B. "Us v Them: The Birth of Populism." The Guardian. The Guardian, 13 Oct. 2016. Web.

17 Hourmant, Francois. "Le FN Capte Les Laissés Pour Compte." Le Courrier De L'Ouest. N.p., 19 Nov. 2016. Web. 
directly to this perceived social schism saying that "rural France feels "abandoned" and "disdained" by Paris"18.

Popular literature and political discourse thus can be said to place great importance on sociological explanations for the rise of the "far-right". A focus on resentment between traditionalist rural communities and metropolitan urban elites is popular both in the discourse of the Frontistes themselves and in the way in which their rise is explained and covered in the media. While such explanations are not nearly as common as economistic explanations, it is nevertheless important to review the academic literature concerning the sociological component of the rise in support of the National Front.

\section{$\underline{\text { Academic literature }}$}

Academic literature that views this phenomenon through the lens of sociology tends to focus on two particular sources for the increasing popularity of this, and other "far-right" movements. On the one hand one sees a frame of analysis that posits the "far-right" as a perceived bulwark against the "progressive" ideas that threaten the older, rural and less educated constituencies of the French Republic and on the other one sees a focus on the impact of mass immigration and the fears of cultural disinheritance that it provokes among the support base of the National Front. It will be shown that, as with economistic explanations, both of these are popular lenses of inquiry among academics studying this phenomenon but, once again, the academic literature is inconclusive and appears to establish only a limited explanatory value to these sociological explanations.

18 Nossiter, Adam. "An Unlikely Contender Rises in France as the Antithesis of Trump." The New York Times 18 Nov. 2016: n. pag. Print. 


\section{$\underline{\text { Traditionalism }}$}

Academic analysis of the FN will often focus on the traditionalist conservatism of some of their anti-establishment appeal. For example, FN opposition to "progressive" sexual mores and their generally pro-family stance are often taken as evidence of an underlying conservatism in the movement. According to Kauffmann, "the National Front based a large part of its campaigning on the defence of traditional values. It denounces the "madness of libertine pedagogy, the "pornophilia" that masquerades as sex education (from "Le sens de Notre Combat"), the establishment minority's obsession with abortion and the promotion of sexual heterodoxy (from "l'enjeu", [internal communication of the Fronte Nationale)] 19. This idea of the protection of several staples of traditional French life, especially "family-values", certainly plays a part in the rhetoric of the FN and there is consensus in the literature that a certain nostalgia for an imagined past is deeply rooted in the traditions of the party's early days under Jean-Marie Le Pen. Peter Davies argues that "there is also ever-present nostalgia. Although at times the FN would like to define itself as a progressive, forward-thinking movement, it is hampered by its glorification of the "old France". There is a longing for the "good old days" of empire when French grandeur was at its peak, and the memory of Algerie Française remains particularly evocative for party officials." 20 Much as the FN has sought to modernise under the leadership of Marine Le Pen, it is clear that a certain cultural conservatism has remained at the core of the party's appeal.

Evidence of this can certainly be found in the rhetoric of the Fronte Nationale. This was found in James Sheilds' analysis of the FN campaign of 2012 where Marine Le Pen vowed that "she would defend 'Republican secularism' and combat 'radical Islam', while imposing 'authority',

19 Kauffmann Grégoire, "Les origines du Front national », Pouvoirs 2/2016 ( $\left.\mathrm{N}^{\circ} 157\right)$, p. 5-15 URL : www.cairn.info/revue-pouvoirs-2016-2-page-5.htm. 20 Davies, Peter. The Extreme Right in France, 1789 to the Present: From De Maistre to Le Pen. London: Routledge, 2002. Print. 
'moral and civic values' and the 'teaching of the History of France' in schools. The usual suspects were arraigned to answer for the disastrous state of France: 'profiteers', 'a small elite with shady financial interests', those 'in hock to globalised ultra-liberalism' and a 'culture of renunciation' fostered by interchangeable parties of left and right" 21 In this we see a rejection of ultra-liberalism, amoralism and the degeneration of authority alongside other complaints that one often associates with conservative traditionalists. However, once again, we find a disconnect between the rhetoric of the FN itself and the appeal that it holds for its voters. Analysis of "far-right" voting patterns show that they benefit across the board from declining confidence in established parties, "among survey respondents who voted FN in the 1986 legislative elections, 25 per cent had supported a leftist candidate in 1981, but an even greater proportion ( 52 per cent) had supported a moderate right candidate (Ysmal 1989:Table 6.17)"22. "More interestingly, the far right leader also received the support of 15 per cent of those identifying themselves as 'far left'"23. This tells us that the FN has the ability to appeal far beyond the constituencies of traditionalist conservatives and that, while it often uses conservative rhetoric, it's appeal far exceeds conservatives and traditionalists.

There is, then, clearly more to the rise of the "far-right" than a mere rebellion on the part of conservatives against socio-cultural changes and rapidly liberalising social and sexual mores. For Le-Goff this can be understood as a more general and universal rejection of the elite driven projects of progressivism and liberalism. The denunciation of elites by the "far-right" is demagogic, but speaks to a reality: the degradation of relations between government and the governed that we

21 Shields, James. "Marine Le Pen and the 'New' FN: A Change of Style Or of Substance?" Parliamentary Affairs 66.1, 2013. 179-96. Web.

22 Veugelers, John. "Social Cleavage and the Revival of Far Right Parties: The Case of France's National Front." Acta Sociologica 40.1 (1997): 31-49. Web.

23 Veugelers, John. "Social Cleavage and the Revival of Far Right Parties: The Case of France's National Front." Acta Sociologica 40.1 (1997): 31-49. Web. 
cannot dismiss entirely by the all-encompassing term "populism". 24 Thus, rather than understanding the traditionalist elements of the "far-right's" rhetoric as being definitive of the movement as a whole, they should be explored as one part of a broader rebellion against the statusquo in modern France. Or as Goodliffe understands it, "a populist discourse which is simultaneously anti-elitist — pitting the virtue of the ordinary people against the turpitudes of a corrupt elite — and anti-pluralist_ — in that they see themselves as the expression of a general will sharing a common social purpose and aspiration." 25

\section{$\underline{\text { Xenophobia }}$}

Which brings us then to the characterization that, aside from being most popular amongst the opponents of the "far-right", has perhaps become the most influential perception of these movements in the eyes of academic, political and media actors. This is the claim that the FN represents a racist backlash against the rapidly changing demographic reality in France and, more generally, Europe. This position is most directly stated by Van der Brug and Fennema's claim that "in all post-industrial societies there is a substantial group of citizens with so much fear of immigrants that they are willing to support a radical right party if they see it as a democratic party, and if the established parties provide no alternative." 26 In fact, this is a common perception in the literature, particularly when combined with the idea that this identitarian backlash has been fuelled by fears about globalization and de-industrialisation. These processes have led to a hollowing out of the traditional grounds of working class identity, pride in work for example, and have left a void that has been filled by a resurgent nationalism. "From this standpoint, the process of capitalist

24 Le Goff Jean-Pierre, « Le syndrome du Front national. Genèse d'une ascension», Le Débat 4/2011 (n 166) , p. 5362 URL : www.cairn.info/revue-le-debat-2011-4-page-53.htm.

25 Goodliffe, Gabriel. (06/01/2012). The Price of Disengagement: Radical Populism in France and Germany. Journal of contemporary European studies. (20)2. p.137 - 160. ${ }_{26}$ Van der Brug, Wouter, and Meindert Fennema. "Causes of voting for the radical right." International Journal of Public Opinion Research 19.4 (2007): 474-487. 
restructuring during the 1980 s and 1990s induced a profound crisis of representation within the unions and PCF. As these institutions which had sustained their [the workers] class identity for the greater part of a century grew increasingly powerless to redress their grievances, French workers sought out new sources of identification by which to replace them.”27 Consider also, for example, Elinas' claim that "changes brought about by the advent of globalization and postindustrialism....generated popular concerns about national identity and has given rise to public demands for cultural protectionism." 28 This is coupled with the failure of mainstream political parties to speak convincingly about identity in such a way as to acknowledge such concerns, which Mudde believes "furnishes far rightists with opportunities for electoral breakthroughs.29 There thus exists a strong suggestion in the literature that resurgent nationalism, fear of migrants and ethnic identitarianism are the main factors that drive the success of the "far-right". Simply put, globalization has created an identity crisis among Western Europeans that mainstream parties ignore, to the benefit of the "far-right".

Again, this perception appears to be supported by the rhetoric employed by the FN in its pursuit of electoral success. Once again we can turn to Kauffmann who presents the following quote from a founding member of the FN, Francois Brigneau who spoke thus; of the constitution of a "revolutionary party: white like our race, red like our blood and green like our hope. 30 Although much has changed in the FN under the leadership of Marine Le Pen, it is still possible to observe a similar nationalistic and anti-universalist discourse in the current iteration of the party. Le Goff

\footnotetext{
27 Goodliffe, Gabriel. (06/01/2012). The Price of Disengagement: Radical Populism in France and Germany. Journal of contemporary European studies. (20)2. p.137 - 160.

28 Ellinas, Antonis A. "Playing the Nationalist Card: Mainstream Parties, Mass Media and Far Right Breakthroughs in Western Europe." Order No. 3286114 Princeton University, 2007. Ann Arbor: ProQuest. Web. 17 Nov. 2016. 29 ibid 30 Kauffmann Grégoire, « Les origines du Front national », Pouvoirs 2/2016 ( $\left.N^{\circ} 157\right)$, p. 5-15 URL : www.cairn.info/revue-pouvoirs-2016-2-page-5.htm.
} 
describes the outlook of Marine's FN in the following terms: "the promotion of the idea of a "multicultural society" leads one to believe in a modern France that is open to the world, which can only be a society of coexistence between different cultures. Such a radical openness to that which is different is not only revelatory of a utopia which is, according to the "far-right", "no more likely to come than a genuinely classless society," but also, in their eyes, manifests a form of denial- when it doesn't provoke resentment or rejection- of the specificity of the French Republican model which is not exactly the most universally accepted concept in the world" 31 In other words, the rhetoric of the FN would appear to support the claim that their fundamental purpose is as a party that opposes universalism and multiculturalism in the defence of a romantic and ethno-nationalist image of France. This leads Sheilds to "the conclusion that the FN has cast off its demonic image and manoeuvred its way into mainstream acceptability; yet undoing four decades as an authoritarian, xenophobic, dubiously democratic, anti-system party is not so easy. Scratch the new glossy surface and there remains a party culture that is still largely unreformed, from the locked down party headquarters and unwelcoming attitude to visitors to the unrepressed verbal aggression that continues as a feature of $\mathrm{FN}$ rallies" 32

However, once again we see that the results of academic study appear to challenge both the prejudices of the academics themselves and the rhetoric employed by the FN. For example, Mudde concludes that "mixed results have been reported, though there seems to exist consensus regarding the absence of a clear cut relation between the number of immigrants and the electoral success of ERP's [Extreme Right Parties] in a certain territorial unit" 33 and also that "immigration has not

31 Le Goff Jean-Pierre, " Le syndrome du Front national. Genèse d'une ascension», Le Débat 4/2011 ( $\left.n^{\circ} 166\right)$, p. 53 62 URL : www.cairn.info/revue-le-debat-2011-4-page-53.htm.

32 Shields, James. "Marine Le Pen and the 'New' FN: A Change of Style Or of Substance?" Parliamentary Affairs 66.1, 2013. 179-96. Web.

33 Mudde, Cas. "The single-issue party thesis: Extreme right parties and the immigration issue." West European Politics 22.3 (1999): 182-197. 
been the only' 'catalyst issue' of ERPs, nor has it been a catalyst issue for all ERPs" 34 This conclusion is mirrored in Cochrane's assessment that "the level of electoral support for far-right parties is not necessarily a proxy for the level of anti-immigrant sentiment in the electorate" 35 Taken together, this lends a definite credence to Cochrane's final conclusion which he states in the following way: "far-right parties likely benefit from anti-immigrant sentiment. But the electoral prospects of these parties are affected by many other factors as well. For this reason, the level of electoral support for far-right parties is not, in our view, the best dependent variable for mounting a direct empirical test of the influential 'ethnic competition' and 'group-threat' hypotheses." 36 In other words, the academic literature strongly suggests that, while xenophobia and other sociological explanations for the rise of the "far-right" can contribute to an understanding of the phenomenon as a whole, the explanatory value of such analyses are highly limited and do not provide a satisfactory account of this phenomenon.

\section{Part Three: National Front as Philosophical Phenomenon}

Given the unsatisfactory nature of the analyses described above, it appears that there is a need to attempt to understand this phenomenon outside of the boundaries of the economic and sociological logics employed in the majority of academic and popular literature on this subject. As will be restated in greater detail later, philosophical approaches allow for the abstraction of a complex concept to make possible a broader and deeper understanding of the object of study. It must then fall upon us to explore philosophically grounded explanations for this phenomenon. As will be shown, there is not a great deal of this in the popular literature, and at the academic level much of this analysis is either general in focus or only indirectly concerned with the particular case under

\footnotetext{
34 ibid

35 Cochrane, Christopher, and Neil Nevitte. "Scapegoating: Unemployment, Far-Right Parties and Anti-Immigrant Sentiment." Comparative European Politics 12.1 (2014): 1-32. ProQuest. Web. 17 Nov. 2016.

36 ibid
} 
consideration in this thesis. There is thus a gap in the literature that this paper will attempt to fill in its elaboration of a philosophical account for the rise of the "far-right" in the particular case of France.

\section{$\underline{\text { Popular Literature }}$}

Perhaps unsurprisingly, philosophical accounts do not feature heavily in the editorial pages of major newspapers, nor does popular discussion of the "far-right" often consist of consultation with philosophical tracts. However, we do see hints in the popular discourse of some of indirect references to some of the philosophical aspects that will be considered in this paper. For example, The Guardian editorialists highlight "the great division in French politics..... no longer between left and right but between "patriots and globalisers"'" 37 which speaks directly to the rejection of universalism that will be discussed in this paper. Similarly, Barkha of the Hindustan Times posed the following questions in the wake of Donald Trump's electoral victory: "Could it be that the polemics of aggressive nationalism and the "othering" of the "outsider" is the result of liberals refusing to engage with any view different from their own? Has the common cultural and social pedigree of the Left-leaning intelligentsia created the impression of an elite intellectuals' club that carries a "No Entry" sign for the masses? What explains this blow-back to values that were once accepted as the enlightened norm?" 38 In many respect these questions mirror those that are being posed by this study, and suggest that the popular consciousness is not entirely oblivious to the philosophical dimension of the questioning that will be undertaken by this paper. There is,

37 "The Guardian View on the French Elections: Front National Fails to Gain Power but Its Defeat Is Only Partial." Editorial. The Guardian. The Guardian, 14 Dec. 2014. Web. 
however, relatively little of this sort of analysis in popular media and this suggests that such considerations require far more exploration.

\section{Academic Literature}

There is rather more philosophy to be found in the academic literature. This tends to separate into three typologies. Firstly an understanding of the "far-right" as a rejection of liberal thought, secondly as a rejection of universalism and finally as a rejection of materialism as an ethos.

The first of these is often understood in terms of a rejection of egalitarianism. According to Davies, "it [the FN] has no truck with egalitarian ideas and has put forward various justifications for natural selection and inequality. Furthermore, Le Pen has ridiculed the rights of man; and has consistently viewed his values as the antithesis of left-wing values." 39 While it is couched in terms of egalitarianism rather than liberalism, this does serve to illustrate the extent to which the FN as a political movement stands in opposition to one of the foundational ideas of Enlightenment thought, the idea that all mean are created equal. This fundamental antithesis is more directly referenced by Lebourg's claim that Marine Le Pen presents globalisation as a totalizing of itself and of post-modernity: an integral liberalism that motivates the E.U at the European level and the establishment parties in the nations of Europe, creating a man with no identity beyond consumption, and no rooting either temporally or spatially. 40 This undoubtedly suggests that the FN taps into a much more fundamental and deep-rooted resistance to modernity and its liberalising effects, the reference to rootedness betraying the Heideggerian influence that will be explored in this paper. These analyses open the floor to an exploration of the relation between the "far-right"

39 Davies, Peter. The Extreme Right in France, 1789 to the Present: From De Maistre to Le Pen. London: Routledge, 2002. Print.

40 Lebourg Nicolas, «Les dimensions internationales du Front national », Pouvoirs 2/2016 ( $\left.N^{\circ} 157\right)$, p. 105-113

URL : www.cairn.info/revue-pouvoirs-2016-2-page-105.htm. 
and the philosophical project of modernity, linking it with the German romantics and their critique of the Enlightenment. It is precisely this that will be explored in this paper.

We can remain with Nicolas Lebourg in order to observe an example of the second type of analysis in his presentation of the following explanation for the rise of the "far-right": "the transition to a unipolar global system allowed members of the radical right to frame their discourse in terms of a new world in sight of unification under the auspices of "American-Zionist" capitalism and/or globalization...From this is created a planetary conflict between the identitarianism of the National Front and Islamists, and the "new world order", which is to say a globalization synonymous with cosmopolitanism. 41 As before, the language employed is not particularly philosophical. However, the recognition of the dichotomy between the universalism of that against which the FN is engaged and the appeal to particularism lays the groundwork for a deeper philosophical analysis of the relationship between the "far-right" and the liberal thought against which Lebourg situates it. Lebourg also hints at an important element of this movement, its conspiratorial attitude towards existing forms of authority. We also see an underlying reactionary anti-Semitism that suggests a darker aspect underlying this political movement. This is evidenced in Saull's observation that "what continues to characterise the far-right at all points, then, is a view of 'politics as conspiracy': a conspiracy of elites detached from indigenous-nativist ideological moorings and/or 'corrupted' by internationalist and cosmopolitan ideological frameworks" 42 In light of this it is tempting to make comparisons with Nazi Germany, however Saull warns against this in his criticism of scholars that tend to focus obsessively on Hitler in order to make "analytical and political judgements over the character of the far-right using fascism as the analytical base

41 Lebourg Nicolas, « Les dimensions internationales du Front national », Pouvoirs 2/2016 ( $\left.N^{\circ} 157\right)$, p. 105-113 URL : www.cairn.info/revue-pouvoirs-2016-2-page-105.htm. 42 Saull, Richard. "Capitalism, Crisis and the Far-Right in the Neoliberal Era." Journal of International Relations and Development 18.1 (2015): 25-51. ProQuest. Web. 17 Nov. 2016. 
line, which overlooks the longer-term history of the far-right as a major constituent of modern European politics that pre-dates fascism and the wider assemblage of social and political forces associated with it." 43 Building upon this, this paper will attempt to look beyond the Nazi comparison and explore the philosophical root of the rejection of traditional forms of authority and the rejection of universalism that is born of that rejection.

Finally, the academic literature speaks of a rejection of materialism in its analysis of the "farright". According to Alexandra Cole, "in 1986, the top five Front National issues reflected postmaterialist concerns: support for traditional moral values, support for a national way of life, support for individual freedoms and support for social harmony (understood as national unity)." 44 This lays the groundwork for an interesting exploration of the post-materialism of the "far-right" and the philosophical foundations upon which this rejection is built. Taken together, this completes the picture of a good, but far from exhausted, analytical grounding upon which this paper will attempt to build. In light of the gap in comprehension left by the inability of sociological and economic explanations to fully explain the rise of the "far-right" this paper will build upon the philosophical literature written on this subject in order to enhance our understanding of this contemporary phenomenon.

Most pertinently, perhaps, Alexander S. Duff's "Heidegger and Politics: The Ontology of Radical Discontent" examines the relationship between the radical critique of modern thought offered by Martin Heidegger and the "anti-liberalism" of, particularly, the Iranian Revolutionary government. Duff traces the ideological lineage of the Iranian Revolution in part, to the Parisian intellectual scene of the 1960's, where the ideas of Heidegger formed a significant part of the

\footnotetext{
43 Saull, Richard. "Capitalism, Crisis and the Far-Right in the Neoliberal Era." Journal of International Relations and Development 18.1 (2015): 25-51. ProQuest. Web. 17 Nov. 2016.

44 Cole, Alexandra. "Old Right or New Right? The Ideological Positioning of Parties of the Far Right." European Journal of Political Research 44.2 (2005): 203-30. Web. 18 Nov. 201
} 
environment of the time45. Scholars and political activists like Ali Shariati and Ahmed Fardid brought these ideas back to Iran and used them to shape the anti-liberal political movement that developed during the Iranian Revolution46. Such analysis is highly fascinating, and tell us a great deal about what could very reasonably be called the Iranian "far-right". Those familiar with Duff's work will see undeniable parallels between his analysis and the one that is to follow, though the focus on France certainly distinguishes the two, and there is no doubt that this project stands upon his shoulders, and is engaged in an attempt to build upon the foundations set by philosophical approaches such as that of Duff.

\section{$\underline{\text { Conclusion }}$}

It appears, then, that there is what can be described as a "certainty gap" between the popular media's perceptions of the reasons for "far-right" success and those of the academic literature. Most popular coverage seems to favour the economistic explanation, that FN support is a byproduct of economic inequality alienating the "left-behind". Much also focuses on sociological explanations revolving around a fear of foreigners and a resistance to social and cultural "progress". However, academic literature seems to suggest that these explanations are not sufficiently satisfying as they offer only a partial explanation for the phenomenon in question. This becomes especially confusing in light of the fact that the FN itself appears to place great importance on these factors in its rhetoric and political posturing; particularly economic inequality, traditionalist values and the demographic transformation of France. However, academic study appears to show that none of these things fully explains why they have become increasingly popular in recent years. It is without question that the above shows that the phenomenon under

45 Duff, Alexander S. Heidegger and Politics the Ontology of Radical Discontent. New York, NY: Cambridge U, 2015. Print 46 Duff, Alexander S. "Heidegger's Ghosts." American Interest 25 Feb. 2016, Counter-Liberalism sec.: n. pag. Print 
consideration has economic and sociological elements. It is clear that the FN has benefitted from the 2008 financial crisis and has been more than able to mobilize resentment on the part of the economically disadvantaged against the wealthy. However, the movement remains largely middleclass in its activist and voter base while appearing to have the ability to appeal to traditional nonvoters and left wing voters to almost as great an extent as it appeals to disaffected supporters of the centre-right. At first glance, most of the literature that has seriously considered the FN in either of these regards concedes that economic and social explanations offer only a partial explanation for the rise of the FN. In other words, we are left in a position where the dominant frames of analysis; for politicians, academics and journalists alike; that are used to explain and understand this political phenomenon are only able to provide us with a partial account of the rise of "farright" politics.

As a result of this it is invaluable that the scholarship attempt to turn to other analytical factors in order to provide a more comprehensive account of the rise of the "far-right". Because of the more abstract and universalisable nature of philosophical accounts, I believe that it is to philosophy that we must turn in order to fill this gap in our comprehension. Philosophical analyses is relatively rare in the case the phenomenon in question. While popular discourse merely hints at a deeper philosophical contention being at play, academics have begun the process of understanding this phenomenon in these terms. The above review shows that the "far-right" can be understood as a rejection of liberalism, materialism and universalism. This paper will thus focus its attention on such philosophical critiques of modernity that, it will be shown, are creating the conditions that the FN, perhaps partly inadvertently, is exploiting in its meteoric rise. 


\section{Methodology}

Having engaged with the literature within and against which this paper will be situated it is important to clarify and justify the methodological ground upon which the main argument will be built. Often, qualitative analyses of abstract ideas, and interpretations of highly metaphorical sources like those in question can suffer from a lack of methodological rigour in such a way as to render arbitrary the conclusions drawn from the sources by the scholar. However, it is also the case that the application of anything approaching a scientific methodology is equally problematic. To apply the logos of techne to a Heideggerian critique of technology seems intuitively to be missing the point, and as a result it will not be necessary for his paper to apply a "technological" methodological rigidity to the sources under consideration. There will, therefore, not be any single overarching methodological approach that will inform this paper. The approach taken by this paper will incredibly simple. Essays by Heidegger and passages from "Being and Time" were read through a lens which tried to understand how his thought might have influenced the extremist politics of his own time, and these anti-liberal, or anti-modern, interpretations of Heidegger's thought were compared and contrasted with a similar interpretation of Houellebecq's novels. While I am prepared to concede that this is but one way of interpreting Heidegger and Houellebecq, I believe that it will become clear as this project progresses that both writers can be approached plausibly and interestingly through this lens. Once the connections between these two thinkers have been established, this paper will aim to demonstrate the ways in which those ideas of Heidegger's that have presenced themselves in the novels of Houellebecq also have a profound influence on the success of the National Front, as evidenced by their discourse, literature and politics. Given that the mechanics of this methodology quite simply consists of reading texts, and comparing them to other texts, policy statements and speeches, there is little need to dedicate a 
huge amount of time to elaborating upon this. Instead, I will attempt to answer the following question: Why does an analysis of a contemporary political movement necessitate a philosophical analysis? This will expose the only grand methodological claim upon which the paper is reliant; that the ideas of great thinkers, however complex and inaccessible to the general public they might be, are of primary significance in the understanding of political phenomena both in their own time and in subsequent periods. In doing this I will attempt to show that the approaches taken are not indicative of any kind of overarching claim about the way in which philosophy should be done, but rather represent the approaches that allow for the fullest understanding, and the clearest presentation, of the philosophical aspect of the phenomenon under consideration. This approach allows, I believe, for the greatest level of insight to be shed on each of the various aspects of this complex phenomenon in the simplest and, hopefully, most compelling way possible.

When presented with a philosophical explanation for the rise of the "far-right", one might reasonably argue that voters are not generally inclined to go into the polling booth with considerations of fundamental ontology swirling about their brains and, further still, most polling data suggests that the economy and immigration are the dominant issues driving voter considerations in elections across the West. The response to this reasonable argument essentially boils down to the claim that a philosophically oriented analysis of this particular phenomenon carries an explanatory capability that is both broad enough to encapsulate the boundaries of this almost universally ubiquitous phenomenon and deep enough to shed light onto the fundamental underlying reasons for its tenacity and success. This is not to disparage the work of economists or sociologists, but rather to state that in this particular case such approaches are unable to fully explain the phenomenon in question. Economists may maintain that populist politics thrive in times of economic hardship, however this cannot explain why "far-right" political parties are 
experiencing a renaissance in booming economies like those of the United Kingdom and America as well as flat lining and failing economies like those of France and Greece respectively. Similarly, sociological explanations, linking anti-immigrant nativism and opposition to demographic transformation to "far-right" parties cannot account for the popularity of such a politics in both Hungary, with its high fertility rates and low immigration levels, and Germany, with its declining population and porous borders. While there is clearly value to such approaches to this question it is clear, in light of what has just been pointed out, that we must turn to the higher level of abstraction accessed by philosophy in order to be able to ascertain the boundaries of this phenomenon and question it in its entirety. Understanding the ideas and concerns which are prominent at a particular moment sheds light onto why something like the rise of the "far-right", which perhaps seems on its face to be an absurdity, could become an almost ubiquitous phenomenon in developed countries. Approaching a political phenomenon by way of an analysis of philosophical writing allows, for example, the researcher to gain an understanding of the kinds of debates that preoccupy a group of people, the kind of language that is being employed in the making of political arguments and the way in which concepts are being understood in the political arena at any given time. As Pocock puts it, "the historian might approach the political thought of a society by observing, first, what modes of criticizing or defending the legitimacy of political behaviour were in existence, to what symbols or principles they referred, and in what language and by what forms of argument they sought to achieve their purposes." 47 What applies for a historian attempting to understand a past epoch must equally apply to a theorist attempting to explain phenomena of his contemporary era. Thus it takes a philosophical analysis to dig beneath the political language of the "far-right" and their adversaries in order to find the best account of 
this phenomenon. It is this that allows for an approach to the political phenomenon of the rise of the French "far-right" which focuses almost entirely on philosophical sources and says relatively little about more traditional political factors like employment, growth and immigration levels.

Additionally, philosophical analysis accesses a level of abstraction that can allow the reader to see beyond the aesthetic and discursive uniqueness of a particular manifestation of the phenomena, in this case the French manifestation. This makes it possible to shed light on the fundamental qualities that transcend the cultural and social contingencies of this particular case, thus making universal the phenomenological conclusions that will be drawn. On the face of it, it might appear difficult to reconcile the high-minded rhetoric of Jacob Reese-Mogg's Brexit advocacy with the blue-collar vulgarianism of President Trump's electoral campaign; and yet the ideological affiliation between the two becomes apparent when one considers their positions from the perspective of philosophical abstraction. In short, philosophy allows for the abstraction of contextually contingent phenomena into broader theoretical units of analysis. When analysing a phenomenon that can be found in so many different cultural, political, economic and historical contexts it seems intuitively self-evident that there is a need to abstract the interrogation to a sufficiently broad scope as to capture it in full. As stated in the introduction, the phenomenon of the rise of the "far-right" can be observed in a diversity of countries which collectively have few things in common. One of the few things that unites them is that they contain thinking people, the most educated of whom will have some grounding in philosophy, and can therefore be said to be engaged with similar philosophical ideas in spite of their material lack of proximity. Thus we can reasonably assume that a philosophical analysis of one country, such as this paper is undertaking, is able to shed light on the phenomenon as a whole due to the fact that similar ideas are present in all parts of the world. The philosophical approach thus allows us to abstract the phenomenon to a 
theoretical level that transcends the contingent boundaries that limit the scope of demographic, cultural or economic approaches to this same question. In Lovejoy's words, speaking in criticism of the departmentalization of ideas according to the place or time they emerged, "ideas are the most migratory things in the world. A preconception, category, postulate, dialectical motive, pregnant metaphor or analogy, "sacred word," mood of thought, or explicit doctrine, which makes its first appearance upon the scene in one of the most conventionally distinguished provinces of history (most often, perhaps, in philosophy) may, and frequently does, cross over into a dozen others." 48 A universal question like ours requires a universal frame of analysis in order to explain it in full, thus only philosophy and the realm of thought can have the scope necessary to elucidate upon the phenomenon in question. In conclusion, therefore, it is to philosophy that we must turn if we are to grasp this phenomenon, to get it in hand, with a degree of comprehensiveness that eludes our economic and sociological forms of questioning.

48 Lovejoy, Arthur O. "Reflections on the History of Ideas." Journal of the History of Ideas, vol. 1, no. 1, 1940, pp. 323. www.jstor.org/stable/2707007. 


\section{Division One: Science, Technology and Heideggerian Thought in Modern France}

\section{Introduction: Modernity and its Malcontents}

With the preceding being taken care of, it will be possible now to begin to approach the philosophical questioning that will be the engagement of this paper. In this chapter, the first part of this questioning will focus on the most direct expressions of Heidegger and Houellebecq's philosophical critiques of their respective societies, which both writers portray as being dominated by technology and science. For both writers technology and science go hand in hand and are the foundations of modern civilisation. In order to engage with these philosophical critiques it seems evident that one should begin with an exegesis of Martin Heidegger's “The Question Concerning Technology". This essay provides both an operational definition of the technological, one that will be shown to resonate to this day, and an insight into the totalising and revolutionary nature of modern technology that Heidegger wishes to bring to light. Interwoven into this will be a comparison with the alienation of man from nature in Houellebecq's works and the paradoxical result of this whereby man attempts to escape the confines of convention and return to the natural while simultaneously attempting to overcome and tame that nature through technology. This comparison will show that Michel Houellebecq's highly popular dystopian fiction identifies many of the same problems; particularly regarding the relations between man, technology and nature; as Heidegger, and often roots the descent of society precisely in the kind of myopic technological questioning that Heidegger is opposing in his essay. The presence of such anxieties in a work of contemporary dystopian fiction demonstrates the salience of Heidegger's critique to the contemporary context, and when one considers the tension between the National Front and "technological" elites, as well as the importance of the appeal to the mytho-poetical in the political aesthetic of the "far-right", it is clear that Heidegger's ideas have resonated with this political 
movement. Once this connection has been made a similar analysis will be done of Heidegger's essay "The Age of the World Picture". In this essay, Heidegger builds upon his questioning of the technological to argue that the impact of the unfolding of technology in history has been to uproot man from any particular cultural, temporal or spatial context and to throw him, without any moorings to anchor him, into a levelled out and de-racinated world. Once again the direct connection can be made to the novels of Michel Houellebecq, particularly his reflections upon the uprooting of the European man from his Christian moorings and the subsequent cultural crisis that Houellebecq describes, to give one example, in "Submission", as well as in his satire of the tourism industry in "Platform" and the more general account of man adrift in an alien world that represents a common motif throughout Houellebecq's works. Through this, Houellebecq situates his characters in the age of the world picture in a way that directly mirrors and expounds the concerns of Heidegger, particularly regarding scientism and globalisation, once again demonstrating the relevance of Heideggerian ideas to the anti-liberalism present in Houellebecq's work. This too will be shown to be relevant to the contemporary National Front, a fact that can be observed by tracing the intellectual development of the party from its traditional ultra-conservative Catholic reactionary politics to the anti-globalism of its current iteration. Finally, attention will be turned to Heidegger's essay titled "Science and Reflection". Here we find the most direct criticism of science and the most obvious manifestation of Heidegger's aversion to the ever growing dominance of the scientific, particularly the entrapping of the objects of other fields of research into the sciences. This will be compared with Houellebecq's own anti-scientism, which similarly decries the endless expansion of the realm of the sciences at the expense of art, poetry and all other modes of bringing forth as well as the anti-scientific stance adopted by the National Front's leadership and one of its leading intellectual lights, Eric Zemmour. Altogether this will show that despite the decades of 
rapid technological development that separate Heidegger from Houellebecq, both share similar fundamental concerns about the way in which technology, science and modernity have encased our capacity to seek truth in the methodological confines of the sciences; have robbed us of our moorings in place and time; and perhaps worst of all have robbed the world of its poetry, magic and beauty by reducing it to measurable, quantifiable and monetised units. We can thus see that the very same aversion to particular aspects of modernity that animated Heidegger, and to an extent created the conditions that led to the great rejections of liberalism in the early $20^{\text {th }}$ century, are present in the contemporary French context. Houellebecq's works show us the extent to which this is the case and it is clear that this forms a significant part of the status-quo against which the "farright" is in rebellion. When we understand the severity of the disillusionment with modernity that Houellebecq typifies, and the seriousness of the philosophical challenge it presents, we can far more clearly understand the phenomenon of the rise of the "far-right" in its totality. 


\section{Chapter One: Man, Technology and Nature}

"We shall be questioning concerning technology, and in doing so we should like to prepare a free relationship to it. The relationship will be free if it opens our human existence to the essence of technology. When we can respond to this essence, we shall be able to experience the technological within its own bounds" 49 .

It is thus that Martin Heidegger describes the central undertaking of his essay on "The Question Concerning Technology”. This idea of questioning takes on a central importance as Heidegger develops his argument about technology, and the particular way in which it goes about bringing truth into light. Heidegger does not claim to be in the process of "solving" a "problem" of technology nor of exposing any kind of deception but rather is aiming to develop the right questions that one must pose concerning technology in order to understand the essence and boundaries of the thing itself, as well as the ways in which it acts upon man. All of this is done with an eye towards liberating man from the constraints imposed by "Enframing", and the more general myopia that Heidegger feels has resulted from the dominance of modern technological modes of thinking. In order to uncover the correct line of questioning Heidegger approaches technology from a number of angles. Heidegger's essay is in part a brief genealogical account of technology, describing the evolution from the technê of the Ancient Greek's to the "modern" technology of Heidegger's own time; at the same time it is partly a quasi-psychological argument about the way in which technology has shaped the way people think and relate to the world around them. These two aspects of Heidegger's argument contrive to present an account of the essence of technology which, Heidegger hopes, will contribute not only to a more complete understanding of what technology is, but will also begin the process of unconcealing the extreme danger that

49 Heidegger, M. (1977). The Question Concerning Technology. In M. Heidegger, The Question Concerning Technology and Other Essays (pp. 3-35). New York: Garland Publishing inc. pg.4-5 
technology poses to man's relationship with the natural world, truth and his own self. It is thus that the project of questioning can be defined in this context. Heidegger wishes to challenge our understanding of the concept of technology by subjecting it to a line of inquiry that is distinct from the instrumentalist ways in which the phenomenon of technology is generally approached. Heidegger's understanding of being, which will be discussed in greater detail in the second division, necessitates a diversity of "questionings" of a concept which combine to bring forth the boundaries and limitations of its being into unconcealment. This process of questioning in order to bring forth into light is in this case being applied to a concept that, as a direct result of this unique mode of inquiry, will quickly come to be understood in a radically different way to what one might expect

Heidegger begins this form of questioning by way of a critical reflection upon the instrumentalist view of technology as a mere tool, an expedient with little to no philosophical relevance. This is approached at first by reference to the account of Ancient Greek technê, particularly with regards to its relationship with truth and knowledge. According to Heidegger,

"from earliest times until Plato the word technê is linked with the word episteme. Both words are names for knowing something in the widest sense.... techne is a mode of aletheiein. It reveals whatever does not bring itself forth and does not yet lie here before us, whatever can look and turn out now one way and now another" 50

In other words, technê was understood by the Greeks to be a form of knowledge, and an ability to convert the potentiality of a particular thing into a new form. In this way it paralleled episteme and poesis, in its ability to turn potential into being, and was thus to be considered a way of knowing or revealing truth. This earliest conception of technology was in many respects a craft and was not

50 Heidegger, M. (1977). The Question Concerning Technology. In M. Heidegger, The Question Concerning Technology and Other Essays (pp. 3-35). New York: Garland Publishing inc. pg. 13 
to be understood in empirical terms, but was rather a part of a broader process of shedding light onto truth by bringing it from a state of concealment into the light of unconcealment. He draws a direct parallel between this form of revealing and that of poesis. The Greeks understood poesis as being a kind of non-material creativity whereby a non-physical thing could be brought into existence independently of any material cause. Both technê and poesis can thus be understood as ways of transforming the potentiality of the unconcealed into actuality. "Every occasioning for whatever passes over and goes forward into presencing from that which is not presencing is poesis, bringing-forth" 51 , he adds, "Bringing-forth brings hither out of concealment forth into unconcealment. Bringing-forth comes to pass only insofar as something concealed comes into unconcealment. This coming rests and moves freely within what we call revealing." 52 We here see a pre-Platonic conceptualisation of technê that is not "enframed" in the empirical and scientific logics that will be discussed later, but exists in concert and in a state of equality with all other modes of revealing. This concert of equals comes to be disrupted when Aristotle attempts to provide an account of being which is static and which bears the scars of the, according to Heidegger, deleterious impact of Platonic metaphysics. Aristotle attempts to provide an account of the causality of the being, as opposed to the becoming, of objectness that grounds it in four causes. The first of these is the causa materialis, the matter out of which the thing is made, the second is the causa formalis, the form or shape into which this material is manipulated, the third is the causa finalis, the end purpose of the thing, and finally the causa efficiens, the agent forming the material into a particular shape. Heidegger feels that this way of understanding causality is what leads to the purely instrumental conception of technology that prevails. Aristotle uses the

51Heidegger, M. (1977). The Question Concerning Technology. In M. Heidegger, The Question Concerning Technology and Other Essays (pp. 3-35). New York: Garland Publishing inc. pg. 10 52 Heidegger, M. (1977). The Question Concerning Technology. In M. Heidegger, The Question Concerning Technology and Other Essays (pp. 3-35). New York: Garland Publishing inc. pg. 11 
example of a silver chalice to illustrate his four causes. For Aristotle, an agent, in this case a silversmith, manipulates material, in this case silver, into the form that he desires in pursuit of a final end for this object that he intends. This account of causality, therefore, reduces technê to the status of a mere instrument being used by the silversmith. Technê in this context has no spiritual content, nor any essence of its own. As a result, people see technology as a mere tool by which man can shape material into the form he desires. However, he feels that there is more to technology that this. "So long as we do not allow ourselves to go into these questions, causality, and with it instrumentality, and with the latter the accepted definition of technology, remains obscure and groundless." 53 It is in this challenge to a modern conception of technology, grounded in this Aristotelian understanding of causality, that Heidegger is attempting to redefine man's relationship with technology in order that we may genuinely become its master. Heidegger sees this instrumental explanation as highly seductive, as it is difficult to reject or even argue against due to its profound influence on society, but claims that it results from the original error of Platonic metaphysics. Heidegger states this in the following way:

\section{"Instrumentality is considered to be the fundamental characteristic of technology. If we inquire, step-by-step, into what technology, represented as means, actually is, then we shall arrive at revealing. The possibility of all productive manufacturing lies in revealing. Technology is, therefore, no mere means. Technology is a way of revealing. If we give heed to this, then another whole realm for the essence of technology will open itself up to us. It is the realm of revealing, i.e., of truth. " 54}

While this development is certainly considered to be of central importance by Heidegger, it is in the subsequent development of modern technology that the crux of the question at hand reveals

\footnotetext{
53 Heidegger, M. (1977). The Question Concerning Technology. In M. Heidegger, The Question Concerning Technology and Other Essays (pp. 3-35). New York: Garland Publishing inc. pg. 7 54 Heidegger, M. (1977). The Question Concerning Technology. In M. Heidegger, The Question Concerning Technology and Other Essays (pp. 3-35). New York: Garland Publishing inc. pg. 12
} 
itself. Modern technology is distinct from its ancestor in the fundamentally transformative change that occurs with regards to the relationship between man and nature. While pre-modern technology broadly consisted of working with nature's materials in order to alter their form; modern technology issues a challenge to nature herself, setting upon her in order that she might surrender her possessions. The distinction between this new form of technology and the old technê of the Ancients is demonstrated in a comparison between the old wooden bridge crossing the Rhine and the hydroelectric plant that has dammed the river.

"The hydroelectric plant is not built into the Rhine River, as was the old wooden bridge that joined bank with bank for hundreds of years. Rather the river is dammed up into the power plant. What the river is now, namely, a water power supplier, derives from out of the essence of the power station." 55

This represents a paradigm shift. The old bridge represents a form of technology that was able to use the materials of nature, wood, in such a way as to facilitate human existence within the natural world. While allowing man to cross the river, it in no way challenges the river or interferes with it as a force of nature, nor does it challenge the essential being of the river in doing so. Man in such a paradigm is required to reckon with the power of nature and to build his life around it. On the other hand, the new power plant represents a near total mastery over nature. The river itself has been brought in hand, and has been set upon in order to surrender its energy to the needs of man, its being is no longer a derivation of its nature but is defined and mediated by the technology that orders and challenges it. It becomes essentially a power source, and this essence is defined by the will of man and the technology he uses to get nature in hand.

"This challenging happens in that the energy concealed in nature is unlocked, what is unlocked is transformed, what is transformed is stored up, what is stored up is, in turn distributed, and what is distributed is switched about ever anew.

55 Heidegger, M. (1977). The Question Concerning Technology. In M. Heidegger, The Question Concerning Technology and Other Essays (pp. 3-35). New York: Garland Publishing inc. pg. 16 
Unlocking, transforming, storing, distributing, and switching about are ways of revealing. " 56

The Rhine River is thus reduced to a mere tourist attraction where groups are brought to look at the splendour of the old river before, most likely, being hurried off to the gift shop or the next attraction. In many ways this lamenting of the debasement of the Rhine carried echoes of Rousseau's claim that the eye is always turned wistfully to the beauty of nature and his own lamenting of the tragedy that is man's alienation from what is natural.

The idea that the advance of technology has alienated man from nature by creating an additional degree of separation between man and the materials with which he is working can also be found in a contemporary context in the novels of Michel Houellebecq. In Michel Houellebecq's novel "Platform" we see this in the description of the contemporary work environment offered by Houellebecq's protagonist, Michel Renaud. Michel is a civil servant working for the ministry of culture, but has no direct engagement with the cultural world whatsoever. Much as Heidegger decries the alienation of the artisan from the natural resources with which he works, and the intermediary role played by technology that first sets upon nature and calls it forth to present itself to the worker as its composite parts, Houellebecq's narrator feels useless as a result of his detachment from the actual materials with which he is working. He does not interact directly with culture, but only with computers within his office. As a result he describes himself in the following way: "I was perfectly adapted to the information era, this is to say good for nothing ...... We lived surrounded by objects whose manufacture, possible use and functions are completely alien to us." 57 The alienation of man from his labour is as acute in the context of Michel and his work at the ministry of culture as it is for the German looking upon the debased carcass of the Rhine. While

56 Heidegger, M. (1977). The Question Concerning Technology. In M. Heidegger, The Question Concerning Technology and Other Essays (pp. 3-35). New York: Garland Publishing inc. pg. 16

57 Houellebecq, Michel. Platforme. Paris: Flammarion, 2001. Pg. 217 
the context has changed, the information economy has replaced the industrialism of Heidegger's time, the unfolding of technology through history has continued apace and has revealed itself to Houellebecq as starkly as it did to Heidegger.

This sense of alienation, in Houellebecq's works, can often lead to bizarre attempts to rediscover the natural, "authentic" self. These are presented, often satirically, as mostly doomed attempts to rediscover a more direct relation to the natural world. As early as "Extension of the Domain of Struggle”, Houellebecq's first full length novel, his unnamed protagonist is absurdly envious of the "existential unity" of the Breton cow, saying that

"throughout the course of the day it need only worry about mooing, its chest rises and falls with the impressive regularity of its breathing, and no shudder of anxiety comes to trouble the pathetic look in its clear brown eyes.....everything about it seems to indicate a profound existential unity, an enviable unity between its being-in-the-world and its being-in-itself. "58

Aside from the obvious mockery of Jean-Paul Sartre, it is interesting to note that the fascination with the Breton cow is rooted in envy at its ability merely to exist in a direct relation to nature without intermediary or anxiety. The fact that modern man might find himself envying cows speaks directly, though satirically, to the idea that technology is robbing us of our relation to nature. This motif of men suffering through their alienation from nature, and wishing to escape from development and modernity back to the simplicity of nature, is one that is both as old as civilization itself but also one that is finding novel forms of expression, including in the oeuvre of Michel Houellebecq. Houellebecq is far closer to Heidegger than Rousseau on this question in that the desire to return to nature has little to do with any positive aspect of natural existence, and everything to do with the mediocrity of modern life. For Houellebecq, the desire to return to nature is often rooted in a base kind of sexual impotence, as in the case of Bruno in "The Elementary

58 Houellebecq, Michel. Extension Du Domaine De La Lutte. Paris: Falmmarion, 1994. Pgs.9-10 
Particles", and the attempt to reconnect with nature is always ill fated and vulgar. In his essay titled "Science and Religion", from “Humanity and its Aftermath", on the subject of Houellebecq's relation to philosophy, he states:

"several of the male characters in Houellebecq's fiction, including the narrator of Extension, Michel Djerzinski, and, at times, Bruno- as a function of their effective exclusion from the sexual economy-are cast in the role of impotent observers of a system whose rules they dispassionately adumbrate, while being unable to penetrate it. " 59

This does not represent a romantic account of noble savagery, nor does it speak to a spiritual yearning for oneness with nature, but is instead a banal and base rejection of the limitations of convention as a scapegoat for the weaknesses of the characters. Additionally, the economisation of sex, rooted as it is in nature, represents for Houellebecq a significant part of the unfolding of technology in history and also a partial shift in focus from Heidegger. However, it can certainly be considered as a continuation of those concerns highlighted by Heidegger.

Indeed, almost all of Houellebecq's books confront the question of the alienation of man from nature in some way. However, the nature that man wishes to return to is complex. In "Extension of the Domain of Struggle” the liberation of the sexual marketplace (sex as ever is a stand-in for nature here) creates both a strong desire on the part of the protagonist to participate, and an extreme revulsion at the brutality and artlessness of the whole thing. Throughout this novel, as the characters meander meaninglessly through their work lives and attempt to find authenticity in the world of casual sex, nature documentaries are playing on television screens60. Commentary on these documentaries always focuses on the extreme, heartless violence of the natural world. Thus nature is both something we suffer being alienated from and something that we fear to return to.

59 Morrey, Douglas. "Science and Religion." Michel Houellebecq: Humanity and Its Aftermath. Oxford: Liverpool UP, 2013. Pg.117

60 Houellebecq, Michel. Extension Du Domaine De La Lutte. Paris: Falmmarion, 1994. Print. 
At this point we can now return to Heidegger's essay. Heidegger argues that, since the advent of modern technology, a new relationship with nature has thus developed, and the bringing-forth that one might associate with technê has given way to challenging-forth. Heidegger states the following,

"the revealing that holds sway throughout modern technology does not unfold into a bringing-forth in the sense of poesis. The revealing that rules in modern technology is a challenging, which puts to nature the unreasonable demand that it supply energy that can be extracted and stored as such" 61

Modern technology thus represents a significant alteration of the relationship between man and the natural world. Man, in many respects, sets himself in opposition to nature in this schema, and is now empowered by modern technology to overcome nature and transform it into a mass of matter whose objectness is entirely contingent upon the utility that man desires to extract from it.

Perhaps the most significant, however, of the innovations in this new technology is the ability to store energy. Whereas a windmill was able to produce energy only when the wind blew, thus forcing man to reckon with and attune himself to nature, the hydroelectric plant is able to store energy in order that its use can be regulated entirely by the will of man.

"Whatever is ordered about in this way has its own standing. We call it the standing-reserve. The word expresses here something more, and something more essential, than mere "stock". The name "standing-reserve" assumes the rank of an inclusive rubric. It designates nothing less than the way in which everything presences that is wrought upon by the challenging revealing. Whatever stands by in the sense of standing-reserve no longer stands over against us as an object." 62

It is here that Heidegger begins to introduce his argument about the truly revolutionary nature of technology. The standing-reserve is not merely a further development of stockpiling, because it

\footnotetext{
61 Heidegger, M. (1977). The Question Concerning Technology. In M. Heidegger, The Question Concerning Technology and Other Essays (pp. 3-35). New York: Garland Publishing inc. pg. 14 62 Heidegger, M. (1977). The Question Concerning Technology. In M. Heidegger, The Question Concerning Technology and Other Essays (pp. 3-35). New York: Garland Publishing inc. pg. 17
} 
reveals in itself the logic of technology as a way to create truth. In fact, the whole rubric of modern science, where nature is tortured and brought to heel in order that she might spill her innermost secrets is present in this technological practice of exercising dominion over nature in order that her energies might be made available to us for our use. This is in many respects the essence of modern technology that Heidegger is attempting to reveal in this essay. This setting upon of nature, its conquest and finally its reduction to a standing reserve which renders meaningless its objective being and reduces it to a mere supply of material is the basis of the technological paradigm. We can, therefore, clearly see the way in which Heidegger uses his brief genealogy of the evolution of technology from the technê of Ancient Greece, where materials could be shaped and used for human ends, via Aristotle's development of the four causes, to modern technology, and the absolute mastery over nature that it represents. In doing this Heidegger aims to shed light upon the fundamentally transformative impact of modern technology on man's relationship with the world, and the way in which this shapes both the world and the human agents who operate within that world.

Again one can see a similarly critical perspective on modern technology and its pursuit of the mastery of nature, in order to bring it to heel, in the works of Michel Houellebecq. For Houellebecq the mastery of nature is every bit the double-edged sword that it is in Heidegger's essay. In the present-day setting of "The Elementary Particles" and the distant-future dystopia of "The Possibility of an Island" we see a vision of scientific and technological progress that is at once both limitless in its possibilities and terrifying in its consequences. While the first of these is the more directly related to Heidegger's questioning of technology, with the search for the titular particle literally involving the challenging forth of the entirety of the natural world into a singular element that can be harnessed and stored to make whatever man wills, the second presents the 
most startling and thought-provoking application of Heidegger's philosophy in a way that reflects the rapidity of technological development since his time.

In “The Elementary Particle” Houellebecq's protagonist, Michel Dzerzinski, occupies a world where the conventions of Judeo-Christian civilisation have been stripped away and replaced by the liberal mores of the free love movement, supposedly a return to a more natural state of affairs, with the abandonment of Christian moral aversions to adultery, abortion and divorce 63. However, the result of this version of the death of God is not anything close to a return to the state of noble savagery but rather concludes with the absolute domination of nature by technology. This occurs in thought before in occurs in practice, the way in which life is understood can be seen to have changed by observing attitudes towards the old and the unborn.

\section{"On one hand the foetus, a small mass of cells at differentiated stages of development, could not be seen to have an autonomous individual existence..... On the other, the elderly, a mass of cells in a state of constant degradation, could only really be availed of the right to survive on condition of maintaining sufficient organic functionality" 64}

This represents a technological account of natural life that relies upon the setting upon of the individual, the breaking down of the body into its composite parts, and the separation of bodies, according to these compositions, into those with the right to life and those without it. This recalibration of man's relationship to nature from the Judeo-Christian to the technological precisely mirrors the transition to the technological relation to nature that is described in Heidegger's essay. However, while Heidegger exemplifies this trend with a discussion of the damming of a river, Houellebecq, writing decades later in light of unforeseeably rapid technological advances, can project this trend into a far more ambitious direction. Scientific

63 Houellebecq, Michel. Les Particules Elementaires: Roman. Paris: Flammarion, 1998. Pg. 60 64 Ibid 
advances in the novel lead to the discovery of an "elementary particle" that is the building block of all matter in the universe65. With this particle, scientists gain absolute mastery over nature and are able to modify and create cells, atoms and minerals. Strangely, one of the first applications of this new scientific power was the elimination of sexual desire by way of the covering of the entire body with erogenous tissue, allowing for the non-sexual satisfaction of lust. For Houellebecq, sex is always linked to the natural order and its overcoming here represents an important part of the mastery of nature. Eventually this leads to human cloning, which in turn severs the link between man and reproduction by placing technology in between. Humanity thus drifts into a sort of purgatory and waits for its extinction, having overcome all natural compulsions and revulsions.66 "The Elementary Particle" can therefore be considered as a continuation of the concerns expressed by Heidegger about the damming of the Rhine River. Much as he saw this as a rupturing of the symbiotic relationship between man and nature, Houellebecq predicts a future where this rupture will reach its logical conclusion, and where technology will entirely sever the link between human being and human nature.

"The Possibility of an Island" describes a similarly dystopian vision of a technological future where this process of the technological transcendence of human nature has resulted in the advent of the "neo-human". The neo-human is the result of a failure to be reconciled with the inevitability of death and the technological capacity to clone human bodies, upload human minds into digital code and achieve immortality by downloading these codes into new bodies at the point when age begins to take its toll.67 Houellebecq leaves the reader in no doubt that this is not an actual escape from mortality but merely gives the dying mortal the comfort of believing that he

65 Houellebecq, Michel. Les Particules Elementaires: Roman. Paris: Flammarion, 1998. Pg.126-127

66 Houellebecq, Michel. Les Particules Elementaires: Roman. Paris: Flammarion, 1998. Pg.315

67 Houellebecq, Michel. La Possibilite D'une lle: Roman. Paris: Flammarion, 2005 
will live on in the body of a clone. These clones dedicate the entirety of their lives to the reading of accounts of their predecessors' lives and attempting to construct a complete "autobiography". This is done in order to aid the next clone in completing the transfer of the original person's being into a new body. The mortals lived while the clones read and write about their lives. This novel contains, therefore, an interesting perspective on the overcoming of nature. Houellebecq is attempting to show that technology allows us to escape from the struggle against nature, only to discover that it is this very struggle that gives meaning to existence. This leads to defections among the neo-humans, who leave their habitats to wander the barren wastelands of a drought stricken future earth in search of "savages", those that resisted the advances of technology and rejected the opportunity to become neo-humans68. Daniel 25 , the $24^{\text {th }}$ descendent of the novel's protagonist, becomes one such defector, and explains the defectors motives in the following way: "rejecting the incomplete formalist paradigm, we aspire to return to the universe of infinite potentiality. Having ended the unfolding of becoming, we have found ourselves in a state of limitless, indefinite stasis.69 The clones have no need for food, drink, sex or companionship beyond the presence of a pet. Their lives are thus entirely empty beyond the obsessive compilation of details about their mortal progenitor's doings in the hope that this will allow for a genuine transference of personhood to the next clone, rather than the bizarre form of reproduction that has been taking place thus far. Aside from the allusion to Heidegger's existential writings, to be explored in the next division, this speaks directly to Heidegger's belief that the overcoming of nature, as it unfolds in history, would begin to reveal itself to man as these technologies develop and become progressively more successful in their goal.

68 Houellebecq, Michel. La Possibilite D'une lle: Roman. Paris: Flammarion, 2005

69 Houellebecq, Michel. La Possibilite D’une lle: Roman. Paris: Flammarion, 2005. Pg. 393 
As we have seen in this section, Houellebecq postulates an interesting relationship between man and nature. Man wishes to return to a more natural state and attempts to do so by destroying the conventions of religion that stood in the way of the fulfillment of natural urges, particularly sexual urges. However, as this is happening technology is rapidly engaging in the overcoming of nature and the separation of the human being from his natural environment. This is best exemplified in "The Possibility of an Island" where Vincent, leader of the new age "Elohimite" commune, who pursue immortality through cloning, sets up the cult in order to escape from the conventions of modern life and return to nature, and then proceeds to fill it with scientists engaged in the pursuit of immortality. At one point he leads his followers in meditation and asks them to strip naked and lie on the floor in order that they can "imagine the volcanic energy emanating from the earth, this incredible energy, greater than that of atomic bombs; make that energy your own, incorporate it into your bodies." $70 \mathrm{He}$ goes on to ask them to attune themselves similarly to the power of the sun. This desire to be one with nature, to strip off the confines of convention, represented here by clothes, and develop a more direct relation to nature eventually morphs into something entirely hostile to this end. Vincent's sermon proceeds to embrace technology's settingupon of nature and the entire process described by Heidegger when he continues, asking his followers to

\section{"try, by meditation to visualise our cells, which contain the DNA that is the depository of our genetic information.... Absorb the idea that this contains your schema, the schematic for the construction of your body, and that this information, unlike material, is immortal." 71}

Thus the Elohimites attempt to escape from the confines of convention by returning to a nature of which they are engaged in the conquest. They cannot conceive of any alternative way to approach

70 Houellebecq, Michel. La Possibilite D’une lle: Roman. Paris: Flammarion, 2005. Pg. 230

71 Houellebecq, Michel. La Possibilite D’une lle: Roman. Paris: Flammarion, 2005. Pg. 230 
their world, because technology has so fundamentally defined the relation of man to nature, the nature of the quest for truth and the way in which man goes about interacting with the world around him. For Houellebecq, technology has fundamentally changed the way in which truth and wisdom are pursued, and it will not be evident to man quite what the repercussions of overcoming nature will be until it is far too late. It is not until Daniel 25, that Houellebecq's novel features a character who genuinely understands what man has done by transcending his own mortality through technology, and his only option is to wander into the desert in search of a kind of authentic, nontechnological relation to the world and himself that he cannot even conceptualize. For Daniel 25, this rediscovery of life in nature does not come until he begins to die, recognises his being towards death, and finds an authenticity of a kind in death.

From this we can conclude the Houellebecq shares Heidegger's concerns about the impact of the technological project of overcoming nature. Both see the purpose of technology as being hidden behind the obvious material or vulgar benefits that it provides and both see this hidden transformative power as something which threatens to alter fundamentally the relationship between man and technology in a way that is alienating and self-negating. Houellebecq, though, is separated from Heidegger by several decades of rapid technological change and is thus able to root his critique of the technological in far more frightening possibilities than could have been conceived of by Heidegger. The damming of the Rhine River, while less overtly concerning, can certainly be considered as a baby step in the journey towards the neo-human. However, while both clearly share this fear of the awesome transformative power of technology, Houellebecq's characters are, without exception, either powerless in its face or incapable of ever seeing the ruin towards which they are thrown. However, Heidegger, at this stage in his career, is significantly less pessimistic. 
Heidegger's relative optimism is solely due to his belief in the saving power of technology. The more that the aforementioned dangers presence themselves in the unfolding of technology, the more evident this saving power becomes. In brief, it is precisely in the increasing evidence of the threat to our connection with nature that Heidegger believes the saving-power of technology lies. In order to demonstrate this Heidegger introduces a tentative answer of his own, rooted in the poetic way of bringing-forth, that he hopes will demonstrate the possibility of an alternative to the technological in order to deliver man from the fate outlined above. Perhaps unsurprisingly, he makes this argument by drawing back to his belief that Platonic metaphysics represents the original error of the modern world. He proposes that the unfolding of technological Enframing has revealed the limitations of the current conceptions of essence as well as causality. He proposes a new way of understanding essence. "If we speak of the "essence of a house" and the "essence of a state," we do not mean a generic type; rather we mean the ways in which house and state hold sway, administer themselves, develop and decay- the way in which they essence" 72 This represents a change from the classical idea that essence is derived from a permanent and unchanging generic form, of which manifestations in the world are mere instances or variations, to a conception of essence which recognises things as being in a constant state of becoming. It is therefore the dynamic becoming of the state and the house that constitute their essence rather than a permanent essential being. In light of this, Heidegger proposes, tentatively, that this saving power may take the form of a rediscovery of the poetic mode of bringing forth into light that the Greeks understood to be a kind of technê itself.

"Why did art bear the modest name technê? Because it was a revealing that brought forth and hither, and therefore belonged within poesis. It was finally

\footnotetext{
72 Heidegger, M. (1977). The Question Concerning Technology. In M. Heidegger, The Question Concerning Technology and Other Essays (pp. 3-35). New York: Garland Publishing inc. pg. 30
} 
that revealing which holds complete sway in all the fine arts, in poetry, and in everything poetical that obtained poesis as its proper name"73

In other words, Heidegger feels that his own questioning of technology might have revealed the saving power in the form of poesis. The Ancient Greeks understood technê, poesis and episteme as equally valid and important modes of revealing truth. Heidegger's essay argues that modernity privileged a particular form, technê, over all other paths to truth; and that it is perhaps in the rediscovery of the poetic that man might be able to bring forth the truths that have become alien to him as a result of his being "Enframed" in technological modes of thinking. Simply put, the unfolding of technology has revealed to us the absence of a more abstract and beautiful form of truth and has awakened Heidegger to the need for a restoration of poetic truth to the same level of prestige as technological or scientific truth. This is perhaps the saving power that technology has unconcealed in its unfolding. Rather than seeing the purely rational, observable and measurable element of what is we should also be open to the poetic and non-material qualities of what is becoming. Not only does this form of knowledge-by-poesis reintroduce some of the beauty and exaltation that Heidegger laments as having been lost to us, it also opens the possibility for an exploration of the whole truth of technology that is not captive to the logics of technology itself. "The poetical brings the true into the splendour of what Plato in the Phaedrus calls ekphanestaton, that which shines forth most purely. The poetical thoroughly pervades every art, every revealing of coming to presence into the beautiful." 74 It is possible that in allowing ekphanestaton to come into unconcealment by way of a poetic bringing-forth of truth, man might be able to liberate himself from the confines of technological "Enframing". However, Heidegger cautions that this is not necessarily the correct questioning, and is only a possible solution to the problem at hand. $\mathrm{He}$

73 Heidegger, M. (1977). The Question Concerning Technology. In M. Heidegger, The Question Concerning Technology and Other Essays (pp. 3-35). New York: Garland Publishing inc. pg. 34 74 ibid 
concludes by arguing that man's salvation lies in the asking of questions such as that posed in his essay and by the exploration of potential solutions as he briefly does in the case of poesis. He concludes his essay with the hope that, "the closer we come to the danger, the more brightly do the ways into the saving power begin to shine and the more questioning we become. For questioning is the piety of thought." 75

While the connection between all of this and the rise of the "far-right" in France may not be entirely obvious, it is the contention of this paper that in the analysis above we can observe the beginnings of a philosophical explanation for this phenomenon. Houellebecq's novels demonstrate that the concerns and anxieties about technological development and modernization have persisted into the present and have, if anything, become heightened by the rapid advance of technology rather than assuaged by it. The belief that, for all the obvious material benefits of technology, we are being torn from our natural moorings and thrown into a new, and alienating, relation to the natural world is clearly acute and it is therefore unsurprising that a political movement that stands in opposition to the project of technological modernity might gain traction. This is not to say that the Le Pens and Trumps of this world are avid readers of Heidegger or Houellebecq, but rather is to suggest that they have come to be seen as an embodiment of opposition to a political mainstream whose embeddedness in the unfolding of technology, personified by their reliance on economic metrics and aversion to the natural passions of "the masses", make the "far-right" the beneficiaries of the anxieties about the unfolding of technology that have been described above. While the above does not tell us much about the nature of the reaction personified by the "far-right" it does tell us a lot about the conditions that have created the desire for an alternative, conditions that will be shown to have been exploited, perhaps unwittingly, by the National Front. Those who share

75 Heidegger, M. (1977). The Question Concerning Technology. In M. Heidegger, The Question Concerning Technology and Other Essays (pp. 3-35). New York: Garland Publishing inc. pg. 35 
Houellebecq's pessimism find them attractive as a protest or insult thrown at the political mainstream while those who share Heidegger's relative optimism find in their mytho-poetic invocation of patriotism, past glory and the promise of restored greatness a political project that transcends the boundaries of the technological. In fact, much of the culture of the "far-right", perhaps even more so that of the "alt-right", can be understood as a mytho-poetic aesthetic response to the technological status-quo. Observers of these particular movements, particularly online, will notice the prevalence of the invocation of semi-mythologised historical figures and events. The fact that Marine Le Pen names her daughter Jehanne (the first name of Joan of Arc)76; the fact that "far-right" online avatars often sport names in honour of Charles Martel (commander of the Frankish troops at the battle of Tours) or John Sobietski (leader of the Polish Cavalry in their lifting of the Siege of Vienna); the adoption of Wagner's "Pilgrim's Chorus" and Kipling's "The Wrath of the Awakened Saxon" as a sort of unofficial anthem and poem of the "alt-right"; the importance of Crusader and Nordic iconography to neo-Nazi gangs and Hungarian fascist paramilitary groups77; all combine to suggest that such groups are indeed looking beyond the bounds of the technological in order to develop a mytho-poetic aspect to their political projects. Like the Nazi's before them, they seem to wish to develop a political aesthetic that appeals to this mytho-poetic image of a great national past that stands in stark contrast to the staid, technological civic nationalism of the Western liberal tradition78. At this point, admittedly, the argument is

76 "Les Trois Enfants De Marine Le Pen." Les Trois Enfants De Marine Le Pen. N.p., n.d. Web. 10 Feb. 2017.

77 "A Look at Racist Skinhead Symbols and Tattoos." Southern Poverty Law Center. N.p., n.d. Web. 10 Feb. 2017. <https://www.splcenter.org/fighting-hate/intelligence-report/2006/look-racist-skinhead-symbols-and-tattoos> 78 It is important at this point to discuss what I mean by "liberal". I will not attempt to provide an exhaustive or comprehensive account of liberalism in this footnote. However, it will become clear as this thesis progresses that I am discussing a particular kind of liberalism that defies political boundaries or easy classification. This is a liberalism that is not specific to either the left or the right, but which finds perhaps its best expression in the values of Silicon Valley. It consists of the making of a virtue of openness, the new over the old, technological advancement and the breaking down of boundaries. It is related to, but distinct from, the classical liberalism of the Scottish Enlightenment in particular, whilst also being separate from the neo-liberalism that is the bete noir of the Bernie Sanders left, which is also not liberal in this way. Its advocates range from David Cameron and Emmanuel 
Division One.

somewhat vague due to the fact that abstract philosophical concepts like those discussed above are so far removed from our political environment. However, narrowing the focus to more concretely political considerations brings the substance of this argument more sharply in to view.

Macron to Hillary Clinton and Tony Blair. The difficulty in pinning down precisely what liberalism, of this kind, is will be shown later on to form a large part of the challenge in confronting the "far-right" 


\section{Chapter Two: Globalisation, Equality and the Age of the World Picture}

In order to provide this more focused picture it is fitting next to look at Heidegger's “The Age of the World Picture”. In this text Heidegger introduces his concept of the world as picture, arguing that this is the defining characteristic of the modern technological age, and criticising the globalisation and the democratization, or levelling out, that results from the paradigm shift in the relation between the individual and the world. This will be approached in the following way. Two key claims made by Heidegger will be examined. To begin with, that science is in the business of metaphysics, and has, via Christianity, become the grounding and basis upon which the modern age is constructed. After this, attention will be turned to Heidegger's conception of the world picture and the way in which this has demolished spatial, temporal and hierarchical boundaries, leading to a simultaneous process of radical levelling out and globalisation. These two critiques of modernity are present in the works of Michel Houellebecq; specifically "Submission", "Platform" and "The Map and the Territory"; therefore, much as they were in the previous section, these Houellebecquian perspectives will be interwoven into the latter half of the exegesis in order to demonstrate the ways in which Heidegger's ideas have survived, morphed and thrived in the context of contemporary France.

Heidegger begins "The Age of the World Picture" by discussing the relationship between the metaphysical grounding of a particular age and its significance to the conceptualisation of everything encountered in that age. He claims that the metaphysical structures that are taken as a given by man as he encounters and confronts phenomena and objects within that world will inevitably influence the forms taken by these objects and phenomena in the eye of their beholder. He says: "Metaphysics grounds an age, in that through a specific interpretation of what is and through a specific comprehension of truth it gives to that age the basis upon which it is essentially 
formed. This basis holds complete dominion over all the phenomena that distinguish the age."79 Simply put, the dominant metaphysical assumptions of any given age will dictate the way in which specific concepts and phenomena are understood in that age. Accordingly, he identifies modern science as the essential phenomenon of the modern age, as it is a scientific understanding that dominates and shapes the way in which we approach and encounter the universe. Heidegger identifies three fundamental developments that result from the dominance of scientific reasoning in the metaphysical reflections of his age. They are, firstly, the transformation of praxis by machine technology, a transformation "wherein praxis first demands the employment of mathematical physical science." 80 This is a fundamental change in the way in which action can be engaged in, demanding as it does a grounding in the logos of science and mathematics, which represents the obliteration of the boundaries between thought and action in the everyday relation of the artisan, worker or craftsman to those things which are most immediately at hand over the course of his day to day life. Secondly, Heidegger identifies the reduction of the work of art to the realm of mere subjective experience and thus the purview of the aesthetic gaze. In other words, the work of art ceases to portray, or seek to bring into unconcealment, those things that transcend the subjective experience of man but rather becomes "an expression of human life 81 ", and therefore loses its ability to connect man with that which transcends his temporal experience of the material world. Finally, Heidegger identifies the loss of the gods as perhaps the greatest metaphysical development of the modern age. For Heidegger this does not mean we live in a secular or atheist world, he is

79 Heidegger, M. (1977). The Age of the World Picture. In M. Heidegger, The Question Concerning Technology and Other Essays (pp. 115-153). New York: Garland Publishing inc. pg. 115

80 Heidegger, M. (1977). The Age of the World Picture. In M. Heidegger, The Question Concerning Technology and Other Essays (pp. 115-153). New York: Garland Publishing inc. pg. 116

81 In the original German, according to William Lovitt, the term human life, or Erlebnis, is employed as a pejorative to connote the banality of this human experience in comparison with the transcendent subjects of venerative religious art. Ibid. 
quick to point out that "the world picture is Christianized inasmuch as the cause of the world is posited as infinite, unconditional, absolute." 82 However, he believes that Christianity has transformed a genuine metaphysical belief, that there is in fact an interested and involved agent looking upon the world and orchestrating all human affairs, into a vague and platitudinous "worldview" that requires only an indecisive commitment to actual religious belief, preferring the subjective "religious experience". The void left by this loss of the gods is filled by psychological or historiographical myth, and the real business of providing metaphysical foundations for our age is left to science alone. As a result Heidegger wishes to explore the essence of modern science, a science which is far removed from the ancient Greek episteme or the science of the Middle-Ages. The essence of science is discussed in greater length in the following chapter. For now, let us merely state that, in short, the differences between modern science and ancient science are not rooted in a progressive improvement of the work of the scientist over time but rather are reflective of different metaphysical foundations and a different understanding of truth. As outlined in "The Question Concerning Technology" the boundaries of the questioning are what lead modern science to its conclusions rather than the superiority of its methods.

Subsequently, it is precisely towards these supposedly objective methods that Heidegger turns his attention next. He argues that science establishes its claim to objective truth by projecting onto the world a "fixed ground plan" to which research must adhere if it is to be considered rigorous. Again this is a critique that will be elaborated upon in the next chapter; but we can conclude for now that, in sum, Heidegger's critique of modern science fundamentally rests upon the idea that science presupposes particular metaphysical claims about truth and makes the imposition of a "fixed ground plan", based on these claims, the necessary condition of rigour in

$82 \mathrm{lbid}$. 
the study of the subjects of scientific inquiry. This creates a sphere in which science and mathematics can seek to fully understand a world that it has reduced to a set of scientific and mathematical units, creating an illusion of completeness where in fact there is only the most partial of truths. Heidegger develops this critique further, and this will be discussed in the next section of this chapter, but the basic notion that science directs itself towards certain conclusions, imposing upon the objects of its study a particular schema which begs a scientific kind of answer, is introduced here. This is in order to postulate that there might be a part of the "true" whose bringing into unconcealment is beyond the methodological capabilities of the sciences. In other words, Heidegger wishes to convince us that we need to be open to the possibility of a non-scientific way of encountering the universe, an openness to the non-inevitability of those outcomes of globalisation and levelling out that he goes on to describe subsequently.

It is at this point that our attention may turn to some of the impacts that this scientific way of encountering the world has had upon the objects under observation. Heidegger begins by highlighting the abandonment of the order and hierarchy of the classical view of the cosmos for the mere motion of matter across space. "Motion means change of place. No motion or direction of motion is superior to any other. Every place is equal to every other. No point in time has preference over any other." 83 Herein we see the metaphysical roots of the "levelling out" that Heidegger is so critical of. All ordering of the cosmos is voided of any content and we are left merely with the inconsequential movement of matter from one place to another. Only an event that is visible as a movement of matter can be considers as an event in nature, and physical research is bound by its methodologies to adhere to this schema. This applies also to the humanistic sciences, which due to the processes discussed above, must by definition engage in the reduction of the 
human being to a mere mass of matter in motion. Similarly, history ceases to be the same art form as was practiced by Thucydides and becomes subject to the scientific definition of research. This results in a similar forcible conforming of historical events into a pre-ordained schema with great people and events being described as exceptions. "Because historiography as research projects and objectifies the past in the sense of an explicable and surveyable nexus of actions and consequences, it requires source criticism as its instrument of objectification." 84 Thus the history of a people is reduced to a series of objects, source materials, that are to be subjected to the same setting upon that challenges forth that defines, corrupts and trivializes our relationship with the natural world. We are therefore no longer engaged in the admiration of the great civilisations of the past, we no longer look upon the great thinkers and leaders of the past as example to be imitated but rather see them as objects to be placed within a timeline or schema and shown to be a part of the progression of history from one thing to another. The "academic neutrality" of the social scientist and the historiographer makes impossible the creating of hierarchies that could distinguish between the virtues of different states, political orders and civilisations. This is an example of the process of levelling out, in this case in the realm of history and memory, which is playing out because our encounter with the universe has come to be dominated by the non-discriminatory and nonhierarchical schema of a scientific metaphysics where no weight, or value, is given to beauty, goodness and honour. This is an ever intensifying process due to the ongoing nature of scientific research. Science must constantly adapt itself to its findings, adapt its methodology to those things it encounters, and respond to the fact that "the methodology of the science becomes circumscribed by means of its results." 85 Heidegger then begins to circumscribe the development of what he

84 Heidegger, M. (1977). The Age of the World Picture. In M. Heidegger, The Question Concerning Technology and Other Essays (pp. 115-153). New York: Garland Publishing inc. pg. 123 85 Heidegger, M. (1977). The Age of the World Picture. In M. Heidegger, The Question Concerning Technology and Other Essays (pp. 115-153). New York: Garland Publishing inc. pg. 124 
believes to be a modern technological intellectual. "The scholar disappears. He is succeeded by the research man who is engaged in research projects. These, rather than the cultivation of erudition, lend to his work its atmosphere if incisiveness." 86 As such, the pursuit of wisdom, the elaboration of the boundaries of the beautiful, is replaced by the endless reproduction of scientific research and the compilation of data, units of information and the expansion of the domain of the scientific into the territory of the scholar. "Alongside him, the increasingly thin and empty Romanticism of scholarship will still be able to persist for some time in a few places." 87 As such the scientific is slowly engaged in the conquest of every aspect of intellectual life while simultaneously differentiating itself from other forms of knowledge seeking. It promotes and requires a kind of intellect that is unable to differentiate between the beautiful and the ugly, and is only able to set upon the objects of research in order to extract from them something of use.

That the relationship between the scholar and, to take one example, our history has been corrupted and neutered by the scientific way in which we relate to the objects of research is strongly evidenced in the works of Michel Houellebecq. Houellebecq often situates his characters in scientific milieu, or at least in the world of intellectual pursuits, and this, when coupled with the miserable, meaningless lives that they usually live, forms a sustained and often highly moralistic criticism of the processes described above. His characters are unable to appreciate beauty and are always alienated by their very intellect from those things that might be revered or honoured, they are essentially the type of intellectual that Heidegger derides above. One such example can be found in "Submission". In this novel, the protagonist, François, visits the town of Rocamadour, where Charles Martel repelled the final offensive of the Islamic Caliphate into Western Europe

86 Heidegger, M. (1977). The Age of the World Picture. In M. Heidegger, The Question Concerning Technology and Other Essays (pp. 115-153). New York: Garland Publishing inc. pg. 125 $87 \mathrm{lbid}$. 
and "saved" Christian Europe from Islam. He discusses the significance of Rocamadour with a friend who explains to him its central importance to Christian history and civilisation, telling him the following:

"the pilgrimage to Rocamadour was one of the most famous in Christendom, you know? Henry Plantagenêt, St. Dominic, St. Bernard, St. Louis, Louis XI, Phillipe le Bel...all came to kneel at the feet of the Black Madonna, all crawled, on their knees, up the stairs that lead to the sanctuary, praying humbly for the forgiveness of their sins. At Rocamadour, you can really measure to what extent medieval Christendom was a great civilisation" 88

Even having been made aware of the significance of this place to the history of his people, and the extent of its very centrality to the history of the Christian West and France, François quickly finds his relation to this place being defined entirely by utility. After a week or so in Rocamadour, his attention is taken up by the titillating pictures being sent to him from Israel by his mistress, the availability of hotel rooms and the "permanent renewal of tourists, all a little bit different, all a little bit the same, who proceed, camera in hand" 89 This historical town has been transformed into a mere tourist attraction where tourists can find good food, a nice hotel room and lots of good photographic opportunities. This is both exactly like the Rhine River, discussed in the previous section, and the indifference manifested by François towards this is evidence that the "thin romanticism of the scholar" has been entirely replaced by the detached neutrality of the researchers. This is a direct exemplification of the attitude towards history that is described above by Heidegger, where the historian avails himself of a collection of facts, and observes sites and artifacts, but feels no sense of community with his ancestors and no sense of the spiritual and historical significance of a place that once drove kings and saints to crawl on their knees in awe.

88 Houellebecq, Michel. Soumission: Roman. Paris: Flammarion, 2015. Pg. 161

89 Houellebecq, Michel. Soumission: Roman. Paris: Flammarion, 2015. Pg. 164 
As this conception of knowledge-as-research becomes more ubiquitous and totalising, the way in which man relates to his world is increasingly framed by this process of a subjectified man calling an objectified world to account in order that it represents itself to him. This becomes the basis of the "world picture" (Weltbild). Weltbild is a compound noun consisting of two parts that Heidegger defines in the following way. Welt, or World, refers to the totality of what "is" and bild, though literally image, is translated to picture for the following reason. Bild in this context refers not merely to a copy of an object but rather, as in the context of the statement "we get the picture", it refers to a certain synthesis of the subjective representation, or the signifier, and the essential being of the object being signified. Thus the world picture refers to a holistic and globalized conception of the whole of being that synthesises the symbol and the symbolized in a way that resembles comprehensive knowledge. This is the fundamental conceit of science, that it can bring forth the whole of the truth into unconcealment. The great innovation of this is not that the world picture has changed from that of the Middle-Ages but that the world is picture at all. In the MiddleAges "to be in being means to belong within a specific rank of the order of what has been createda rank appointed from the beginning- and as thus caused, to correspond to the cause of creating." 90 This is in stark contrast to the modern world picture, which contains nothing beyond the calling forth of the object world so it may report itself to the human subject. For Heidegger, the consequence of this is a radical levelling out of the world is a metaphysical outlook where the foundations of the classical hierarchies, that distinguish the beautiful from the ugly for example, are levelled out to a neutral conception of being that is merely the reporting of matter for our observation.

90 Heidegger, M. (1977). The Age of the World Picture. In M. Heidegger, The Question Concerning Technology and Other Essays (pp. 115-153). New York: Garland Publishing inc. pg. 130 
This is represented in Houellebecq by the belief that the Western world has abandoned any ambition towards greatness and has instead embraced mundanity. This loss of faith in the virtue of their own civilisation is a by-product of the process of levelling out described above but is also revelatory of the Heideggerian aversion to globalisation. Houellebecq describes this change in Western outlook by saying:

"My European ancestors had worked hard for several centuries; they had undertaken to dominate and then to transform the world, and to a certain extent they had succeeded. They had done so out of economic interest, a taste for work, but also because they believed in the superiority of their civilisation: they had invented "the dream", progress, Utopia, the future. This consciousness of a civilizing mission had evaporated during the course of the twentieth century. Europeans, at least some of them, went on working, and sometimes working hard, but they did so for gain or out of a neurotic attachment to their work; the innocent consciousness of their natural right to dominate the world, and to direct its future, had disappeared. "91

The abandonment of hierarchies, and the desire for greatness that is dependent upon it, has led to a levelling out that has robbed western life of much of its purpose. Having no attachment to its own civilisation, because to modern Western eyes the West is just one of many types of society called to report itself to scientific observation, and being unable to make any kind of moral or aesthetic distinction between one type of society or another, the idea of Utopia, of the civilizing mission or of the destiny of a people is irreconcilable with the metaphysics of modern science. The idea that the West has lost its ability to distinguish between things, and prefers merely to see differences, is a relatively common theme in Houellebecq's books. The most striking, and familiar sounding, example of this comes in "Platform" where, in the aftermath of a Jihadist terror attack on the hotel in which the protagonist is staying, " the journalist (...) squarely accused the Aurore group of promoting sex tourism in third world countries; and added that under these circumstances

91 Houellebecq, Michel. Platforme. Paris: Flammarion, 2001. Pg. 287 
the reaction of the Muslims was understandable." 92 The inability to make a moral distinction between sex tourism and mass murder is directly linked to the transition described by Heidegger whereby the placement of beings in particular ranks within a hierarchy has been replaced by the neutral separation of beings into categories that are merely different. This example, sadly, is undeniably applicable in today's world, where so many showed themselves incapable of making a moral distinction between the drawing of mildly offensive cartoons and the cold-blooded murder of 17 people in the attacks on the Charlie Hebdo offices. Similarly, in Houellebecq's often disturbingly direct critiques of the contemporary age, we see a portrayal of an art world incapable of distinguishing between the great works of art and faddish kitsch93; a comedy scene that cannot distinguish between satire and gratuitously vulgar cruelty, where Houellebecq's protagonist makes a career out of malevolently offensive sketches with titles like "Pound my Gaza Strip (my Powerful Jewish Settler)"94; and an intelligentsia that sees no problem in being complicit in the replacement of Western democratic norms with religious theocracy95.

This results from what Heidegger sees as a fundamental recalibration of the relation of man to that which is "at hand", and the world more generally. This also means that man no longer stands at a particular place in relation to the world at hand but rather becomes the agent that makes the representations of that which is. "What is decisive is that man himself expressly takes up this position as one constituted by himself, that he intentionally maintains it as that takes up by himself, and that he makes it secure as the solid footing for a possible development of humanity."96

\footnotetext{
92 Houellebecq, Michel. Platforme. Paris: Flammarion, 2001. Pg. 328

93 Houellebecq, Michel. La Carte et le Territoire. Paris: Flammarion, 2010.

94 Houellebecq, Michel. La Possibilite D’une Ile: Roman. Paris: Flammarion, 2005

95 Houellebecq, Michel. Soumission: Roman. Paris: Flammarion, 2015

96 Heidegger, M. (1977). The Age of the World Picture. In M. Heidegger, The Question Concerning Technology and

Other Essays (pp. 115-153). New York: Garland Publishing inc. pg. 132
} 
This is equally present in Houellebecq. Though he does not make such a direct link between the scientific method and rootlessness, he certainly sees the de-racination of man as an inevitable outcome of modernity. He situates this more so in modern institutions such as capitalism and political liberalism but these share the same essential characteristics as science in Heidegger's works. Specifically, they create a direct and unmediated subject-object relationship between the individual and the world. In "Platform" the Western world is characterised as being entirely devoid of any genuine attachment to home, which is merely the place of work, and beset by an unquenchable thirst for temporary escape. "As soon as they have a few days of freedom, Western Europeans rush to the other side of the world, they fly half way across the world, literally behave as if they had just broken out of jail... My dreams are mediocre. Like any other Western European, I dream of travelling." 97 The need to flee half way across the world is a product of the advent of the world picture. Western Europeans have no specific connection to their places of birth, because they are abstract individual subjectivities rather than members of a national community, and therefore are alone in the face of the object of the world. He thus seeks mediocre satisfactions, "most of them do nothing; sometimes, they pay for sexual tourism. But only in the best case scenario: to go and see a whore remains a way to maintain a tiny bit of human contact." 98 , or merely the break from work that travel can offer. The modern European "citizen of the world" is thus entirely incapable of seeing any depth in his own culture, or indeed in those cultures he wishes to temporarily escape into to get away from his work. The tourists show a facile interest in the ancient civilisations of Thailand and Cambodia but are mostly concerned with lying on the beaches and visiting the brothels. Much as their own country is defined in their eyes purely in terms of the purpose it serves for them, the countries they visit are defined purely by their ability to provide 
relaxation, underage prostitutes and exotic experiences99. This leads to a bizarre kind of mutual objectification where the tourists and the Orientals both consider one another in purely objective terms. Houellebecq describes this relationship as follows,

"on one hand you have several hundred million Westerners who have everything they could want except they no longer manage to obtain sexual satisfaction. They keep looking ceaselessly, but they cannot find anything, and they are miserable to the core. On the other hand, you have several billion people who have nothing, who are starving, who die young, who live in conditions unfit for human habitation, and who have nothing left to sell except their bodies and their unspoiled sexuality. "100

This is directly related to Heidegger's concept of the world-picture and the way in which modernity has torn people from any moorings in their home countries, and any understanding of the moorings of others in their homelands, and thrown them into a new relation to the world. They stand alone as individuals, are the sole reference around which their entire experience of the world is oriented, and can only relate to the world around them as an object for observation and utility. Houellebecq recognises this directly in "Submission", where his protagonist is unable to understand his Jewish mistress' desire to return to Israel saying, "it seemed strange, I told myself, to leave a country, France, because one fears hypothetical dangers to emigrate to a country where the dangers have nothing of the hypothetical."101 For the modern Frenchman, the calculus is entirely one of personal physical safety and rational choice, the desire to be among one's people and in touch with one's roots in entirely alien to such uprooted people. However, there is a certain irony present in Heidegger's work, that is lacking in Houellebecq's bleaker picture, as it is precisely this uprooting of man from any mooring, and the transformation of the individual into a rootless subject adrift in the universe that reveals to man the need for a different kind of knowledge

99 Houellebecq, Michel. Platforme. Paris: Flammarion, 2001.

100 Houellebecq, Michel. Platforme. Paris: Flammarion, 2001. Pg.234

101 Houellebecq, Michel. Soumission: Roman. Paris: Flammarion, 2015 Pg. 165 
and the transcendence of the hegemony of the technological. Part of this is the effect of the replacement of genuine adherence to metaphysical principles with the vague conception of a world-view. This results from man's absolute mastery of his world. "The phrase 'world view' asserts itself as the name for the position of man in the midst of all that is, is proof of how decisively the world became picture as soon as man brought his life as subiectum into precedence over other centers of relationship." 102 As a result the whole universe is oriented around the subjective experience of the individual and his particular view of the world. All is taken in to and referred back to this subjective experience, an experience that is absurdly posited to be a novel insight. "Just as necessarily and legitimately as everything must change into life-experience for modern man the more unlimitedly he takes charge of the shaping of his essence, just so certainly could the Greeks at the Olympian festivals never have had life-experiences."103 Having re-oriented the world around his own viewpoint, man becomes the ultimate authority from whom all measures and guidelines emanate. The political, then, becomes a struggle between competing worldviews where the guile, ingenuity and calculation with which science equips man serves to contribute to this struggle. Science thus becomes indispensable in order for annihilation to be averted. Thus the universalization of the scientific and technological becomes inevitable, as the political struggle is now global in scale, and thus the gigantic makes its entrance on to the scene.

The gigantic, counter-intuitively, often appears as a shrinking or a reduction.

"The gigantic presses forward in a form that actually seems to make it disappear- in the annihilation of great distance by the airplane, in the setting before us of foreign and remote worlds in their everydayness, which is produced at random through radio by a flick of the hand." 104

102 Heidegger, M. (1977). The Age of the World Picture. In M. Heidegger, The Question Concerning Technology and Other Essays (pp. 115-153). New York: Garland Publishing inc. pg. 134

$103 \mathrm{Ibid}$

104 Heidegger, M. (1977). The Age of the World Picture. In M. Heidegger, The Question Concerning Technology and Other Essays (pp. 115-153). New York: Garland Publishing inc. pg. 135 
As a result, the distance and boundaries that separated people are being annihilated. This will, he believes, result in the annihilation of the nation and of peoples, to be replaced by the abstract individual subject. The flight into tradition is an inevitable result of this, Heidegger predicts this correctly, but for Heidegger it is not so much in this as in reflection that man can hope to escape the confines of the age of the world picture. Heidegger does not advocate a return to bellicose nationalism, stating that such a flight would be "nothing in itself other than self-deception and blindness in relation to the historical moment."105 Instead, he finishes his essay by advocating for a position of reflection and creative questioning that allows man to be both within his own temporal context but separated to the extent that he can reflect upon it critically and begin to discern its boundaries and limitations. In his words, "Reflection transports the man of the future into that "between" in which he belongs to being and yet remains a stranger amid that which is."106

We can therefore conclude that the above comparison of Martin Heidegger and Michel Houellebecq's criticisms of the levelling out of hierarchies and the obliteration of spatial boundaries that has resulted from the rendition of the world as picture by the metaphysics of science demonstrates the extent to which Heidegger's concerns about the impact of globalisation and the scientific relation of man to the world have survived and thrived in the contemporary French context. Heidegger's fear that the dominance of the scientific worldview would make impossible the kind of hierarchies that were so vital to the ancient conception of the cosmos appears to have been borne out by the evidence of Houellebecq's descriptions of contemporary France. Houellebecq's characters, who tend to be artists, academics or scientists, are possessing of an intellect that is wholly incapable of distinguishing the base from the beautiful, the holy site from

105 Heidegger, M. (1977). The Age of the World Picture. In M. Heidegger, The Question Concerning Technology and Other Essays (pp. 115-153). New York: Garland Publishing inc. pg. 136 106 Ibid 
the tourist attraction, the love of home from the fear of danger, and are every bit the academically neutral scientific intellectuals that Heidegger describes in his essay. Similarly, it appears that Houellebecq shares Heidegger's belief that the scientific rendering of the world as picture, and the creation of the detached scientific observer looking upon the world as a set of objects for research, would tear man from his moorings in any particular place or culture, and would lead to a sense of rootlessness among men. The tourists looking only to extract useful commodities like relaxation or sex amidst the ancient civilisations of the third world, and the entirely objective relation between the Westerners and the locals that results from their mutual objectification is entirely in keeping with the rootless, "objective" scientific worldview described by Heidegger in "The Age of the World Picture".

The connection of this to the French "far-right" is fairly self-evident. Constantly decrying "globalists" and "citizens of the world" who are "citizens of nowhere" speaks directly to the rejection of the world as picture and the relation of the individual to his homeland, culture and to those outside of the national community that is elaborated in the preceding analysis of the relation between Heidegger and Houellebecq's writing. However, the adoption of this kind of discourse by the National Front is a relatively recent phenomenon, being a large part of the shift in focus of the party after the transfer of power from Jean-Marie to Marine Le Pen. The National Front had been founded in the ashes of French Algeria, based on a betrayal narrative where the cosmopolitan leftist Parisians had sacrificed the pied-noire and their harkis allies. This National Front traded in a fairly straightforward "Poujadist" reactionary nationalism107; far more aligned with the thought of De Maistre, Charles Maurras and Maurice Barrès than Heidegger; that tended to target de Gaulle personally, Jews and immigrants. It positioned itself to the right of Gaullism and its policies were

107 Bell, D. S. "The French National Front." History of European Ideas 18.2 (1994): 226. 
conservative; “The economic part of Le Pen's 1988 programme was perfunctory, but included a bow to the free market, the inevitable demand for lower taxes (an eventual end to income tax), and threats to unfair competitors"108 Under Marine Le Pen, who took control of the party in 2011 (around the time of Houellebecq's "The Map and the Territory), the party shifted away from ultraconservatism towards anti-capitalism, opposition to globalization109, anti-elitism and a softening of the parties attitudes towards Jews, sexual minorities and race. A new focus has emerged that is partly an opposition to globalisation, sharing in the Heideggerian belief that the "world-picture" is a malign force that levels out cultural particularities and flattens out national greatness, and partly an opposition to elites, who are seen as rootless and out of touch because their technological intellect has so far removed them from the concerns of ordinary people. This shift coincided with an explosion in electoral success and represents a shift from traditional ultra-conservatism towards the kind of anti-globalist, anti-technological ideology described in these last two chapters. Interestingly, however, it does still fly somewhat in the face of the predictions of Houellebecq, pre-"Submission" and the hopes of Heidegger in this essay. Heidegger felt that a return to bellicose and base nationalist romanticism, which the National Front has not abandoned, would be selfdeception and ignorant of the reality of the modern world, while Houellebecq felt that the West would simply limp towards post-humanism, or its own slow death, without being shaken from its torpor by the misery of its people or the shock of terrorism. The rise of the "far-right" suggests that, as Houellebecq appears to have come to believe by the time of his latest novel, the West will not be entirely idle, and that the unfolding of technology in history and the advent of the world picture has triggered the backlash that Heidegger expected. However, it could be argued that what

108 Bell, D. S. "The French National Front." History of European Ideas 18.2 (1994): 234.

109 Tharoor, Ishaan. "The Man Who Declared the 'end of History' Fears for Democracy's Future." The Washington

Post. WP Company, 9 Feb. 2017. Web. 10 Feb. 2017 
has truly been realised is Heidegger's great fear, that the response would be self-deceptive romantic traditionalism rather than reflection and creative questioning, a response that he hoped would open new possibilities for thought and action. 


\section{Chapter Three: The Extension of the Scientific Domain}

It is precisely towards this project of reflection that Heidegger turns in his essay titled "Science and Reflection". Towards this end, Heidegger attempts, in this essay, to demonstrate the boundaries surrounding the sciences; both by giving his most direct and coherent critique of the scientific method as a mode of bringing truth into unconcealment by providing a quasigenealogical account of the development of science from its humble ancient origins to its modern, revolutionary status. Having done this Heidegger begins to elaborate upon a concept that he terms the entrapping-securing of objects, whereby the sciences ever expand their reach and their purview into realms, like the arts, which on their face lie outside of the sphere of scientific sovereignty. This will be compared directly with the several examples in the works of Michel Houellebecq where the prejudices and assumptions of the sciences are imposed onto the worlds of art and of religion. Both Heidegger and Houellebecq, in different ways, demonstrate the limitations of the scientific method and are keenly aware that it is precisely in its expansion into spheres wherein it does not belong that science most clearly demonstrates its limitations and weaknesses. Heidegger does this by way of a criticism of physics, historiography and psychology while Houellebecq does this by confronting a social scientist, François of "Submission", with the statue of the Black Madonna at the chapel of Notre Dame de Rocamadour and describing a failed conversion attempt that demonstrates the incapacity of the scientific mind to grasp what is represented by that work of religious art. As before, this will demonstrate the way in which the ideas of Heidegger have survived and gained salience in the context of contemporary France and form a part of the backdrop against which the rise of the "far-right" is taking place.

Heidegger begins by introducing an idealistic vision of the essence of art claiming that "art is a consecration and a refuge in which the real bestows its long-hidden splendour upon man ever 
anew, that in such light he may see more purely and hear more clearly what addresses itself to his essence." 110 In other words, art, like the poesis mentioned in "The Question Concerning Technology", is a means by which the truth, particularly the truths of man's inner life, can shine forth into unconcealment by a method of bringing forth that does not set upon, but rather which opens itself for consecration and bestowal. It is a way in which things can present themselves to us, but one that is losing out from the ever increasing dominance of the technological. He juxtaposes this with a similar description of science to that which we explored in relation to the previous two exegesis. However, he does introduce a new definition of science as the "theory of the real" and links this to Ancient Greece by stating that "the essence of modern science, which has become world-wide meanwhile as European science, is grounded in the thinking of the Greeks, which since Plato has been called philosophy." 111 Therefore this modern kind of knowing, Wissenschaft, can be understood as distinctly new but still fundamentally rooted in the "essence of knowing as the Greeks experienced it."112 This type of knowing is dominant, as he has been at pains to point out before, but needs to be questioned in relation both to a dialogue between it and its Greek forbearers and in relation to the inevitable confrontation between it and the Eastern world. This reflection upon the true essence of science will not consist of any kind of modern resuscitation of ancient poetry, Heidegger feels that the poetry of the Greeks is still alive in the modern world, but that its unconcealment will require that we free ourselves from the historiographical representation of history that is dominant in favour of a view of history that does not objectify it or challenge it forth to report to us.

\footnotetext{
110 Heidegger, M. (1977). Science and Reflection. In M. Heidegger, The Question Concerning Technology and Other Essays (pp. 155-182). New York: Garland Publishing inc. pg. 156 111 Heidegger, M. (1977). Science and Reflection. In M. Heidegger, The Question Concerning Technology and Other Essays (pp. 155-182). New York: Garland Publishing inc. pg. 157 112 Ibid
} 
This new kind of science is then elaborated by way of the formulation, "science is the theory of the real". Heidegger goes about explaining that this phrase essentially combines two important parts, "the real" and "the theory". The first of these is rooted in "doing", particularly the doing of something that acts upon material reality in a consequential way, a kind of work that brings something forth. This consequential bringing forth requires a "doer" to cause the thing to represent itself to him and an object that he causes to be brought forth by his doing. Next, he discusses what is meant by "the theory", which can be understood as an interested and attentive look at the outward appearance of a thing, "wherein what presences becomes visible" 113 . Thus we see the combination of both thought and action under the umbrella of this theory of the real, science. Whereas the Greeks clearly gave greater importance to the latter, and dedicated huge amounts of time to the way of the thinker's and theoretician's way of life, and felt that its highest forms did not even need to bring about any kind of material benefit to anybody, modern science does not have this monastic quality. According to Heidegger, it seems that the Greeks were able to relate their "being" fairly directly to these abstract philosophical concepts and had a quasireligious relationship with this mode of bringing forth, appearing to think that a goddess, Thea, was in communion with them and that is was from her that things were being shone-forth into unconcealment. On the other hand, modernity, importantly, understands theories in a slightly different way. Theory is far less likely to describe general reflection and philosophy, though "there yet steals the shadow of early theoria." 114 This developed through the Romans, who used the term contemplari to understand this concept in a sense whereby it was compartmentalised and enclosed. By the time of Christianity, though, there was a further innovation whereby this distinction

\footnotetext{
113 Heidegger, M. (1977). Science and Reflection. In M. Heidegger, The Question Concerning Technology and Other Essays (pp. 155-182). New York: Garland Publishing inc. pg. 163 114 Heidegger, M. (1977). Science and Reflection. In M. Heidegger, The Question Concerning Technology and Other Essays (pp. 155-182). New York: Garland Publishing inc. pg. 165
} 
becomes one between a contemplative, monastic life and an active, material one. These different semantic formulations are said to be revelatory of the different "spirits" speaking through these terms in those ages. Thus the development in the ways in which theory and thought have been understood can be traced by these linguistic changes. However, the trend does appear to be towards a further separation of these two spheres to the point that we are left with the sense that there are thinkers who do nothing and doers who think nothing.

As a result of the convincing nature of the sciences' claim to be able to bridge the gap between thinking and doing, between the theory and the real, science organises an ever growing mass of the objects of its study into an interacting network that can be surveyed and followed out in its processes and sequences. By these relations, emanating throughout these networks, science is able to entrap more and more objects into its sphere of knowing. But again, Heidegger feels that the objects are defined in advance so as to render themselves to the scientist and that, "the all deciding work [Arbeit] that such representing performs in every science is that refining of the real which first in any way at all expressly works the real out into an objectness through which everything real is recast in advance into a diversity of objects for the entrapping securing." 115 Thus science becomes a theory of a particular version of "the real" which imposes upon the objects of its study a kind of "objectness" that, a-priori, renders the real into a form that can be entrapped and then secured within the realm of the scientific.

In a satirical, though often scathing, example of this process of "entrapping-securing", Houellebecq presents an art scene that has fallen into the hands of promoters and business people who apply scientific considerations of market forces and sociology to the arts. The choice to focus 
upon the art world is partly motivated by Houellebecq's desire to mock and offend several high profile members of the French cultural elite but also because the arts are, surely, the fortress of the poetic and the mythological. Because of this, an account of their capture by the logics of science and technology represents a sort of watershed moment in the process described by Heidegger above. This begins in "Platform" with the statement that: "Basically I had little esteem for the contemporary arts scene. Most of the artists I knew behaved like entrepreneurs: they studied with care the location of new niches, then they quickly tried to jostle for market positioning." 116 However, it is the "The Map and the Territory" where this process is most fully developed. In this novel the protagonist, Jed Martin, is pushed into the world of art by his employers at the Guide Michelin where he makes maps of rural France for travellers, commuters and tourists. His employers are attempting to rescue the struggling company and have ascertained a certain trend, towards a fashionable fiction of the countryside, among art collectors, where "for the first time, in truth, since Jean Jacques Rousseau, the countryside has come back in fashion"117. The success of his work is measured almost entirely by its impact on the sales of the Michelin guide and the opportunities that this affords the company in selling historically interesting maps of the French countryside to rich buyers in Russia and China. This logic extends to the artistic community where the single most important move in an artist's life is the hiring of a good press officer. In the art world, the tastes and predilections of the wealthy buyers and the art critics who act as salesmen take precedent over any consideration of form, beauty or reverence. The artists, then, are mere producers responding to the demand generated by these tastes. Through this Houellebecq offers an example of the way in which a form of scientific thinking, though in this case it is presented as capitalism rather than natural science, has been able to entrap the objects of the world of art into

116 Houellebecq, Michel. Platforme. Paris: Flammarion, 2001. Pg. 178

117 Houellebecq, Michel. La Carte et le Territoire. Paris: Flammarion, 2010. Pg. 87 
its purview, to reshape the relation towards the objects of art so that they fit into the quantifiable and measurable schema of the sciences, and finally to secure the objects within a network of buyers, sellers and critics that expropriates art from the aesthetically oriented world of the artist to the scientifically oriented world of the market.

In some respects this most directly relates to the problem of the aesthetic gaze as outlined in Roger Scruton's “An Intelligent Person's Guide to Modern Culture”. In this book Scruton argues that secular morality, which he feels manifests in the great works of literature and art, was only temporarily able to act as a surrogate for a common religion. This surrogacy was temporary because the aesthetic gaze conflated the signifier with the signified, in other words the virtue was in the piece of work itself rather than the absolute virtue which it signified. "Hence arises the idea of taste. We discriminate between the objects of aesthetic interest, find reasons for and against them, and see in each other's choices the sign and expression of moral character." 118 Stated simply, the descent from the immortal signified to the mortal signifier corresponds with a descent from an absolute representation of virtue to a relative representation of value. Thus shorn of its religious groundings, the best of what has been said and written becomes a mere matter of taste and the wisdom carried within it becomes subjective, situational and temporal. This occurs because without the religiously asserted forms that the object once signified, an object of reverence no longer has a higher form to which it can direct our attention, and must itself not only embody but be the Good that it once merely represented. In sum, without religion, that which once signified the form of the Good no longer has any absolute forms to signify. Resultantly, the medium becomes the message and the concept is dragged down to earth where it becomes relativised and loses its authority. This clearly relates to the fallen art that appears in Houellebecq's book, and 
links directly to Heidegger's notion of the "entrapping securing" in an interesting way. What for Scruton is an invasion by secular materialism into the reverential world of religious art, and for Houellebecq is the invasion thereof by market logics, are manifestations, though stated differently, of the same Heideggerian contention that the logics of the sciences are ever expanding into new and different territories, laying claim to the objects within these spaces and eventually edging out all other ways of thinking that might be sovereign of these domains. The work of art ceases to function as a medium between man and something greater than material, as in religious art for Scruton, and becomes the object of the relationship itself. This means that art becomes the object of the setting-upon of technological or scientific thought and is the thing to be ordered and made to represent itself to the art dealers and collectors. From the object of the art is extracted the material worth and the status that it confers upon the owner. Having redefined the work of art so that it may render itself to them in this way, the art critic and the art dealer will survey and follow sequences and processes like trends, demand, fashions and price in order to extract the greatest profit from the work of art. Houellebecq choses the art world, though in other books he describes similar processes in the realms of religion and sex, precisely because art would seem, at face value, to represent something so distant from the scientific worldview. The invasion of the world of art by these logics represents a kind of storming of the last bastion of the non-scientific world and the starkest example of science and technology entrapping and securing the objects of another realm of knowing in order to master them and establish dominance over another realm of thought.

This is not to say, neither in this case nor in the case of Heidegger to which we are now returning, that science is entirely arbitrary or without virtue. Heidegger makes a point of stating that the essence of science is not merely a convenient invention and that "the essence of science is rendered necessary by the presencing of what presences at the moment when presencing sets itself 
forth" 119 , but rather that it is a theorising of the real, a mode of measuring changes that are presencing themselves in a particular moment. In this way science, like mathematics, is somewhat akin to a symbolising of reality for analysis rather than a direct relation to the real as it claims to be. As a result, it is not only modern science, nor even only "physical science" as a whole, that falls into the trap of only seeing that which is measurable as real, and thus concluding that the whole world can be measured by science. Mathematics does much the same. In delineating these areas of object research according to measurement, science then organises them into categories and develops specialisations accordingly. This is not a perversion of science but the result of the calling forth of truth as measurable, classifiable objects between which borders can be erected. We thus have a plurality of sciences, each staking claims to particular areas of object research and particular objects of research but the same fundamental methodology. Heidegger believes that looking at these different areas of science shows us the underlying aspects that are common to all sciences, and thus might shed light upon the hidden saving power of science as it is unfolding in history. Physics reduces everything to inanimate bodies moving through space. It obliterates things into particles and atoms that are further separated into fields such as space, nucleus, proton etc. It strives to call forth and make secure those elementary objects from which the world is made. Its ultimate project, he cites Heisenberg here, is "being able to write one single fundamental equation from which the properties of all elementary particles, and therewhith the behaviour of all matter whatever, follow"120

Modern physics is distinct from its classical ancestor in the observational experience and determination of the object that is set forth from and by nature, but shares the requirement that

\footnotetext{
119 Heidegger, M. (1977). Science and Reflection. In M. Heidegger, The Question Concerning Technology and Other Essays (pp. 155-182). New York: Garland Publishing inc. pg. 168 120 Heidegger, M. (1977). Science and Reflection. In M. Heidegger, The Question Concerning Technology and Other Essays (pp. 155-182). New York: Garland Publishing inc. pg. 172
} 
nature has to render itself to the "entrapping securing that science, as theory, accomplishes." 121 However, in atomic physics, even the object of study itself vanishes and this disrupts the whole process, as the subject-object relation takes precedence over the subject and the object as entities in themselves. Both become "sucked up" as standing reserve. Heidegger argues that because physics is only able to conceptualise nature in one way, as physis, it is unable ever to "get around" nature and grasp it in its fullness. He takes the example of Goethe's struggles with Newtonian physics, where he was able to grasp that his poetic way of representing nature was as much a bringing of nature into unconcealment as physics. Unlike Goethe's poetic representations, science "can never decide whether nature, through its objectness, does not rather withdraw itself than bring to appearance the hidden fullness of its coming to presence." 122 In fact, this is a question that science cannot even ask. Similar critiques are presented for psychiatry, historiography, and philology, all of which appear to suffer from similar confusions about the fullness of their object of study and the narrow ways in which they define and codify those objects in order that they might represent themselves in such a way as to be measured, ordered and pulled into the standing reserve by the scientist. He roots this impotence of the sciences in the fact that anything presencing itself in the world is only ever presencing itself in one particular way at a time, though it has the capacity the presence itself in many. The rigidity of scientific observation, recording, ordering and circumscribing attempts to totalise this particular presencing as the wholeness of the being of the object.

In "Submission", Houellebecq's protagonist is a direct representation of the limitations of the scientific worldview. He is not a scientist, but rather an expert of Huysmans, a philosopher who

121 Heidegger, M. (1977). Science and Reflection. In M. Heidegger, The Question Concerning Technology and Other Essays (pp. 155-182). New York: Garland Publishing inc. pg. 172-173 122 Heidegger, M. (1977). Science and Reflection. In M. Heidegger, The Question Concerning Technology and Other Essays (pp. 155-182). New York: Garland Publishing inc. pg. 174 
famously underwent a conversion to Catholicism upon seeing the statue of the Black Madonna, "La Vierge Noire", at Rocamadour. He has become disillusioned with the state of French academia and seeks a more direct relation with the object of his study by going at looking at the statue for himself. Over the course of several visits to the Notre Dame Chapel where the Black Madonna is housed he demonstrates the understanding of an expert on the subject, which in many respects he is, but eventually recognises that the statue means nothing to him, and that he is too academically detached from it to experience anything like the same spiritual, numinous moment that turned Huysmans' life on its head. In a reversal of Goethe's struggles with Newtonian physics, Houellebecq's protagonist is able to grasp the poetry and glory of the religious wonder elicited by the statue, but unable to grasp that this way of shining light onto the truth of this object is every bit as valid as the more scientific way in which he sought to understand it. He attempts to understand the statue by placing it within the historical context of past representations of Christ and the Virgin Mary. He says

“it wasn't until much later, with Jerome 1[Jeronimus] Bosch for example, that the terrifying representations appeared where Christ separated the cohorts of the chosen from the legions of the damned; where demons dragged the nonrepentant sinners towards the supplications of hell. The Romans before had a different vision. Far more holistic: at his death the believer was thought to fall into a state of deep sleep, and was mixed into the earth. After all the prophecies had been fulfilled, at the time of the second coming of Christ, it is the whole of the Christian people, united and in solidarity, that rises from their graves, resuscitated by his glorious body, to begin the march to paradise" 123

His expertise as an academic, something akin to the research man described in the previous chapter, allows him to place this work in between the individualistic image of the afterlife, with each individual judged according to his sin, and the holistic image of the Romans, with the community as a whole returning to become one with the earth before rising up to walk together to

123 Houellebecq, Michel. Soumission: Roman. Paris: Flammarion, 2015 Pg. 167 
heaven, but this is not enough to produce the same kind of rapture that overcame Huysmans. His understanding is still mediated by the scientific desire to approach the object of study by way of the recording, ordering and classification of things rather than engaging with the poetic aspect that so struck Huysmans. He then attempts a sociological explanation of the statue where he compares it to the patriotic poetry of Charles Peguy and argues that perhaps the statue symbolises the desire to die for a plot of land, as Martel's soldiers did in their battles against the Caliphate, as Peguy's fellow soldiers did for their God and their land in the trenches of Northern France. This also, though, fails to speak to him beyond a merely academic level. "I sensed, myself, ready to die, not for my land specifically, but I felt ready to die in general, after all I was in a funny mood" 124 In the shadow of this great work of art he is able to see that this generalised kind of nihilism cannot compare to the self-sacrificing fervour of the Christians of the past and concludes that his spiritual crisis might just, in fact, be the result of his being hungry, what he jokingly calls "hypoglycemic mysticism". In the end, he gives up. Houellebecq is clearly attempting to demonstrate that the way in which the contemporary western intellect approaches an object such as the Black Madonna, is incapable of opening itself to the same spiritual and emotional response that Huysmans experienced at the feet of the statue. Before leaving he takes a last shot at the spiritual awakening he desires, and returns one final time to the chapel.

"The Madonna waited in the shadows, calm and inaccessible. She possessed suzerainty, she possessed strength, but bit by bit I felt myself distanced from her in space and through the centuries as I sat on the pew, shrivelled, restrained, definitively deserted by the Holy Spirit, reduced to my damned, perishable body, until I sadly descended the steps in the direction of the parking lot.125

124 Houellebecq, Michel. Soumission: Roman. Paris: Flammarion, 2015 Pg. 169

125 Houellebecq, Michel. Soumission: Roman. Paris: Flammarion, 2015 Pg. 170 
Worst of all, returning to Heidegger, the sciences do not truly have the capacity to see these limitations, as their circumscription of the sphere of the real excludes all those things that lie outside of these boundaries. They are thus functionally unaware of their own limitations and even of the existence of any realms of being that lie outside of their field of vision. There is thus a crisis in the sciences, or more accurately a restlessness about it, whereby people are unable to grasp the essence of science and see its boundaries, but are acutely aware that they are failing to fully explain the real. The fundamental problem is that we pass over those things that science cannot explain because they are not shining forth, they are not in fact presencing themselves in a way that we are able to ascertain according to the logics of science. They are fundamentally inconspicuous. "The state of affairs that holds sway throughout the essence of science, i.e, throughout the theory of the real, is that which is inaccessible and not to be gotten around, which is constantly passed over."126 This generates a sort of anxiety. We know that something is missing but are wholly incapable of seeing what it is because, by its nature, it does not render itself visible to us.

Once again the relevance of this to contemporary political movements is fairly direct, and is in many respects similar to that discussed in the context of the previous chapter. Specifically, this was seen in Michael Gove's claim, during the British referendum on European membership, that the public had "had enough of experts from organisations with acronyms saying that they know what is best and getting it consistently wrong." 127 Indeed, one can quite clearly see, in the howling denunciations of the "Ivy League elitists" in America and the "Enarques" in France, that Heidegger's criticisms of the invasion of the intellectual world by scientific logos and the shortcomings of this mode of thinking are highly salient to the anti-elitism of the "far-right". More

126 Heidegger, M. (1977). Science and Reflection. In M. Heidegger, The Question Concerning Technology and Other Essays (pp. 155-182). New York: Garland Publishing inc. pg. 179

127 Nelson, Fraser. "Michael Gove Was (accidentally) Right about Experts." The Spectator [London] 14 Jan. 2017 
generally this perception is seen in the general rejection of the opinions of economists, demographers, political scientists and immigration experts by the French National Front. The reduction of political questions to technological, mathematical or scientific observation represents the entrapping-securing of the matters of the city by the sciences and their inability to perceive the opposition that they generate, and to satisfy fully the political demands of the population, links undeniably to the reflections on science highlighted above. Thus it can be concluded that the concerns about science elaborated by Heidegger, evidenced and refined to the contemporary context by Houellebecq and politicised by the entrapping of political questions by the logics of science, have created the conditions in which the French "far-right", among various other forms of Romantic reaction, has germinated. Nowhere is this more obviously expressed than in Eric Zemmour's call to arms in "The French Suicide", "The time has come to deconstruct the deconstructors.... The entire history of a joyous deconstruction, knowing and obstinate, of the smallest wheels that had edified France; the history of an absolute dispossession, an unrestrained disintegration; a dissolution in the icy waters of individualism and self-negation."128 This quote speaks directly to the idea, expressed by both Heidegger and Houellebecq, that the scientific approach to the world has stripped away, dispossessed or dissolved all non-scientific aspects of human existence, particularly tradition and culture, in order to replace it with a cold and dehumanised rationalised abstraction of the world. For Houellebecq and Scruton, this leads to the death of the arts; for Zemmour, this is nothing less than the total abnegation of the cultural being of the French people, who are now nothing more than rationalized, abstract "individuals".

In light of this, the first part of this thesis will conclude with one final reflection. In "Science and Reflection", Heidegger has attempted to make us attentive to this realm of the inaccessible, 
inconspicuous and impossible to get around, which shows itself to us only as the uncanny space from which the real that we can observe shines forth for our observation. This gives us a new sphere upon which to reflect in order to be able to begin truly to define the boundaries of the sciences. Houellebecq is similar to Heidegger in his concern that science has invaded all other intellectual pursuits and has been engaged in a constant expansion of its domain. Much as Heidegger sees the sciences entrapping and securing objects of interest confronted in the world, Houellebecq sees the logics of materialist science invading the realms of art and religion. Both are also certain that science will not be able to shed light satisfactorily upon the objects in these spheres because of the innate limitations of scientific methodology. Houellebecq offers only a nihilistic resignation in the face of this scientific onslaught. Heidegger, though, obviously sees the possibility of a kind of reflection that is distinct from scientific research but also, interestingly, from the cultivation of the intellect [Bildung]. Bildung presents a model of the wise man and aims to form, cultivate or grow the person into this model in order that he be wise himself. "The putting forward of a common ideal of culture and the rule of that ideal presupposes a situation and bearing of man that is not in question and that is secured in every direction" 129 This clearly is impossible for a thinker like Heidegger, who sees the very conceptualisation of the being of man as being in question. He requires a reflection that places man within his place in space and time and from which he can reflect upon that which surrounds him in this place. As a result, the age of intellectual cultivation is coming to an end and must make way for an age where the thinking man is searching for his place in the universe so that he may inhabit it, be authentic, and replace the act of questioning with mere saying.

129 Heidegger, M. (1977). Science and Reflection. In M. Heidegger, The Question Concerning Technology and Other Essays (pp. 155-182). New York: Garland Publishing inc. pg. 180 


\section{Division Two: Progressivism, Universalism and the Rejection of the Post-War Order}

\section{Introduction: The Question of Being}

In pursuit of a more authentic belonging, for which it will be argued both Heidegger and, to some degree, the "far-right" are in search, it is necessary for both to go beyond the critiques of the shortcomings of technology and science discussed in the preceding section and to engage with the concept of being at a fundamental level. In this section, the questioning of being undertaken by Martin Heidegger in "Being and Time" will be discussed in order to show the ways in which it challenges the fundamental assumptions of modernity and provides the impetus for a deeply rooted antithesis for some of the most basic assumptions of the post-enlightenment world. This discussion will consist of the following parts. Firstly, the form taken by the questioning of being in "Being and Time" will be explained by reference, mostly, to the introduction of this book and the way in which Heidegger describes his quest to discover the essential, authentic, pre-ontological being that is inaccessible to the scientific, formalist and rational modes of questioning that define the technological age. Once this has been done, focus will turn to two key distinctions that this questioning of being elucidates vis-à-vis enlightenment modernity, both of which will be shown to be present both in the writings of Michel Houellebecq and the politics of the French National Front. The first of these is an understanding of "being-with" and "being-in-the-world" described by Heidegger as being rooted in taking care of that which is a hand, an understanding of being as being rooted in the relation between the individual and those things that are most proximate in its encounter with the world. This will be shown to constitute a rejection of universalism that finds voice in the distinction between rooted, authentic persons and rootless inauthentic cosmopolitans that can be found both in Houellebecq and the positions of the French National Front, where it takes the form of a dichotomy between the authentic "Français de Souche" and the inauthentic "Français de Papier". The second will concern the temporal rooting of being; found in 
Heidegger's analysis of being, time and history; which will be shown to represent a rejection of the ideal form of being and the linear history that is so vital to "progressive" conceptions of history. This will be linked to the anti-progressivism of Houellebecq and the National Front. It will be shown that the focus on particularity, derived from the temporal and spatial rooting of being, represents a fundamental, philosophical rejection of two of the foundational ideas of modernity and the enlightenment that presences itself in the contemporary context in the rejection of cosmopolitanism, universalism and progressivism that exist in the writings of Michel Houellebecq and the political ideology of the National Front. In doing this, this thesis will attempt to get to the core of the critique of modernity offered by Heidegger and the anti-modernism of the contemporary "far-right", and show that there exist many similarities at the diagnostic phase.

It is necessary, then, to begin this undertaking by analysing Heidegger's intentions in his questioning of being in "Being and Time". Heidegger expresses his undertaking as a revisiting of a questioning of being that has been ignored because the concept of being is assumed to be so intuitively obvious that any questioning thereof is unnecessary. Heidegger roots this hubris in the Greek claim that being is the most universal of concepts, and in the mistaking of this universality with clarity as to its meaning. We are thus left in a position where we think that our meaning is entirely obvious when we say that something $i$, but are unable to provide a rational account of precisely what we mean. This brings into question our fundamental relationship with the world around us, "It shows that an enigma lies a priori in every relation toward being and beings. The fact that we live already in an understanding of being and that the meaning of being is at the same time shrouded in darkness proves the fundamental necessity of retrieving the question of the meaning of "being"” 130 From this point he provides a criticism of formalist and scientific

130 Heidegger, Martin. Being and Time. Trans. Joan Stambaugh. Albany: State U of New York, 2010. Pg. 3 
approaches to the question of being that raise, for example, the objection of "circular reasoning" as being sterile and suffering from the shortcomings of science that need no further discussion at this point. However, this critique runs somewhat deeper as it not only speaks to the shortcomings of the sciences, but also the focus on an ontological account of the question of being. "The question of being thus aims not only at an a priori condition of the possibility of the sciences, which investigate being as this or that kind of being and which thus already move within an understanding of being, but also at the condition of the possibility of the ontologies which precede the ontic sciences and found them."131 In other words, a genuine questioning of being not only brings into question the possibility of the sciences, which prioritises the internal consistency of its logics over elucidation of truth, but also challenges foundational assumptions about the ontological nature of being that are necessarily presupposed by the sciences. Heidegger wishes to shed light onto the truth of being in a way that does not presuppose these things and wishes to restart the questioning of being from the ground up.

Rather than beginning by the observation of beings, and searching for common characteristics of the being of beings that might provide a basis for this questioning, as a scientist might do, Heidegger introduces the concept of Dasein [there-being]. Dasein is pre-ontological and concerns the essence of being and beings directly. It is this pre-ontological being, this Dasein, which is to be interrogated. Dasein relates to a kind of being that is described in the following way:

"We shall call the very being (Sein) to which Dasein can relate in one way or another, and somehow always does relate, existence (Existenz). And because the essential definition of this being cannot be accomplished by ascribing to it a what that specifies its material content, because its essence lies rather in the fact that in each instance it has to be its being (Sein) as its own. "132

131 Heidegger, Martin. Being and Time. Trans. Joan Stambaugh. Albany: State U of New York, 2010. Pg. 10 132 Heidegger, Martin. Being and Time. Trans. Joan Stambaugh. Albany: State U of New York, 2010. Pg. 11 
Furthermore, "Dasein always understands itself in terms of its existence, in terms of its possibility to be itself or not to be itself. Dasein has either chosen these possibilities itself, stumbled upon them, or in each instance already grown up in them.....We come to terms with the question of existence always only through existence itself."133 This being relates directly to its own existence and this existence can only be come to terms with through existence itself; a claim that will become clearer later. Here, Heidegger is clearly differentiating himself from those formalist and scientific approaches to the question of being that are rooted in theoretically constructed assumptions about being, borrowed from Greece, and his own account which reflects a common romantic appeal to the "real", the "felt" and the "authentic" against the created and the "fake".

It is precisely this kind of desire for authenticity that Heidegger feels has been hampered by the heritage of the Platonism. "What has been handed down is handed over to obviousness; it bars access to those original "wellsprings" out of which the traditional categories and concepts were in part genuinely drawn. The tradition even makes us forget such a provenance altogether. Indeed, it makes us wholly incapable of even understanding that such a return is necessary." 134 The search for this wellspring, this source of authentic being, is obstructed by the unquestioned inheritance of Platonic metaphysics, which posit a conception of being that is accepted as obvious, and will be discussed later, in such a way as to blind us to the need for a questioning of being that sheds light upon this "wellspring" from which being flows. This is exacerbated by the hegemony of scientific approaches to phenomena:

"Science "of" the phenomena means that it grasps its objects in such a way that everything about them to be discussed must be directly indicated and directly demonstrated. The basically tautological expression "descriptive phenomenology" has the same sense. Here description does not mean a

133 Ibid

134 Heidegger, Martin. Being and Time. Trans. Joan Stambaugh. Albany: State U of New York, 2010. Pgs. 20-21 
procedure like that of, say, botanical morphology. The term rather has the sense of a prohibition, insisting that we avoid all nondemonstrative determinations. The character of description itself, the specific sense of the logos can be established only from the content [Sachheit] of what is "described", that is, of what is to be brought to scientific determinateness in the way phenomena are encountered." 135

On top of a critique of science that will now be familiar, Heidegger here is elucidating a differentiation of his project from the rationalistic phenomenology of the technological age. He is thus engaging in a questioning of being that runs counter both to the Platonic conception of being as being rooted in the ideal form of a thing and the scientific calling to account of being. He is searching for an authentic understanding of being that is not influenced by the logics of science or the tradition of Platonism.

However, this focus on authenticity creates a further problem. Phenomena can presence themselves in the world in a variety of ways, this is to say that the same phenomenon can presence itself differently depending on how it is questioned or how it has revealed itself, and some of these presencings are inauthentic. The problem of authenticity is a central part of this undertaking as Heidegger wishes to distinguish the authentic form of being that he is shedding light upon from the inauthentic forms that can be presenced by the inessential questionings favoured by scientists and rationalists. This leads Heidegger into an interesting critique of the empirical intuition of Emmanuel Kant.

"If by the self-showing we understand those beings that are accessible, for example, through empirical intuition in Kant's sense, then the formal concept of phenomenon can be used legitimately. In this usage phenomenon has the meaning of the vulgar concept of phenomenon. But this vulgar concept is not the phenomenological concept of phenomenon." 136

135 Heidegger, Martin. Being and Time. Trans. Joan Stambaugh. Albany: State U of New York, 2010. Pg. 33 136 Heidegger, Martin. Being and Time. Trans. Joan Stambaugh. Albany: State U of New York, 2010. Pg. 29 
Thus the phenomenology of being accounted for by Kantian intuition, which is legitimate only within its own logical structures, is dismissed as vulgar while the goal of Heidegger is a phenomenological concept of phenomena, particularly being itself, that is absolute, essential and authentic.

Thus we can summarise Heidegger's undertaking as follows. Heidegger's project in his questioning of being links directly to the project proposed at the end of "The Question Concerning Technology". It is not relativistic nor merely deconstructionist in its ambitions, but aims to establish the limits of the ontological conception of being in order to open other lines of questioning that allow for elucidation of the essential, authentic, pre-ontological nature of being.

Or as Heidegger puts it in his first chapter,

"We must show that all previous questions and investigations which aim at Dasein fail to see the real philosophical problem, regardless of their factual productivity. Thus, as long as they persist in this attitude, they may not claim to be able to accomplish what they are fundamentally striving for at all...... the scientific structure of the above mentioned disciplines (not the "scientific attitude" of those working to further them) has today become completely questionable and needs new impulses which must arise from the ontological problematic." 137

137 Heidegger, Martin. Being and Time. Trans. Joan Stambaugh. Albany: State U of New York, 2010. Pg. 45 


\section{Chapter One: Care, Rootedness and the Critique of Universalism}

This brings us to the first point of fundamental departure from modern enlightenment orthodoxy that will be discussed in this paper. The relationship between the individual and the world that is critiqued by Heidegger, and could realistically be described as the prevalent enlightenment position on the question of being-in-the-world, is perhaps best described by way of Rene Descartes' concept of the cogito. This concept, similar as it is with the scientific gaze discussed in Part One, asks that man strip himself of all particular and parochial characteristics in order to observe the objects encountered in the world from the position of a tabula rasa, and to make "objective" judgements on these phenomena from this point of abstracted, individualistic neutrality. This universalisable and non-contingent iteration of the subject-object relation, where the abstract, internally oriented individual being stands in relation to an objectified external world with only itself as a point of reference, can be directly opposed to the conception of being offered by Heidegger in "Being and Time". Heidegger's questioning of being roots the becoming of the individual subject, the development of its self, in a relation of "taking care" of those things that are "at hand". Of particular importance is the rooting of the being-with to the "they" that are at hand, an understanding of being that makes of man a cultural animal and potentially has nationalistic implications. Together this posits that, by way of an interactive relationship with the things, the people, the culture and the ideas that make up the immediate surroundings of the being, the self becomes in a way that is rooted in the contingencies of its surroundings. This places Heidegger's conception of being in direct contradiction to any abstraction of the self as championed by Descartes, which has been shown to be central to Heidegger's philosophical objections to modernity. From this we are presented with a dynamic and developing conception of being, becoming, that is linked in a multitude of ways to the particular things that inhabit the 
immediate surroundings of the subject, and is thus contingent upon the particularities of the place in which it becomes.

It falls first upon us, then, to explore what it means to "take care" of that which is "at hand". Perhaps the most direct elaboration of this idea is presented when taking care is described as the first way in which the Dasein encounters the world.

"This nearest and elemental way of Dasein encountering the world goes so far that even one's own Dasein initially becomes "discoverable” by looking away from its "experiences" and the "center of its actions," or by not yet seeing them at all. Dasein initially finds "itself" in what it does, needs, expects, has charge of, in the things at hand which it initially takes care of in the surrounding world." 138

This constitutes an existential critique of the abstract "I" that is described above. Since the preontological being that is Dasein must be "there" [Da], there must be a "there" in which it is. The development of the self does not come through theoretical considerations of the nature of self, or of otherness, but rather becomes as a result of specific interactions with one's surroundings. These interactions are often utilitarian in nature, as the individual encounters objects that can serve him a particular purpose, and comes from an external orientation, towards things in the world, rather than an internal orientation towards the self. Interestingly, such a position on the interactive, even tactile, nature of the development of the self sits well within the field of developmental psychology, though this comparison would likely horrify Heidegger: the interaction of a child with those toys and people that are most immediately "at hand" are thought to have an important formative influence on the person that the child becomes. To extend the analogy further, the young child will begin with no particular sense of its own being, its Dasein will only become discoverable by its interaction with the objects that it confronts. These interactions will often be practical in nature. It 
will attempt to discover the uses of these objects and the pleasures or pains that these objects might cause, and this will reveal the child's being to itself by way of the development of a relationship between it and the objects that it can access in the world. More importantly for our purposes, though, it has the consequence of anchoring the becoming of the self in a particular spatial context.

This interactional essential becoming not only applies to the human subject but also to those things that he encounters in the world. The utility of an object, a key part of its object-being, is not innate and does not exist a-priori, but rather is derived from its place in a network of useful things, and using agents, that define the purpose that it can serve.

"Strictly speaking there "is" no such thing as a useful thing. There always belongs to the being of a useful thing a totality of useful things in which this useful thing can be what it is. A useful thing is essentially "something in order to....". The different kinds of "in order to" such as serviceability, helpfulness, usability, handiness, constitute a totality of useful things. The structure of "in order to" [um-zu] contains a reference [Verweisung] of something to something" 139

This is to say, in more straightforward terms, that a hammer cannot be a hammer in a world with only screws. The "hammerness of the hammer" is dependent upon there being other objects through which its being can be realised, nails to hammer and hammerers to do the hammering. This raises two interesting considerations. Firstly, it tells us that the foundation of authentic being is anchored in a mutually definitive encounter between a multiplicity of different beings. This is in clear opposition to the idea, popularised by Sartre, that man can be free to define his being for himself. By arguing that the development of the self is so profoundly impacted by that which is confronted in the world, the self is irreversibly wedded to its environment and the possibility of transcending ones roots, of becoming a citizen of the world for example, is profoundly reduced. Secondly, it put a striking existential importance upon utility. That the properties of a thing are not

139 Heidegger, Martin. Being and Time. Trans. Joan Stambaugh. Albany: State U of New York, 2010. Pg. 68 
inherent, but contingent upon its place in a broader network of things, when applied to people rather than hammers, this negates the idea of inherent rights of man and hints at the anti-humanism that comes into fruition in the writing of Michel Houellebecq.

The nature of this becoming gains an even stronger anti-universalist undercurrent when it concerns interpersonal encounters as it does in Heidegger's considerations of "being-with" and "being-in-the-world". This relational view of being shares many of the characteristics described above regarding being in relation to objects in the world. Heidegger roots this elaboration of the inter-personal development of Dasein in the "everydayness" of the quotidian interactions that the being is exposed to with those other beings whom it encounters in its day-to-day existence. He is, though, at pains to differentiate this questioning of Dasein, which focus on those encounters that drive the essential development of Dasein, from the "primal" questioning of being in a "state of nature".

"The interpretation of Dasein in its everydayness [Alltaglichkeit], however, is not identical with describing a primitive stage of Dasein, with which we can become acquainted empirically through the medium of anthropology. Everydayness is not the same as primitiveness. Rather, everydayness is also and precisely a mode of being of Dasein, even when Dasein moves in a highly developed and differentiated culture." 140

He is thus focusing on the phenomenologically essential presencing of Dasein rather than the ontologically primal iterations of being that can be found in the anthropological accounts of the primitive man who is posited as living in a state of nature. As well as constituting a veiled critique of the state-of-nature-based accounts of human being that can be found in the works of such thinkers as Rousseau and Hobbes, Heidegger is clear that the anthropological nature of these accounts renders them subject to the shortcomings of the scientific approach to the world that he 
is positioning himself against. He is similarly in opposition to the kind of being-with-others that is purely rooted in causal transactional interactions, sometimes this is called "geselschaft" and is a technological rationalisation of the phenomenon of culture, and argues that this produces an abstraction of the "they" that the being encounters that leads to atomisation and levelling down. However, this process of levelling down is also a key aspect of the being-with-others that plays a key role in the spatial rooting of man.

"In its being, the they is essentially concerned with averageness. Thus, the they maintains itself factically in the averageness of what belongs to it, what it does and does not consider valid, and what it grants or denies success. This averageness, which prescribes what can and may be ventured, watches over every exception which thrusts itself to the fore. Every priority is noiselessly squashed. Overnight, everything that is original is flattened down as something long since known. Everything won through struggle becomes something manageable. Every mystery loses its power. The care of averageness reveals, in turn, an essential tendency of Dasein, which we call the levelling down of all possibilities of being." 141

These processes are caused by the desire not to be excluded from this "they" and to stand out from this crowd of the average. This desire, linked with the desire of the majority not to see themselves shown up by those capable of more, drives the process of levelling out that prevent genuine ambition, originality, mystery, eccentricity and greatness. Thus the becoming of beings is always dragged towards conformity, averageness and mediocrity by the "they" because the Dasein is required to "be-with" in cultures that are dominated by the technological. It is precisely through this impulse that the prejudices and cultural mores of those closest to the individual inescapably shape the form of his being and root his becoming in the community. This introduces both the idea that the Dasein is rooted in the cultural context in which it finds itself, and will struggle to escape both the positive and negative implications of this bond, and also an interestingly paradoxical 
relationship between the individual and the collective that reveals itself in Heidegger's account, a relationship that will be discussed in a later chapter.

This rooting in the "they" has the effect of making of man a cultural, rather than political, animal. The world cultural is derived from the Latin word cultura which signifies growing or cultivation, particularly in the context of plants. Heideggerian man is cultural because he grows, becomes, out of the soil of the "at-hand", and is cultivated by the "they" who seek to direct his growth towards the average type of their collective. Thus his becoming is highly influenced by contingent factors that he cannot control. A comparison with Aristotle reveals interesting parallels: both see men as being born into particular circumstances that impact the foundation on which the being is built, either the "at-hand" or the family. Both also see man as, by nature, an active social participant in a broader collective rather than an isolated individual. However, the distinction between the political animal and the culturally rooted being has important implications with regards to agency. Politics is an active pursuit that can be engaged with through voluntary actions while cultural rooting is far more passive and is absorbed unavoidably through engagement with the "at-hand". Additionally, the nature of Aristotelian man drives him to participate in politics, but does not circumscribe the content of this participation, whereas Heideggerian man is influenced and formed by the specific substances of his culture, including prejudices and opinions, in a way that is largely outside of his control. Thus Heidegger's claims about the rooting of man in the "athand" have the effect of putting into question the intellectual freedom of man, and suggest that cultural attitudes, prejudices and mores become a central part of man's being, whether or not he ever makes a conscious decision to affirm them. In fact, the "they" actually discourages the individual from dissenting from these common characteristics by its tendency towards "averageness", discussed above, and by the stultifying conformist force of "reassurance" 
"The self-certainty and decisiveness of the they increasingly propagate the sense that there is no need of authentic, attuned understanding. The supposition of the they that one is leading and sustaining a full and genuine "life" brings a reassurance [Beruhigung] to Dasein, for which everything is "the best order" and for whom all doors are open." 142

It is by reassuring man with the comfort of belonging, the security of order and the illusion of freedom that the collective can ensure the imposition of its average characteristics upon the individual. This discourages man from any attempt to escape from the confines of the "they" and ensures that his becoming takes place within these limits.

As a result, man is within the spatial context of the world that surrounds him. This "beingin-the-world" directs itself towards that which is "at-hand" and therefore belongs somewhere. Rather than having an abstract relation between its "subjectness" and "objectness" as a whole, its relation is to that which is relevant to its life, be they objects or people, which is naturally limited to things that are nearby, or which act upon the individual directly. The being thus belongs to a particular world whose horizons end where his relation to things ceases to be relevant. Thus the being discovers a spatial region to which he belongs and becomes by way of interacting with those things that lie within this horizon.

"Being-in-the-world that takes care is directed, directing itself. Belongingsomewhere has an essential relation to relevance. It is always factically determined in terms of the context of relevance of the useful things taken care of. The relevant relations are intelligible only in the horizon of a disclosed world. Their horizontal nature also first makes possible the specific horizon of the whereto of regional belonging. The self-directive discovering of a region is grounded in an ecstatically retentive awaiting of the possible hither and wither." 143

It is necessary here to be a little more esoteric. Heidegger is not speaking the language of nationalism here, but the implications of the concept of being that he is developing are clear. The

142 Heidegger, Martin. Being and Time. Trans. Joan Stambaugh. Albany: State U of New York, 2010. Pg. 171 143 Heidegger, Martin. Being and Time. Trans. Joan Stambaugh. Albany: State U of New York, 2010. Pg. 351 
creation of a horizon beyond which the individual does not belong, and within which the objects and peoples that can be found are alien and undisclosed, makes impossible the universalist human understanding that enlightenment thinkers thought could be obtained by the stripping away of parochial prejudices. The nationalistic implications of this, and the relation of this rooted spatial being with Heidegger's embrace of national socialism have been discussed to such a great extent in the literature that nothing much needs to be added here except for the observation that Heidegger's spatial rooting of being is far more complex that the vulgar nationalisms that are, undeniably, related to its conclusions. Firstly, Heidegger, though undeniably an anti-Semite, by rooting being specifically in space and in the "at-hand" does not equate with the kinds of race theories that might suggest the existence of a "white-being" or a "Jew-being". Indeed the entire concept of the "Universal Jew" is at odds with the spatial rooting of being described above. Similarly; though Heidegger's conviction of the superiority of the German people, whilst fairly ordinary for Germans of his time, is well documented; the understanding of being elucidated above is far less garrulous and xenophobic than the more vulgar forms of German nationalism that were in currency at the time, though to an extent these too were embraced in action by Heidegger. Thirdly, the discussion of the "they" in the preceding paragraph clearly demonstrates a freethinking streak to Heidegger's thought that suggests that this rooting, though inevitably a part of becoming, is not something to be embraced wholeheartedly. We can thus conclude that the spatial rooting of being described above has clear nationalist, or at least particularist, implications that directly challenge universalism. Heidegger is unambiguous in his belief that the Dasein comes to know itself within boundaries that are delineated by the horizons of the "at hand", and this is a claim that cannot allow for the universal consciousness that is necessary for a truly universal humanism. 
In conclusion, Heidegger argues that the becoming of a being is rooted in interactions between the subject and those things that are "at-hand", and that these interactions shape the development of the subject and make it what it is. These interactions, when between people, cultivate the being in a way that locates him within the horizons of the particular spatial and cultural region within which he is rooted. This represents a compelling and highly convincing departure from the abstraction of the individual, into the cogito of the "objective" scientific thinker, that underpins so much of Enlightenment thought and the orthodoxy against which Heidegger rebelled. Thus, "Being and Time”, when subjected to scrutiny, represents a thoughtful, compelling and, it will be shown, highly influential critique of the concept of universalism. Heidegger makes an undeniable link between alienation and the tearing of man from his grounding in a particular place and culture. The idea that the relation between man and the world can be abstracted and thus universalised is rejected, and thus the enlightenment dream of universal understanding and the destruction of "created" or "arbitrary" divisions separating the "brotherhood of man" find a strong and influential adversary in the work of Martin Heidegger.

It is important as this point to note that Heidegger's "Being and Time" is a philosophical tome that is unlikely to fulfill direct comparison with a popular novel or the platform of any political party. It is also important to address the fact that the following analysis will, to an extent, conflate universalism and multiculturalism as concepts. In part, this is a result of the conflation between the two that is made in "far-right" politics, but it also stems from the fact that the relation between the two is fairly strong. The multiculturalism criticised by the "far-right" is accused of robbing a nation's people of their specific attachment to their homeland and replacing this particularistic rootedness in their culture with a kind of universal humanism that makes no value distinction between the "native's" culture and that of others. However, there is undoubtedly a fairly 
straightforward link between the anti-universalist conception of being offered by Heidegger and the rejection of multiculturalism that forms so large a part of the ideology of the "far-right" and is equally prominent in Houellebecq's critique of contemporary France in "Submission". It will become clear that the polemic offered by Houellebecq and the "far-right" against multiculturalism is directly linked to the concepts of rootedness, authenticity and alienation that find expression in the writings of Heidegger.

Houellebecq's critique of the shallowness of multicultural France will be explored by way of a comparison of some of the characters that appear in his novel. One can observe a dichotomy that is created in Houellebecq's novels whereby those characters that find themselves rooted in the particularities of their own cultural heritages are granted a kind of authenticity that is not granted to those more cosmopolitan characters who attempt to embrace multiculturalism and lose themselves to anxiety in the process. Having done this, attention will be turned to the nativism of the National Front, and it will be shown that, once again, this political stance is based in a similar conception of rootedness as that described by Heidegger.

Houellebecq's novel presents an image of a contemporary France where many people have been entirely robbed of their own rootedness in their cultures. Parts of this have been discussed in Part One, but it is important to speak beyond the levelling out discussed before with regards to the "world picture". This can be explored by way of a comparison of the culturally rooted characters, Muslim Brotherhood leader Ben Abbes and, posthumously, Huysmans with the faculty at the Parisian university, who personify the cosmopolitan being that is uprooted from the "at hand". It will be posited in this part of the argument that the rooted characters are granted a kind of authenticity that is denied to the rootless. Thus it can be shown that, like Heidegger, Houellebecq feels that being must be rooted in the culture and community that is "at hand" in order to be 
authentically, and that the uprooting of being from this grounding leads to inauthentic Dasein and anxiety.

Huysmans, though long dead, is perhaps the second most prominent character in "Submission". His story is primarily told by way of a summary of the various pieces of scholarship that the narrator has produced in his career as a Huysmans scholar; and we can therefore consider this narrative as being deliberately filtered through the narrator's, and therefore Houellebecq's, eyes rather than being an attempt at a faithful biography of Huysmans. The early Huysmans is characterised as an aesthete who has become disenchanted and is lost in a kind of existential ennui. The narrator reflects that

"we know well that it is not only his characters who are left stranded in their pitiful sojourns in the countryside, but Huysmans himself. We almost have the impression that he is attempting a return to nature (a sordid naturalism where the country folk reveal themselves to be every bit as abject and promiscuous as the Parisians) were it not for dream-like perorations, perforating the narrative, that render these works definitively ill-fated and un-classable."144

Huysmans is thus presented as a rootless cosmopolitan aesthete whose existential ennui drives him to seek homecoming in the countryside, only to find that his romantic expectations are an illusion and that he is no more able to find himself in nature than he is in Paris. In Heideggerian terms we might say that this attempted homecoming fails because Huysmans was trying to find his authentic Dasein in ground that lay beyond the horizons of his "at hand". Indeed, it is not until Huysmans turns inwards from aesthetics, beginning to create protagonists that are avatars of himself, that his search for authenticity begins to bear fruit. It will be shown in later sections that this too corresponds with the Heideggerian idea of finding authenticity by returning to one's fundamental relation to

144 Houellebecq, Michel. Soumission: Roman. Paris: Flammarion, 2015 Pg. 48-49 
the world, but for now let us be satisfied with what follows. Huysmans' recurring protagonist and avatar, Durtal, is able to come home to an authentic being and escape the existential ennui of the early Huysmans in a conversion to Catholicism. "The pivotal aspect of the evolution of Durtal (and so that of Huysmans himself), from "Là-bas", in the last pages of which he says his goodbyes to naturalism for good, to "L'Oblat", by way of "En Route" and "La Cathédrale", was the conversion to Catholicism."145 Two interesting and important things are raised in this account of the philosophical evolution, and pilgrimage towards authenticity, of Huysmans as described by Houellebecq's narrator. Firstly, it is important to discuss the significance of homecoming in this particular context. To understand the kind of homecoming being described here, which is close to but not entirely compatible with Heidegger, it is useful to contrast it with the following:

"Through our thinking we temporal creatures may leave the cosmos and thereby reflect on what it means to exist temporally within its eternity; but if we wish to remain men we must always return home, and like any homecoming it will always be bitter-sweet. The sweetness comes from the fact that home is always there and the bitterness comes because it does not mean the same for us always and is therefore never quite what it ought to be. As temporal beings we have a choice: we could return home and never again venture into the bitterness of meaning, or we could venture out never to return again. In either case, the choice would be our last, for both would entail the loss of our humanness. "146

This account shares with Houellebecq's biography of Huysmans the idea that a man might go out into the unknown in order to find truth, but in the process find himself longing for home. Thus the odyssey back home becomes an integral part of the authentic humanity of the human being. However, once his home has finally been rediscovered in the Catholic Church, Huysmans has

145 Houellebecq, Michel. Soumission: Roman. Paris: Flammarion, 2015 Pg. 49

146 Darby, Tom. "Homecomings." The Feast. Toronto: U of Toronto, 1982. Pg. 227 
found his authentic self and has attained a kind of authenticity that is alien to the atheist narrator of the novel. Unlike Darby, Houellebecq does not feel that Huysmans remaining comfortably within the fold of the Catholic Church until his death represents a kind of renunciation of his humanity, but rather that it is from this point that he is able merely to exist, having attained an unspecified kind of authenticity that will elude the narrator first in his own failed conversion to Catholicism and later in his ambiguously fated conversion to Islam. Because of the ambiguities regarding the "they" that will be discussed later, it is difficult to locate precisely which side of this Heidegger stands upon. The notion of home, the idea that there is a realm within which being can "belong" in a way that it cannot elsewhere, certainly corresponds with Heidegger's claim about the horizons of the "at hand" and the rooting of being in these grounds. Indeed, Huysmans' ability to find authenticity in the Catholic Church, which forms an integral part of the cultural grounding of France, as opposed to his failure to find it in naturalism, which requires grounding in a countryside that is not in the "at hand" of the Parisian urbanite Huysmans, is also in keeping with Heidegger's idea of rooted being. Regardless of the disaccord that may exist between Houellebecq's satisfaction with a return to the groundings of home and Darby and Heidegger's suggestion that more is required of man than merely this, it is undeniable that Houellebecq links the authenticity of Huysmans' being, his eventual escape from the existential ennui of his cosmopolitan early life, to a return to the grounding of the "at hand", a very Heideggerian proposition. The authentic being, then, is the one that can come home to the grounds of his own culture, in order to root himself therein, and not the one who sees himself as equally open to the wisdom of all cultures.

Though Ben Abbes, unlike Huysmans, is a living character in the book, he makes no actual appearance in the story. Rather, his political career and ascent to the Presidency form the backdrop 
against which the action takes place. Ben Abbes possesses a kind of authenticity and non-cynicism that is totally absent in all the other politicians described in "Submission", though he is still skilful as a politician. It will be shown that, as with Huysmans, the authenticity of Ben Abbes is directly linked to his grounding in his dual French and North-African heritage, to which he remains true, and that this is juxtaposed strongly with the cynical universalism of the parties of the centre. These three parties, in the novel, form a "Republican Front" in the 2017 election to prevent the victory of Le Pen's National Front. They quickly find themselves competing with a newly reformed Muslim Brotherhood party. One of the first acts of Ben Abbes as leader of this party is to sever ties with the global movement of the Muslim Brotherhood and to abandon the principal of universal Muslim solidarity by backing away from any particular commitment to the cause of the Palestinians 147. This represents a turn away from a particular kind of universalism. It is interesting that Houellebecq should consider this to be so crucial a part of the establishment of the character of Ben Abbes. The Muslim Brotherhood of France then moderates its positions on almost all parts of Islamic doctrine that do not correspond to the traditional Catholic conservatism of the French terroirs, and are thus able to establish themselves as the non-nationalist face of traditional values. This is made especially clear by the way in which Ben Abbes presents the Sharia as a nonthreatening return to traditional values, rather than a revolutionary upheaval.

"The real genius of the Islamic leader was to understand that the elections would not play out on economic grounds, but on those of values: and that, here too, the right was about the win the 'battle of ideas', without even going to battle. Where [Tariq] Ramadan presented the Sharia like a new option, a revolutionary option, he re-establishes its reassuring traditional value- with an exotic perfume that made it ever more desirable. "148

147 Houellebecq, Michel. Soumission: Roman. Paris: Flammarion, 2015 Pg. 51

148 Houellebecq, Michel. Soumission: Roman. Paris: Flammarion, 2015 Pg. 153 
This process of orienting the Brotherhood towards those traditional values that are clearly considered to form the ground in which France is rooted, rural Catholic France in the eyes of Houellebecq, is presented as both a shrewd political move and an honest reflection of the FrancoMaghrebian hybrid that forms the heritage of Ben Abbes. Ben Abbes is authentic in his grounding in his own Islamic roots, those tinged with the influence of his French-Muslim upbringing, and as a result he is seen as a refreshingly authentic voice whereas Tariq Ramadan, a prominent French Muslim political commentator, is seen as an opportunistic cynic. Ben Abbes is thus able to tap into the ennui that has developed, largely because of his ability to ground his political project in the Catholic traditions of France, thus becoming the candidate of rootedness for those who share the Islamist aversion to secularism, rationalism and cosmopolitanism. This becomes even clearer on questions of foreign policy. Speaking of this, Marie-Francoise, a colleague of the narrator, has the following to say about Ben Abbes' early writings: "His great inspiration, it leaps from the page, is the Roman Empire, and the European Union is, for him, nothing but a means to realise this millenarian ambition. The central tenet of his foreign policy will be to shift the centre of gravity in Europe to the south." 149 This political project is, once again, firmly rooted in the traditions of France, which since the early middle-ages (when Charlemagne was crowned Emperor of the Romans) has understood itself as a continuation of the Roman Empire. This is placed in direct opposition with the European Union as it exists in the real world, which has little in common with the traditional interests and self-understanding of the nations of Europe. These examples show that Ben Abbes is aware of the importance of rootedness to the existential wellbeing of the French people and is attuned to the possibility of expanding his appeal beyond his religious base by aligning his politics with the traditions of a pre-Enlightenment France that finds itself alienated 
from the mainstream of French politics. It is important to note, at this point, that Abbes is not presented as any kind of hero in this novel and there is a great amount of ambiguity presented both as to whether or not he is merely opportunistic and whether or not his political programme represents a negation of France, an Islamic invasion, under the reassuring guise of a return to traditional values. However, Ben Abbes is distinguished from the mainstream politicians he opposes by his rootedness in the traditions of the Islamic world and his own Franco-Islamic heritage, and the fact that his return to the roots of French tradition is embraced by the public in light of a general sense of anxiety and malaise brought about by the secular, universalist cosmopolitanism of French society. Both of these show that Heidegger and Houellebecq clearly share the belief that universalism, and the uprooting of man from his grounding in a particular place, is a significant cause of existential ennui and anxiety. It is an interesting narrative move to put this ideological point across through the character of a bi-cultural Muslim like Ben Abbes; but there is no doubt in his actions that he remains rooted in his own heritage, is not a champion of multiculturalism and is therefore authentic in a way that, we will see, other characters are not. It is not coincidental that the two most sympathetic characters in the novel are distinguished by their ability to find authenticity by rootedness in the cultural tradition that is within the horizons of their "at hand".

This dichotomy between authentic, culturally rooted beings and inauthentic cosmopolitans becomes especially clear when Houellebecq's attention is turned towards those rootless cosmopolitans that are characterised as making up the bulk of the French intellectual and media landscape. Houellebecq's narrator, his colleagues at the university and those figures from French public life that Houellebecq lampoons are all characterised by a shallow worldliness, based more on eating microwaved curries and sushi than any real knowledge of other cultures. However, at 
this point it is also worth noting that all of these characters are completely alienated from the relationship with the "at hand" that Heidegger considers so central to the authenticity of Dasein, because they are alienated from their own cultural heritage. This is most obvious in the inability of the narrator to relate on any level to Huysmans novels that concern conversion and Catholicism. "In the absence of any real emotional adherence, the sentiment that imposes itself bit-by-bit upon the atheist confronted by the spiritual adventures of Durtal, to these alternating movements of the retreat and interruption of grace that constitute the drama of these last three Huysmans novels, is boredom."150 This is typical of the university faculty, as characterised by Houellebecq. They study, for the most part, the great writers of the French past; Rimbaud, Chateaubriand and Péguy for example; but do so at a level of detachment that comes from their lack of genuine rooting in the traditions and heritage of France. They embrace other cultures at a superficial level and eventually many of them chose to convert to Islam as a result of career ambition, financial greed and convenience rather than because they have found a spiritual home in the religion itself. At every turn these characters are cynical, self-interested and duplicitous. They are entirely inauthentic. That Houellebecq makes this dichotomy between the rootless, alienated and inauthentic liberal intellectuals, who embrace multiculturalism, and the authentic rooted characters of Huysmans and Ben Abbes, who do not, represents the overt anti-multiculturalist polemic that is clearly present in Houellebecq's novel. By linking this polemic to conceptions of anxiety, inauthenticity, rootlessness and anti-universalism Houellebecq is demonstrating the extent to which Heidegger's rejection of universalism, described above, has permeated into contemporary French right wing thought. In short, Houellebecq has adopted the Heideggerian position that being must become in the context of a particular place and culture, and that any attempt to tear man from these roots will 
result in his alienation from authentic Dasein. The foundation of his anti-multiculturalist polemic is thus firmly rooted in the anti-universalist positions of Heidegger.

This link is equally evident when one considers the version of this polemic offered by the French "far-right". This will be explored by brief consideration of a revealing dichotomy created between two different kinds of "Frenchness". The first of these is the concept of the "Français de souche", the second is the concept of the "Français de Papier". The juxtaposition made by the far right between the inauthentic Frenchness of the "Français de Papier" and the authentic Frenchness of the "Français de souche" shows that the "far-right", like Houellebecq, is also availing itself of this Heideggerian concept of spatial rootedness, and its implicit rejection of universalism, in its distinction between "real" and "superficial" Frenchness.

The term "Francais de souche" is a difficult one to translate. Most commonly it is translated as "old stock French" but a more accurate translation, though impossible to put in such a pithy three word formulation, reveals the true Heideggerian undertones at work in this concept. The "souche" refers to the part of the tree at the bottom of its trunk that is directly connected to the roots. Therefore, the "Français de souche" is the Frenchman who is most closely connected to the roots, and therefore most directly rooted in the soil of France. There is no doubt that this term is used to distinguish the "real", or authentic, Frenchman from the "superficial" or "new stock" Frenchman. The idea that the authenticity of one's Frenchness can be linked so directly to one's alleged proximity to the roots of the nation represents a clear employment of at least the language of Heidegger in the "far-right" but also, undoubtedly, a metaphorical connection between the authentic being of a person, or people, and the grounds in which their being is rooted. The reasonable objection that most of the politicians employing this language have probably never read any Heidegger only attests to the degree to which his ideas have permeated political discourse in 
"far-right" circles 151 . That even the most base and vulgar elements of the "far-right" reach, unconsciously, for Heideggerian language is, I believe, a strong indication that the ideas of Heidegger have shaped the language, and profoundly influenced the ideology, of this political movement.

Those Frenchmen that are seen to lack rooting in France; immigrants, ex-pat's, multinational corporations and financiers; find the authenticity of their "Frenchness" questioned on precisely these grounds. Nowhere was this attitude more clearly exemplified than in the indirect exchange between former National Front leader, Jean-Marie Le Pen and Spanish born French Prime Minister Manuel Valls, an exchange that reveals two distinct conceptions of being and belonging. Responding to criticism from Valls over comments made by Le Pen regarding immigrants and the holocaust Le Pen tweeted "I am 'Français de Souche" of Brittany. My $16^{\text {th }}$ great-great grandparents were born in Morbihan. Should I be expected to apologise for this before Manuel Valls? 152 " The implication of this is fairly clear, Le Pen clearly believes that his Breton lineage means that he ought not answer to Spanish born Valls on questions of French identitarianism, and suggests that he is being victimised on account of his homogeneous lineage by the more cosmopolitan Valls. To this, speaking at the launch of a governmental program combating racism and anti-Semitism, Valls states that, "French people who love their country are constantly reminded of what others regard as their origins. They are accused of not being French enough. On one hand you have Frenchness going back a thousand years and on the other, a Frenchness going back only thirty years, should this latter make you a lesser Frenchman? This is

151 So much so, in fact, that even Steven Harper, hardly a firebrand identitarian, reached for this precise term in his courtship of Quebecois right-ting voters in the elections of 2015 152 Le Pen, Jean-Marie (lepenjm). "Je suis Français de souche bretonne. Mes 16 arrière-arrière-grands-parents sont nés en Morbihan. Dois-je m'en excuser auprès de M. Valls ?" 27 February 2015. 9:55 AM. Tweet. 
not what France is all about."153 The distinction between these two conceptions of Frenchness is entirely comparable with the claims made by Heidegger about the spatial particularity of being and the importance of "rootedness". Though Heidegger's account could be construed as being more contingent upon the environment in which the individual is rooted, and less concerned by lineage, there is still a clear relationship between Le Pen's appeal to a rooted being based on grounding, cultural inheritance and proximity to the soil and Heidegger's spatial rooting of being. To make an appeal to rootedness in contrast with the type of belonging described by Valls, based on love of country and citizenship speaks directly to the distinction made by the "far-right" between the "Français de souche" and the "Français de papier" This distinction is rooted in a Heideggerian understanding of being and authenticity that portrays the universalisable "Frenchness" grantable to all by citizenship and their love of France as inauthentic in contrast to the spatially rooted and particular "Frenchness" of the "Français de souche". Thus we can see that the Heideggerian critique of the universality of being finds a vulgar kind of expression in the "farright" understanding of authentic, versus inauthentic, communitarian belonging.

153 Valls, Manuel. La République Mobilisée Contre Le Racisme Et L'anti-semitisme. Asembéle Nationale, Paris. 17 Apr. 2015. Orange.fr. Web. <http://actu.orange.fr/politique/videos/francais-depuis-1-000-ans-manuel-vallsrepond-a-jean-marie-le-pen-VID0000001AxPx.html>. 


\section{Chapter Two: History, Time and the Critique of Progress}

With this being established, it falls upon us to consider the second great departure from enlightenment orthodoxy that can be found in Martin Heidegger's “Being and Time”. This constitutes a rejection of the notion of progress and is rooted in a rejection of the idealism of Platonic metaphysics. While the connection between Platonic metaphysics and the enlightenment view of progress is not self-evident, it will be shown that Heidegger, both indirectly through his substitution of becoming for the ideal forms of being and directly through his account of history and temporality, creates a metaphysical structure that does not allow for a conception of change that can be considered "progressive". The replacement of the pursuit of an ideal form of being with a focus on resoluteness in the face of a storm represents a fundamental departure from "progressive" thought which will be shown to be highly influential for the opponents of "progressive" liberalism in the modern context. This will be demonstrated in two steps. Firstly, the rejection of Platonic forms will be analysed and shown to represent a rejection of the idea of an ideal form to which being can progress in favour of a more value-neutral conception of change and becoming. Secondly, Heidegger's overt critique of historicism will be examined, and it will be posited that this represents a rejection of the idea of an end of history towards which man is progressing. Together, all of this will show that Martin Heidegger's thought rejects the notion of progress and, in doing so, departs from the enlightenment in a way that challenges the very basis of modern liberal thought.

Heidegger throws down the gauntlet of his challenge to this Platonic, or in his words traditional, understanding of being in his introduction, where he characterises the traditional understanding of being as a "prejudice" that must be overcome if we are to engage seriously in the questioning of being. As described previously, this begins with the assertion that the universality 
of being is mistaken for self-evidence in Platonic philosophy. To this is added a description of this approach to being which proceeds as follows: "The "universality" of "being" "surpasses" the universality of genus. According to the designation of medieval ontology, "being" is a transcendens. Aristotle himself understood the unity of this transcendental "universal," as opposed to the manifold of the highest generic concepts with material content, as the unity of analogy."154 In characterising this understanding of being as a transcendental phenomenon that stands above the manifold iterations of "beings" that exist in the material world as a prejudice that must be overcome, Heidegger is placing himself in direct opposition to the idea of the "forms" as understood by Plato. Heidegger believes that it is a mistake to formulate an ideational concept of being that is independent, and transcends, those genus' of being that can be encountered in the world. It is also a mistake to postulate that this transcendent form should constitute the essential and authentic manifestation of "being" from which all worldly manifestations of those "beings" are derived. Put simply, Heidegger questions why one should formulate an ideal form of, say, a dog and posit that this represents the authentic and essential form of "dogness", and see all dogs as deviations from this ideal form, rather that rooting our conception of "dogness" in actual dogs that can be encountered in the world. In more general terms Heidegger posits that a more satisfactory questioning of being must, in fact, be rooted precisely in the questioning of those genus' of being that can be encountered, and they must be made accessible to this questioning as they are "in themselves" rather than as they exist in some ideal conceptual form. "Insofar as being constitutes what is asked about, and insofar as being means the being of beings, beings themselves turn out to be what is interrogated in the question of being. Beings are, so to speak, interrogated with regards to their being. But if they are to exhibit the characteristics of their being without

154 Heidegger, Martin. Being and Time. Trans. Joan Stambaugh. Albany: State U of New York, 2010. Pg. 2 
falsification they must for their part have become accessible in advance as they are in themselves." 155 This last sentence raises the additional challenge that suggests that the Platonic understanding of being is, in fact, an obstacle to the questioning of being, because it renders inaccessible the being of beings pre-ontologically and falsifies the characteristics of being and beings that presence themselves when questioned under the influence of this "prejudice". This challenge to Platonic metaphysics has political implications that will be explored shortly, but for now let us content ourselves with the recognition that this constitutes a fundamental confrontation between Heidegger and the majority of the canon of Western philosophy. In rejecting the notion of the transcendent form, and positing instead a questioning of the existent essential being of beings encountered in the world, Heidegger is rejecting the possibility of ideal types at the most fundamental metaphysical level imaginable. If there is no ideal dog, that beautiful and ugly dogs are close to and far from respectively, there can also be no teleological progression towards an ideal man or an ideal city against which we can measure our current status or towards which we can aspire to approximate ourselves and our society. This cannot be squared with any conception of "progressive" history. In order to distinguish progress from change it is necessary to have a fixed end point towards which motion can be construed either as progress or regress. Without this end point, without the ideal type towards which we can be approximated or distanced, progress is merely change, and "progressive" history must be abandoned.

In light of this last observation it follows naturally that we should continue with a discussion of Heidegger's reflections on temporality and history. At this point it is also important to speak briefly about the historical context in which Heidegger was writing. Heidegger's experience of the Second World War is a subject of great controversy, and no small interest, but

155Heidegger, Martin. Being and Time. Trans. Joan Stambaugh. Albany: State U of New York, 2010. Pg. 6 
is clearly far too significant of a subject to be discussed satisfactorily in the cursory form that would inevitably be imposed upon this essay at this time. For our purposes it suffices to say that "Being and Time" was written in the shadow of two great, millenarian and Utopian forces. The Soviet Union and Communism in general had the appearance of ascendency, and were oriented towards the creation of a permanent and ideal socialist Utopia across the globe. Less overtly, the liberal order, headed by America, championed freedom and democracy, backed by the development of Democratic Peace Theory. This coincided with the efforts of Jean Monnet and Konrad Adenauer towards the creation of the European Coal and Steel Community, with an eye to the creation of a European Union (against which the National Front also militates), an undertaking with similarly millenarian ambitions to end war on European soil for ever. Therefore, it is clear that Heidegger wrote within the context of a world dominated by idealist visions of a future global order building towards the attainment of various ideal forms of human political organisation. Most obviously, Communism was also imbued with a progressive view of history that held; frighteningly at first, then irritatingly, and finally laughably as the Communist experiment slowly unravelled; that irresistible forces of history were pushing the peoples of the world towards inevitable revolution and the final end of a global communist era. This environment inspired certain of Heidegger's contemporaries, most notably Alexadre Kojéve, to embrace the idea of a last-man at the end of history, but triggered a violent reaction in others. Leo Strauss held that this sense of inevitability and finality drove young German intellectuals to embrace National Socialism as a desperate measure against this seemingly irresistible force 156 , and such an explanation ought to be taken seriously, but for the purposes of this paper it is sufficient to limit

156 Leo Strauss, "German Nihilism"_Interpretation_26:3 (Spring 1999): 353-378 
speculation on Heidegger's intentions in writing this work at the preceding acknowledgement of the environment in which it was written.

Instead, this question of history and progress can be examined by reference to the text, where Heidegger offers ample insight into his position on historicism157, teleological history and progress. Heidegger roots his analysis in a direct critique of Hegel, who he believes has bought into a vulgar characterisation of "within-timeness" that privileges a levelled out version of the experience of the now and makes it a universal standpoint from which man looks back into the past and projects forwards into the future. He roots this in the Hegelian notion that man, from his particular point in time, rebels against all other points. It is only in the now, according to Hegel, that man can posit himself, and his perspective upon the world must always come from this point of view. Heidegger reflects upon this, saying that "Hegel is wholly moving in the direction of the vulgar understanding of time. Hegel's characterisation of time in terms of the now presupposes that the now remains covered over and levelled down in its full structure, so that it can be intuited [angeschaut] as something present, even if it is only present "ideally"."158 The appeal to the "ideal" presencing of being in the now ties directly into Heidegger's critique of Platonic metaphysics, as does the need to reduce the now to a universal, abstract idea rather than recognising the particular characteristics that make up the "innerworldlyness" of being and beings. For Heidegger, this mistake comes from a conception of the spirit, and it is the spirit that perceives time, as a free and pure concept, that precedes the differentiation between the I and the non-I. This spirit is shorn of any specific characterizations:

157 Some may still protest that Heidegger cannot be put so firmly in opposition to historicism, and that one cannot think of Heidegger outside of his deep emulsion in historicist thought. However, I believe that this is a fundamentally pedantic argument, because the distinctions between Heidegger and Hegel discussed in this section are so profound, and so fundamental, that whatever version of historicism Heidegger might be claimed to have been engaging with is so far removed from the writings of Hegel. 158 Heidegger, Martin. Being and Time. Trans. Joan Stambaugh. Albany: State U of New York, 2010. Pg. 409 
"The I is pure concept itself that has come to existence as the concept." (Hegel. Wissenschaft der Logik) "But the I is this first pure unity relating itself to itself, not directly, but rather, in abstracting from all determinateness and content and going back to the freedom of the limitless identity with itself." (ibid) Thus the I is "universality," but it is "individuality" just as immediately." 159

Thus our relation to time is every bit as abstracted and robbed of its unique characteristics as the relation to being criticised previously. This universalisation of the individual's place within time through abstraction clashes directly with the temporally contingent being-in-time posited by Heidegger. Heidegger's perception of being as temporally rooted is built upon his claim that being at its primordial level is the temporalisation of temporality that "falls prey" to its place in time rather than "falling into" it as Hegel posits. It belongs to its time insofar as it has "fallen prey" to it, and has thus been lured from its authenticity. ““'Spirit” does not first fall into time, but exists as the primordial temporalizing of temporality. Temporality temporalizes world time, in whose horizon "history" can "appear" as an occurrence within time. Spirit does not fall into time, but factical existence "falls", in falling prey, out of primordial, authentic temporality."160 Again, this introduces a certain paradox whereby Heidegger criticised both the attempt to abstract being out of the time in which it becomes, but also, in a sense, the claim that being is limited to the horizons within which history can appear as occurrence represents a "fall" from authenticity. As with the relationship between the individual and the "they", the relation between the individual and the time in which he is located is somewhat ambiguous. There is, though, no question that Heidegger sees the historicism of Hegel as being founded upon an erroneous abstraction of being that levels out those distinctions that result from the becoming of being by taking care and creates a universalisable, abstract notion of being, "the spirit". Heidegger feels that this results in an inauthentic construction of being-in-time that creates a vulgar understanding of time and history. 
In contrast to this vulgar conception of time and history, Heidegger wishes to shed light upon an authentic kind of being that is rooted in time, as it is in place, a kind of being that, by definition, cannot unfold in history in quite the way that Hegel imagines. Heideggerian man is temporal, rooted in his time, in a different way to that of Hegel. "This being is not "temporal" because it is "in history," but, on the contrary, it exists and can exist historically only because it is temporal in the ground of its being." 161 In other words, being is not within-time because it occupies a particular place within the unfolding of history, qua Hegel, but rather the place in history occupied by a being is a by-product of the temporal nature of the ground in which it is rooted. Further still, Heidegger feels that the authentic Dasein, because of its grounding in a particular place and time, cannot unfold in time. Also, the historicism of Hegel reduces the history of Dasein and the world to "world-history" an inauthentic history of inauthentic Dasein that takes a materialist and rationalist approach to things "in-the-world" and ignores their innerworldlyness.

"in inauthentic historicity the primordial stretching along of fate is concealed. With the inconsistency of the they-self, Dasein makes present its "today." Awaiting the next new thing, it has already forgotten what is old. The they evades choice. Blind towards possibilities, it is incapable of retrieving what has been, but only retains what is and receives the "real" that has been left over of the world-historical that has been: the remnants, and the information about them that is available. Lost in the making present of the today, it understands the "past" in terms of the "present" 162

Put simply, we are not of our time because of any pre-existing place in history into which we happen to have fallen by accident of birth, but rather our being can be considered historically only because the ground in which being is rooted is temporal, and we are therefore rooted in a ground that is particular to our time, in which history itself is also rooted. Thus being and history are equiprimordial, largely because history requires being. Helpfully, Heidegger provides us with a 
useful analogy to understand this somewhat confusing proposition. He chooses the example of an artefact that one might encounter in a museum, saying:

"What is "past"? Nothing other than the world within which they [museum relics] were encountered as things at hand belonging to a context of useful things and used by heedful Dasein existing-in-the-world. That world is no longer.... But what does it mean that the world no-longer-is? World is only in the mode of existing Dasein, which, as being-in-the-world, is factical. "163

As a result of the temporal rooting of being, history must therefore be as temporal as those beings that make it. The relic in the museum can be said to belong to a particular time even though it is clearly present as one looks upon it in a museum. It's being is grounded in its relation to that which was at hand in the period in which it was a useful, everyday object; while now it exists outside of this temporal rooting and therefore is considered to belong not to this time but to that previous time. A spade ceases to be a spade and becomes an artefact when it ceases to be able to perform its essential purpose and becomes an attraction in a museum, torn from its grounding in the athand in which its authentic being is rooted. In short, we see here the development of a key argument about the temporal particularity of Dasein. Dasein does not fall into the occupation of a particular place in the unfolding of history over time, but rather is entangled in the taking care of things around it. It can therefore only derive its authentic characteristics, and be authentic, within its temporal context. Heidegger thus rejects the kind of historicist thinking that leads Hegelian thinkers of his time to posit an inevitable "end of history", a teleological view of history that, it will be shown, forms the foundation of the "progressive" thought against which the "far-right" is in rebellion.

This position of a being limited by temporal horizons confines the relation of being to history in such a way that is vital to understanding Heidegger's rejection of teleological history. 
Heidegger begins to describe these limitations by elaborating upon a particular definition of "understanding" that is temporally limited, and demonstrates the impossibility of the Hegelian understanding of being and history. Heidegger provides a definition of understanding that rejects the possibility of universal cognition in favour of rootedness in a circumstantially contingent being-there which provides the perspective from which we look at and understand the world. "Understanding constitutes the being of the there in such a way that, on the basis of such understanding, a Dasein in existing can develop the various possibilities of sight, of looking around, and of just looking. All explanation, as discovery that understands, is rooted in the primary understanding of Dasein."164 Thus understanding becomes the result of a relation between the Dasein and that which it can encounter by looking around and seeing the things that are at hand. Beyond the horizon of what can be looked at, metaphorically of course, everything is incomprehensible and the Dasein is unable to relate to those things in such a way as to create the necessary relation for a universal cognition. This becomes clearer as Heidegger distinguishes between an authentic kind of self-understanding, which comes from remembering a forgotten authentic part of one's being, with an inauthentic kind, that comes from a "taught" memory or from no memory at all. This last kind still preserves being, but does so in an inauthentic way. One might reasonably protest that Heidegger is constructing a highly subjective account of being and time that rejects the kind of eternal truths for which philosophers are supposed to be in search. Heidegger essentially concedes the subjectivity of this part of his argument, though this creates some tension as he is so critical of subjectivity elsewhere. For him, the world is experienced and understood by thrown beings who can only authentically be what they are. As before, the authentic being is grounded in the temporal and the contingent, "If the subject is conceived ontologically as 
existing Dasein, whose being [Sein] is grounded in temporality, we must say then that the world is "subjective." But this "subjective" world, as one that is temporally transcendent, is then "more objective" than any possible "object"."165 The world is perceived by the Dasein and is thus different to each Dasein, and those differences are circumscribed by the place and time in which the Dasein is located. At its core, this provides us with the foundations of Heidegger's rejection of the idea of universal history, which is the central pillar of his rejection of the idea of teleological history and therefore progressive historicism. The Dasein exists within the temporal boundaries of that which can be seen and encountered in its own time period. We can thus not claim that there is a universal being that unfolds alongside history, nor can we say that this unfolding can be observed and conceptualised in its entirety, as Hegel claims to be able to do. We are thus unable to make claims about being "on the right side of history" or to believe ourselves to be embodying "progressive" principles because we cannot ascertain an end point that lies beyond the temporal horizons of the world that is at hand. Therefore the idea of an "end of history", even if it could withstand the critique of the ideal type outlined above, would be incomprehensible and uncanny because, by definition, it must lie outside of the temporal horizons within which being is able to grasp the world.

In conclusion, it becomes clear in light of this analysis that Heidegger's thought stands in direct opposition to the understanding of being and history that is a necessary condition of any teleological account of history, and therefore any notion of historical progress. At the most fundamental level, this comes from his critique of Platonic metaphysics, where he rejects the idea that it is possible to theorise an ideal, perfect form of being, be it the being of an individual or a state, and set up this ideal as a yardstick against which our current situation, and changes thereto, 
can be measured. Secondly, it consists of a rejection of the Hegelian historicism that claims to be able to identify a direction of history, a broad process within which an individual happens to fall and is located, and the rejection of the possibility of a universal historical being that can relate comprehendingly to the whole of time. This renders the claims of contemporary progressives impossible and, as will now be discussed, provides the philosophical foundations of Michel Houellebecq's anti-progressivism.

As with the critique of universalism discussed in the previous chapter, the sceptical stance towards ideas of universal progress and teleological history is similarly present in the writing of Michel Houellebecq. In fact, this aspect of Houellebecq's thought is fairly well documented. For example, Louis Betty considers Houellebecq to fit directly into the lineage of the most celebrated anti-Utopian thinkers of the $19^{\text {th }}$ century:

"Beginning with Edmund Burke, and passing through Joseph de Maistre, Chateaubriand, Baudelaire, and others, the nineteenth century's anti-moderns all colluded in suspicion of their century's "cult of progress" inherited from the French Revolution....For de Maistre, the Revolution augured a dialectical return to pre- revolutionary social order; while Baudelaire, in "Mon cœur mis à nu", described the cult of progress as a lazy doctrine worthy only of the Belgians. If the utopias of Comte, Fourier, Saint-Simon and others can be understood to represent the most extravagant examples of progressive, utopian thinking in nineteenth century France, figures such as Baudelaire and de Maistre surely supply their foils along with Houellebecq, in experimenting with and rejecting utopia." 166

Understanding Michel Houellebecq as an anti-Utopian novelist with a profound scepticism of the "cult of progress" is a fairly fruitful way both to try to understand these works in themselves and also to understand the connection between his anti-Utopianism and the account of being provided by Heidegger. Like Heidegger, we have seen that Houellebecq sees technological advancement, and its promise to cure all the ills of the world, as the primary Utopian force in modern society. 
Also, like Heidegger, Houellebecq identifies a profound anxiety as an unintended consequence of this idealistic vision of history. Like Burke, Chateaubriand and Baudelaire, Heidegger and Houellebecq both clearly react to the "cult of progress" that they encounter in their time periods. In the case of these last two, this rejection takes the form of a scepticism about the possibility of the ideal "city in speech", not merely in practice, and a rejection of the idea that there is an arc of history that bends in a particular direction. In the case of Houellebecq, as stated by Betty, this takes the form of experimentation with particular types of Utopia, particular images of an "end of history", which ultimately reveals both their non-finality and their undesirability.

The most obvious example of this can be found in "The Possibility of an Island". As stated before this novel provides an account of the successful pursuit of immortality by way of cloning, and the eventual freedom from all want, suffering and struggle. The connection made between the elimination of want and the "end", so to speak, "of history", has previously been mentioned, and discussed before, in "The Elementary Particles" where the history of man is brought to an end by the placement of erogenous zones all over the human body. By eliminating sexual desire, the need for fulfillment that is posited as the primary motivation for human action is permanently satisfied and the significant public actions that make history cease to occur. While Houellebecq is perhaps being fairly glib in suggesting that all significant human action is, at root, driven by the desire for sexual fulfillment, the idea that the very attainment of desire might in fact negate human action is one that comes to play a central role in the anti-Utopianism of Michel Houellebecq. The notion that lack is a necessary component of desire, because one must lack something in order to desire it, and that once that lack has been fulfilled, desire dissipates is a fairly conventional position to take in considerations of eros and action. However, the advent of modern technology, and particularly the kinds of technological advances; such as synthesised food, animal cloning and 
artificial intelligence; that are considered by Houellebecq but were inconceivable to Heidegger, has introduced the possibility of the permanent fulfillment of all lack, rather than just the temporary satisfaction that comes, for example, from eating something. This is precisely the "Utopia" achieved by mankind in "The Possibility of an Island". As stated before, the neo-humans have no need for companionship, sex, food or joy, partly because the annihilation of the boundary of finitude, immortality, has taken all of the urgency out of these pursuits, but also because the desiring nature of man has been slowly engineered out of them in order to alleviate the suffering of want. This leads, Daniel 25 to make the following comparison between the cloned neo-humans and their human ancestors: "The humans, at least the humans of the final period, adhered, it seemed, with great ease to all new projects, a little independently of the proposed direction of these projects; but change itself had, in their eyes, a kind of value. We, on the other hand, view innovation with the greatest of reticence, and only adopt it if it seems to us to be beyond all dispute in its benefit." 167 We can observe, then, that all boldness, all innovation and the drive for action and change itself is obliterated once man is freed from the pursuit of those things that he lacks. The connection between this and Heidegger's critique of the ideal forms is complicated, but undeniable. Heidegger posits that the ideal form is a pure construct of theory that has no actual connection to the existent being of beings. The idea of the perfectly beautiful ideal form of a thing being the font of the thingness of things, and the idea that we can measure the beauty, and therefore goodness, of a thing by its proximity to this ideal is fundamentally undermined by Heidegger's account of Dasein. Houellebecq takes this even further. Houellebecq is not merely arguing that ideals are unobtainable. He is instead arguing that should they ever be obtained, they would reveal themselves to be far from ideal, and that their perfection itself would reveal itself to be the cause 
of this imperfection. Much as one might imagine that the perfectly proportioned human face would look ugly on account of its perfect proportion, Houellebecq suggests that any posited Utopia, once achieved, would be ugly and imperfect precisely on account of its Utopianism. A society where all needs are met would be a society beset by meaninglessness and entropy, by extension any perfect ideal form of being would be blighted by its own perfection.

In "Submission" we see something of an evolution of Houellebecq's position, where his belief that, however miserable it may be, this future technological "dystopia" is inevitable is abandoned. Whereas the scientific "post-historical" modes of being inevitably triumph against the, often reactionary, forces that oppose them; the Islamic terrorists are doomed in their fight against western materialism in "Platform", the humans that refuse immortality go extinct in "The Possibility of an Island", and Bruno finds refuge in madness in "The Elementary Particles"; the conclusion of Submission is different, as progress is rejected in favour of a return to the religious traditionalism of a moderate Islamist party. This speaks to Heidegger in an interesting way. Recall that Heidegger's anti-historicism was shown to emerge from a rejection of the idea of a universal historical consciousness, as a result of the temporal horizons limiting the comprehensibility of the world to the Dasein and the equiprimordiality of being and history. It can be argued that the abandonment of Enlightenment ideas of progress in favour of religious traditionalism makes a similar point in less philosophical language. This is primarily explored in the conversion of the narrator to Islam, a process whereby he weighs the benefits of this return to tradition against the promise of progress as he understands it. At its core, the narrator trades the freedom of secularism for the convenience and certainty of religious life. He is very amenable to the argument of a colleague who has moved from the university to work in the new Islamic government who tells him 'I've been used to power struggles in the context of the university; but here there is definitely 
a big boss. That said, Ben Abbes is a really great man, I'm proud to work for him."168 That the narrator is attracted to the idea of being "freed" from the pursuit of power and success and being comfortable "knowing his place" under a leader whom he admires is a precise inversion of the ideal of liberty between men that was so central to the French revolution. This inversion of values is even more pronounced when it comes to the freedom of women. In the novel French women embrace the Niqab because it allows them to dress comfortably, not worrying about being judged or objectified by men, and eventually warm to the idea of arranged marriages because it freed them from the interminable rigmarole of sexual exploitation, disappointment and heartbreak that characterises love in Houellebecq's universe 169. More generally, however, the French embrace of Islam is driven by the "calm" that it creates as it replaces the anxieties, uncertainties and problems that result from a serious secular questioning of the human experience with the clear rules, easy answers and comfortable conformity of the new Islamic order. By situating the embrace of Islam specifically in such staples of progressivism as freedom, the advance of women's rights and the escape from the inflexible rules of religion, Houellebecq is demonstrating the temporal rooting of being elucidated by Heidegger. The values and world-view of the French Enlightenment and the woman's rights movement are posited as being specific products of the "at-hand" in the particular time that they occurred. Freedom and equality are not universal and eternal human desires but rather appear as such only within the horizons of one's place in time. When the grounds of an age change, these values can be abandoned and, in this case, their polar opposites become the animating desire of most people. A woman's desire to dress as she wishes, or a man's desire to be equal to all other men, is thus not a universal aspect of human being but rather is something that becomes as a result of interaction with the world "at hand". In conclusion, being in Houellebecq's 
novels can be said to be spatially rooted in much the same way as it is for Heidegger and this, combined with the scepticism of ideal types that both express, creates a strong link between Heidegger's analysis of the Dasein and Michel Houellebecq's anti-progressivism.

One could reasonably protest that, granting the similar perception of a temporally rooted being, Houellebecq is embracing a kind of flight into tradition that is explicitly in contradiction to Heidegger's thought. This is undeniably true, and becomes even more so when the comparison is shifted from Houellebecq to the French "far-right". The nature of the "far-right's" antiprogressivism is far less rooted in serious consideration of the possibility of universal historical consciousness, nor of consideration of Plato's theory of the forms, but rather is a fairly conventional reactionary politics. It is here that the limitations of the Heideggerian comparison become fairly evident. Unlike Heidegger and Houellebecq, the National Front do not reject progressive conceptions of history in themselves, rather they object to particular conception of progress that they associate with the left. This becomes clear when one considers the idealization of traditional gender roles in much "far-right" discourse, and their obvious appeal to a better, simpler, idealized past. For example, Eric Zemmour laments feminism and "feminization" in the following terms:

There is a feminine malediction that is the opposite of benediction170. They don't destroy, they protect. They don't create, they gossip. They don't invent, they conserve...[etc.].... In feminising, men sterilise themselves, they forbid all audacity, all innovation, all transgression. "171

There is a certain parallel between Zemmour's claim that audacity and innovation have been sterilised and the stultifying entropy that is the result of "progress" in Houellebecq's books, 
Houellebecq can hardly be considered a feminist. However, the above quote is just one example of the fairly unsophisticated form of reactionary politics advocated by Zemmour. Zemmour presents a discourse that construes Arabs and black people as a physical and sexual threat172, which likens immigrants to an invasion force 173 , that sees gender equality as a threat to a vulgar conception of manliness and that seeks to revise, minimise and negate the shame of the Vichy regime's involvement in the Holocaust174. This last ties Zemmour into a long tradition of French reactionary politics that often falls prey of vulgar prejudice and anti-Semitism. The antiprogressivism of the "far-right" is far more deeply rooted in this reactionary tradition than in the Heideggerian ideas discussed in this thesis. Jean-Marie Le Pen's holocaust denial 175 and the involvement of the National Front with the most reactionary elements of the European Parliament betrays the vulgarity of the "far-right's" opposition to "progressivism". This is a vulgarity that, for all his flaws, Heidegger is at least able to transcend in his philosophical writings; suggesting that in this regard, the link between Heidegger's philosophy and the politics of the "far-right" can only take us so far. In fact, this chapter can conclude with the claim that, rather than taking up Heidegger and Houellebecq's challenge to "progressivism" in itself, the National Front merely objects to what it perceives as a leftist image of progress, and wishes to substitute it for its own ideal of a France returned to its "true" French culture, a utopia of a different kind

\footnotetext{
172 Zemmour, Eric. "Immigration: Zemmour Dérapé." Interview by Thierry Ardisson. Salut Les Terriens. Canal+. Paris, France, 06 Mar. 2010. Television 173 Zemmour, Eric. "Grand Débat No 2." Interview by Anais Bouton. Zemmour Et Naulleau. M6. Paris, France, 09 Mar. 2016. Television 174 Zemmour, Eric. Interview by Léa Salamé. On N'est Pas Couché. France 2. Paris, France, 04 Oct. 2014. Television 175 Waterfield, Bruno. "Jean-Marie Le Pen Repeats Holocaust Comments in European Parliament." The Telegraph. N.p., 25 Mar. 2009. Web.
} 


\section{Chapter Three: Departures}

It is precisely to the limitations of the comparison that we must turn in order to conclude this project. Two such departures will be explored in this final chapter. The first of these is the matter of the "they". It will be shown that the relationship between the "they" and the Dasein is somewhat ambiguous in "Being and Time", where the "they" is presented as both an integral part of the becoming of authentic Dasein, but also as a source of the levelling out that receives such criticism throughout Heidegger's writings. It will be shown that this ambiguity does not really exist in the writings of Michel Houellebecq, who conceives the "they" as a purely negative force, nor in the politics of the "far-right", who embrace and claim to champion the "they" in the guise of "the French people". Secondly, attention will turn to what one might term the "project" of authentic Dasein, a project that has very little in common with the simple solutions offered by the "farright". This realisation should serve to demonstrate that, for all the similarities posited between the French "far-right" and Heidegger over the course of this paper, there remain serious departures from his thought that should give us significant pause before conceiving of the "far-right" as an example of Heideggerianism in action.

Throughout this section it has become increasingly clear that a certain paradox, or at least a great ambiguity, exists surrounding Heidegger's position on individualism and collectivism. At many points Heidegger decries the "averageness" of the "they" and the way in which man's belonging to a larger community can have the effect of pulling him down towards mediocrity. In fact, the very description of this process as "falling prey" suggests a clear negative connotation and ties into an age old philosophical tradition of considering man to have "fallen" from a higher previous state. However, it is equally clear that Heidegger rejects the kind of individualism that is rooted in the detached rationalism of Kant or Descartes, which are seen as an uprooting of man 
from his grounding and, as has been shown above, this sense that abstract individualism alienates the Dasein from its authentic being is a large part of Heidegger's critique of enlightenment modernity. It is impossible to give an account, even one so particularly focused and therefore noncomprehensive as this one, of "Being and Time" without engaging with this tension. Attempting to resolve this paradox is far beyond the modest ambitions of this essay but, it will be shown, this tension between the desire to escape from the "group-think" of the collective whilst simultaneously striving for an authentic being that is rooted in precisely this same collective is a tension both in the works of Martin Heidegger and in the political project of the "far-right". Heidegger's rejection of rootless individualism has been discussed at length already, and therefore this part of the essay will focus on the concept of the "idle-talk", anxiety and the flight of Dasein that comes from beingwith the "they".

The concept of "idle-talk" presents us with an interesting point of departure from which to understand this ambiguous relationship between the individual and his community. Heidegger is explicit in the claim that "idle-talk" is not meant to be pejorative. However, it is fairly clear that this is dishonest. Some, including Emmanuel Faye, see this as a function of Heidegger's post-war attempts to conceal the unreconstructed Nazism that lies at the heart of Heidegger's world view176. However, if one does not wish to adopt this accusatory stance, it is still possible to see that Heidegger's concept of "idle talk" holds great similarities to Soren Kierkegaard's notion of "chatter" and "talkativeness". Thomas Hoberman makes precisely this observation in saying,

"Two Ages is filled with references to degenerate speech forms signifying the loss of passion and character: 'gossip and rumor', 'talkativeness', 'to chatter', 'pure drivel', 'to be loquacious'. 'By this chattering the distinction between what is private and what is public is nullified in a private-public garrulousness, which

176 Faye, Emmanuel, et al. "Nazi Foundations in Heidegger's Work." South Central Review, vol. 23, no. 1, 2006, pgs. 55-66. 
is just about what the public is. For the public is public opinion that is interested in what is utterly private.' Both authors address the phenomenon of 'idle talk', conjoined with the idea of a public sphere, as a threat to the authentic self of the individual."177

Kierkegaard suggests that the alienation of man from his authentic being is in part a function of the replacement of serious and meaningful speech that deals with questions of being in favour of a kind of aimless chatter that nullifies the Dasein in the everydayness of the "they", much like the averageness that will be discussed shortly, and it is clear that this sort of speech is considered to be degenerate. It is difficult to imagine that Heidegger is any less critical when he argues that "idle talk" is a function of the "averageness" of the "they" who speak without truly grasping that of which they speak and misrepresent, simplify and vulgarise complex ideas into pointless gossip. "Gossiping is based not so much on hear-say. It feeds on sporadic superficial reading: the average understanding of the reader will never be able to decide what has been drawn from primordial sources with a struggle, and how much is just gossip." 178 "Idle talk" is thus also an impediment to natural curiosity as it impedes that which one is entitled to take an interest in as complex concepts are filtered through the average understanding of the public and even original philosophical work will always be corrupted by the filtration.

"Idle talk also controls the ways in which one may be curious. It says what one is to have read and seen. The being everywhere and nowhere of curiosity is entrusted to idle talk. These two everyday modes of being of discourse and sight are not only objectively present side by side in their uprooting tendency, but one way of being drags the other with it" 179

Thus everything is given the appearance of being understandable and accessible as gossip and serious discussion become indistinguishable. This is exacerbated by the stultifying nature of the

177Hoberman, John. "Kierkegaard's Two Ages and Heidegger's Critique of Modernity," International Kierkegaard Commentary, 1984, pgs. 248-249.

178 Heidegger, Martin. Being and Time. Trans. Joan Stambaugh. Albany: State U of New York, 2010. Pg. 163

179 Heidegger, Martin. Being and Time. Trans. Joan Stambaugh. Albany: State U of New York, 2010. Pg. 166 
"they", the "reassurance" noted above, that allows the "they" to comfort itself with a kind of tranquility born of the delusion that they have grasped the things about which they gossip.

"The self-certainty and decisiveness of the they increasingly propagate the sense that there is no need of authentic, attuned understanding. The supposition of the they that one is leading and sustaining a full and genuine "life" brings a reassurance [Beruhigung] to Dasein, for which everything is "the best order" and for whom all doors are open." 180

This leads Hoberman to the following conclusion:

"Do terms like 'authenticity' and 'inauthenticity' function in a purely descriptive manner? Rather, does Heidegger not choose them to call us, if not to a particular life, at least to a way of living? Being and time can be read as an edifying discourse disguised as fundamental ontology. Heidegger may insist that 'inauthenticity' and 'idle talk' are not being used in a derogatory sense but he himself acknowledges that finally we cannot divorce ontological enquiry from the concrete stance adopted by the enquirer"181

Indeed it is difficult to imagine that Heidegger could not have found less value-laden terms than "gossip", "idle-talk", "averageness" and "superficiality" if he genuinely felt that the phenomenon in question was merely descriptive and non-pejorative. The idea that being stultified by a reassurance that comes from a self-certainty rooted in an incomprehension of serious thought resulting from the filtration of these ideas through the averageness of the "they" cannot seriously be interpreted as a non-critical account of "idle talk". Whatever residual doubt might remain can be dismissed by reference to Heidegger's claim that "Thus, by its very nature, idle talk is a closing off since it omits going back to the foundation of what is being talked about." 182

180 Heidegger, Martin. Being and Time. Trans. Joan Stambaugh. Albany: State U of New York, 2010. Pg. 171 181 Hoberman, John. "Kierkegaard's Two Ages and Heidegger's Critique of Modernity," International Kierkegaard Commentary, 1984, pgs. 228 182 Heidegger, Martin. Being and Time. Trans. Joan Stambaugh. Albany: State U of New York, 2010. Pg. 163 
There remains, however, an important distinction between Heidegger's complaints about "idle talk" and Kierkegaard's criticisms of the spiritual flattening of his own age. This distinction is observed by Hubert Dreyfus in his piece titled "Heidegger on the Connection between Nihilism, Art, Technology and Politics". In this piece Dreyfus grants that there are certain undeniable similarities between Heidegger's thought and the criticisms offered by Kierkegaard, particularly in their antagonism towards the detachment of scientific thought from the direct relation between man and the world, but also in their identification of levelling out/down, indifference, lethargy and the abandonment of valuative hierarchies as a consequence of this 183. Also similarly, both thinkers believe that this detachment has the effect of alienating man from his authentic self. However, Heidegger departs from Kierkegaard, who argued that this phenomenon was specifically the result of the influences of the media184, by suggesting that this process is as old as technology itself and that the present age has little of particular distinction about it in this regard. Both thinkers, therefore, hold that "idle talk" is a by-product of detached, non-committal modes of questioning phenomena in the world, but while Kierkegaard links this to the contemporary phenomenon of mass media, Heidegger posits it's rooting at a far more fundamental level. The two stances, then, must be considered similar but not identical if one is to properly understand the far more intractable and difficult problem that Heidegger is identifying vis-à-vis Kierkegaard. While, conceivably, Kierkegaard's anathema might be assuaged by slight changes in the way in which the public consumes information, Heidegger presents us with a problem rooted in the very foundations of man's interaction with the world.

\footnotetext{
183 Dreyfus, Hubert L. "Heidegger on the Connection Between Nihilism, Art, Technology, and Politics." The Cambridge Companion to Heidegger (1993): 289-316.

184 Dreyfus, Hubert L. "Heidegger on the Connection Between Nihilism, Art, Technology, and Politics." The Cambridge Companion to Heidegger (1993): 289-316.
} 
Idle talk is, though, undoubtedly held up as evidence of the way in which the "they" can "close-of" the Dasein from authenticity. This presents an interesting question. How can the "they" close us off from authentic Dasein whilst simultaneously being a central part of the "at-hand" in which this authentic Dasein is rooted? Heidegger leaves us in the position where we are rooted in an "at-hand" that closes us off from authentic Dasein whilst simultaneously providing the ground in which that Dasein must be rooted. It is difficult to know what to do with this, and it is unclear whether or not Heidegger sees the community, the "they", as something to escape from or to embrace one's rootedness in.

This ambiguity is exacerbated when we analyse the relationship posited by Heidegger between the "they", anxiety and the flight of Dasein therein. Heidegger claims that in-authentic being results in part from the flight of Dasein from itself, a kind of turning away from the disclosedness of Dasein. This is partly the result of the reassurance provided by the "they" but also as a result of the fear of the authentic Dasein that results from being pulled down by the averageness of the "they". Mostly what is feared is the indefinite nature of authentic Dasein in contrast with the reassuring certainty of the "they". This leads to a general anxiety that is simultaneously an anxiety about everything and nothing. Heidegger dedicates a large part of chapter six of the first division to the development of his account of anxiety, an account that roots anxiety squarely in the "they". Anxiety is described as a kind of ever present mood whereby the limitations imposed by the averageness of the "they" are felt, but not clearly perceived. The anxiety that "crowds in upon us" lies in the unconscious awareness of potentiality. "What crowds in upon us is not this or that, nor is it everything objectively present together as a sum, but the possibility of things at hand in general, that is, the world itself."185 In making this claim, Heidegger is positing 
that, as with technology, the limitations that circumscribe man's being are drawn from the increasing awareness that a world lies outside of the boundaries imposed upon us, and that some kind of authenticity can be found there, but this realm eludes man as he is pulled into the "falling prey" that alienates the Dasein from its authentic being. Because it lies beyond these bounds, this anxiety is an anxiety about nothing that can be clearly substantiated, and thus the anxiety is one about one's fundamental relationship with the world. Heidegger puts this as follows: "Anxiety is not only anxiety about..., but is at the same time, as attunement, anxiety for.... That for which anxiety is anxious is not a definite kind of being and possibility of Dasein. The threat itself is, after all, indefinite and thus cannot penetrate threateningly to this or that factical concrete potentiality of being. What anxiety is anxious for is being-in-the-world itself."186 This is directly linked to the problem of the "they" insofar as the realisation of the potentiality of authentic Dasein is hampered by the "idle talk" that corrupts and confuses clear thinking about this potentiality and the "averageness" that drags man away from the encounter with this non-regulated being-in-the-world. Thus anxiety can be said to result directly from the entrapment of the Dasein within the "they" that is at hand. This becomes especially problematic when one considers the centrality of the "standing against" of the "they", that must surely be akin to the rejection of the conventions of the "they", that is so fundamental a part of the pursuit of authenticity. Heidegger argues that "because Dasein is lost in the "they," it must first find itself. In order to find itself at all, it must be "shown" to itself in its possible authenticity. In terms of its possibility, Dasein is already a potentiality-forbeing-its-self, but it needs to have this potentiality attested" 187 Here we see perhaps the most concise crystallisation of the tension that we are faced with. Authenticity appears to depend upon a rejection of both the democratic spirit, and the conventions and practices of the community,

186 Ibid

187 Heidegger, Martin. Being and Time. Trans. Joan Stambaugh. Albany: State U of New York, 2010. Pg. 258 
whilst simultaneously being dependent upon this community both to root one's being and to reveal to the Dasein the possibility of its own authenticity. While one might attempt to resolve this by positing a narrative of Dasein whereby it roots its initial development in the at-hand, becomes attuned to anxiety as a result of the revealing of the limiting horizons of this locality and then stands against these limitation in order to escape from them and encounter the world authentically, therein discovering the authentic Dasein, we are still left wondering as to precisely what the relationship between the individual and the community in which he finds himself should be once he has turned. Heidegger is unclear as to whether or not the culture and community of the "they" is something to be escaped or something in which man must root himself in order to be authentic. It is similarly unclear as to why the authentic Dasein, having broken free of the "they", would not become the kind of rootless individualism criticised so frequently by Heidegger.

It is difficult to find anything approaching this level of ambiguity in the writings of Michel Houellebecq or the politics of the "far-right". For entirely opposite reasons, each of these latter two take an unambiguous position on the relationship between the individual and the collective. Houellebecq's characters are only able to find belonging in an authentic form of being when they choose to remove themselves entirely from the social context. This flight takes a variety of forms. In "Extension of the Domain of Struggle" this takes the form of the absolute abandonment of the limitations of social convention, as the protagonist goads a friend into stabbing a love rival188, presenting an interesting possibility of an escape from participation in the "they" without actual physical removal of the body from proximity with others. In a similar sense, Bruno flees from the "they" by choosing to retreat into the comforting delusions of insanity in the face of the suicide of

188 Houellebecq, Michel. Extension Du Domaine De La Lutte. Paris: Flammarion, 1994 
his lover189. More overtly, this can be seen in the self-exile of Michel Djerzinski, to rural Ireland190, interestingly this is precisely where Houellebecq himself fled under threat of violence as a result of comments made about Islam; and of Jed Martin, to a cottage in the countryside never to be seen until his death191. Daniel 1 and Daniel 25 both flee towards their own deaths, one by suicide the other by abandoning himself to a solitary wandering of the barren wasteland until his death by starvation192. This can be contrasted with those characters that chose to remain in the "they", and in doing so sacrifice the authenticity of their being indefinitely. François' ability to remain in French society, for example, requires a dishonest conversion to Islam193. One can also observe a certain amount of "idle talk" in Houellebecq's writing that plays a large part in the disillusionment of Houellebecquian man. Whether it is the pointless waffle of television personalities and politicians, the corporate speak and obsession with profit of the business world or the pretentious posturing of art collectors and travel and tourism marketing professionals, Houellebecq surrounds his characters with "idle talk", and this kind of speech often serves to reveal to his characters the extent of their alienation from the "they" that surrounds them. We are thus left with an unambiguous choice by Michel Houellebecq. Either we escape the "they" and find authenticity, and even a kind of home, in the solitude of insanity or exile, or we lose our authentic self, either in the absolute negation of physical destruction or the acceptance of an inauthentic, but comfortable, kind of being.

The same kind of certainty is offered to us, from the other side, by the "far-right". It is important to note that the "far-right" often takes on the guise of a free-thinking dissent from the

189 Houellebecq, Michel. Les Particules Elémentaires: Roman. Paris: Flammarion, 1998.

190 Ibid

191 Houellebecq, Michel. Platforme. Paris: Flammarion, 2001

192 Houellebecq, Michel. La Possibilité D’une Ile: Roman. Paris: Flammarion, 2005.

193 Houellebecq, Michel. Soumission: Roman. Paris: Flammarion, 2015. 
"dominant ideology" of society as a whole. This often manifests in a kind of victim complex, where "far-right" voices will complain of being subjected to a man-hunt or a kind of soft oppression by the majority. One can also point to the fact that they often criticise what they perceive to be the overly communitarian nature of France's Islamic and, sometimes, Jewish populations, condemning them for their refusal to abandon their own cultural roots and embrace the values of the French Enlightenment194. However, it is clear that this stance is less of a rejection of communitarianism itself and more an objection to the perceived substance of these kinds of rooted "they" beings. In other words, it is not so much the communitarianism of "Islamic communitarianism" that is rejected by Le Pen, but the Islamic nature thereof. In response, the National Front proposes, hypocritically, an embrace of a French communitarianism that corresponds far more closely with Heidegger's "falling prey" that it does with the pursuit of authentic Dasein. The relationship of the Dasein to the culture in which it is rooted is far more complex than the Romantic nationalism of the National Front, who idealise the history of France and the "French Genius" that they feel to be a unique characteristic of France. Taking comfort in an unquestioning acceptance of the superiority of one's culture, particularly when this involves ignoring or negating uncomfortable truths about the Vichy regime, is precisely the flight into the reassuring averageness of the "they" criticised by Heidegger. While Heidegger's actions, particularly during the Second World War, suggest that he was not immune to falling into this error himself, it is clear that at the level of his philosophy, he was not advocating for anything resembling the vulgar nationalism of the French "far-right"

Furthermore, when Heidegger begins to provide more positive reflections upon the pursuit of an authentic Dasein, it becomes clear that the political projects of the "far-right" fall far short 
of the ambitions of Martin Heidegger. Heidegger's project is difficult to define and appears to evolve over the course of his career, taking a turn towards pessimism as Heidegger aged and concluded that only a God could save us. The optimistic version of his project, upon which we shall focus, can, in a very skeletal form, be summarised by way of the following narrative: man's initial becoming must be rooted in an interaction of taking care of that which is most immediately at hand. However, this relation will soon lead to man falling prey of the "they" who will drag him towards the averageness and reassurance of the non-authentic relation to being. The in-authenticity of the Dasein that will be revealed by this process will lead to a profound anxiety on the part of thinking men, and by this saving power the limitations of such a relation to the world will be revealed. Up until this point, it has been shown, that there exist a great many similarities between the argument offered in "Being and Time" and the objections to modernity that manifest in the writings of Michel Houellebecq and the politics of the French National Front. However, the more that Heidegger elucidates a positive project in order to remedy the malaise of modernity, the more evident it becomes that the "far-right" are entirely inadequate as a political vehicle for Heidegger's pursuit of an authentic being. In order to demonstrate this, two particular aspects of Heidegger's existentialist project are relevant, the turning from and "being-towards-death". It is fairly clear that there is little to no relation between the openness to the calling towards authentic being proposed by Heidegger and the romantic, parochial nationalism of the National Front. In fact, the politics of Le Pen and her followers correspond far more directly to the fears expressed by Heidegger about a retreat into the comfort of romantic traditionalism.

Heidegger defines the turning towards death as a choice, and as a result his description of it has the characteristics of a call to arms. Heidegger is calling us to re-orient our being towards 
the fate of Dasein, death, and to be resolute in the face of our throwness towards the inevitable telos of our being.

"The resolutess in which Dasein comes back to itself discloses the actual factical possibilities of authentic existing in terms of the heritage which that resoluteness takes over as thrown. Resolute coming back to throwness involves handing oneself over to traditional possibilities...If everything "good" is a matter of heritage and if the character of "goodness" lies in making authentic existence possible, then handing down a heritage is always constituted in resoluteness. "195

Thus resolution in the face of our throwness towards death is tied inextricably to a fairly conventional conservative ambition to conserve and honour the traditions of one's people and hand them down to future generations. This is posited as an integral part of the quest to understand authentic being and to reclaim the Dasein in its throwness towards death. Dasein thus becomes a kind of fate. Dasein must abandon itself to death and to the authenticity that comes from heritage, rather than from itself. The fate of the community, and simultaneously the individual, is therefore tied up in the preservation of its heritage, and the taking care of this thing. As a result Heidegger believes that we must aspire to be oriented towards our future and towards our ultimate destiny. In other words, one is called towards authentic being when one has turned to face death, is resolute in the face of this destiny, and responds to this by turning towards the world, taking care of the heritage that one has and being authentic and true to one's authentic self in the face of this destiny.

It is very difficult to square this project with the ideology of a political party primarily concerned with preventing immigration and re-orienting French foreign policy towards Russia. While certain aspects of Heidegger's call to arms, particularly regarding the preservation of heritage, might find partial satisfaction in the social and cultural conservatism of the National Front, it is impossible to find anything in the political platform of the National Front that 
corresponds to this project for the unconcealment of authentic Dasein. For this reason it can be concluded that, in spite of the many similarities, connections and parallels that make Heidegger's thought an excellent reference point in understanding the environment that has allowed for the rise of the "far-right", the political project of the "far-right" can only be considered to correspond with Heideggerian philosophy in a very limited sense. This chapter has shown that departures regarding both the relationship between the individual and the community and the way in which authentic being ought be pursued brings into unconcealment the limitations of the connections made in this essay between the philosophy of Martin Heidegger and the "far-right" movement in France. 


\section{$\underline{\text { Conclusions }}$}

Over the course of these pages I have attempted to shed light upon the reasons behind the transformation of the post-war liberal order from its position of absolute ascendency, at the time of the fall of the Soviet Union, to the precipice upon which it appears to be perched today. During the course of the researching and writing of this essay, several events transpired that have served to dramatically increase the urgency of this enquiry. The victory of Donald Trump in the American elections of 2016 seemed unlikely in the preliminary stages of this project, and in many respects the decision to focus on France, which appeared in the summer of 2016 to represent the strongest of the Western Worlds "far-right" movements may appear unusual in the absence of such a rejoinder. However, the type of analysis that has here been provided to question this phenomenon in its French iteration, should in no way be considered to apply only to France and say nothing about the rest of the world. The phenomenon in question has revealed itself to be more powerful, and more advanced in its unfolding, than could possibly have been imagined before the political earthquakes of 2016. This makes the analysis provided in this thesis all the more relevant and important. Due to the urgency of our situation, I will follow the recapitulation of my argument with a series of reflections that will concern the "far-right" as a global phenomenon, rather than merely focusing on the French manifestation explored in this paper. These reflections will concern both the correct identification of this political force in a global context, and the way in which I believe philosophically minded individuals ought react to what may well come to be seen as the most momentous political upheaval since, at least, the events of May 1968 and a reflection upon the applicability of the findings and methods of this essay to an exploration of the Trump phenomenon in the United States of America. 


\section{$\underline{\text { Recapitulation }}$}

This paper begins with a consideration of the literature dedicated to explaining the phenomenon of the rise of extremist, anti-liberal political parties in Europe. It emerges, in reviewing this literature, that there is an overwhelming reliance on economic factors; deprivation, unemployment and inequality; and, to a lesser extent, sociological factors; such as innate racism and xenophobia. It becomes fairly clear, though, that such explanations are simply unable to account for the international scope of these "far-right" movements who are able to flourish in economically prosperous Holland and economically deprived Greece; in open tolerant Sweden and isolationist, guarded Switzerland. As a result it becomes clear that one must look at the broader and deeper understanding of phenomena that comes from questioning at the level of philosophy. Building upon philosophical approaches to the "far-right"; such as those of Lebourg, Saull, Cole and Duff; this essay endeavored to develop an understanding of the "far-right", using the example of France, focusing on the philosophical stance that it can be said to be taking against what it perceives to be the "dominant ideology" of the post-Enlightenment Western world. In pursuit of this understanding, Division One attempted to demonstrate the salience of Heidegger's critique of modernity as demonstrated by the presence of so many Heideggerian critiques, anxieties and concerns in the novels of Michel Houellebecq. In the first chapter, we saw that the intense alienation that results from a complicated and corrupted relationship between man and nature in Houellebecq's works links directly to the critique of the technological setting upon, and then mastery, of nature provided by Heidegger in "The Question Concerning Technology". This was then linked to the appeal to the mytho-poetic that forms so large a part of the "far-right" political aesthetic. In the second we saw that the hollowing out of cultural belonging and the loss a national identity, that is such a force in the novels of Houellebecq, directly conforms to the critique of 
globalisation and scientific detachment criticised by Heidegger in "The Age of the World Picture". This too was linked to the "far-right", specifically to their rejection of "globalist elites". In the final chapter of this division, the invasion of the world of art by scientific logics, and the limitations to scientific illumination that were demonstrated by this in Houellebecq's novels were shown to bear distinct similarities with Heidegger's conception of the entrapping-securing and the invasiveness that results from this in Heidegger's "Science and Reflection". This was linked to the antotechnocratic discourse of the "Far-right" and their appeal to the romantic against the rational. Altogether this leaves us in no doubt that a large part of the disillusionment with modernity, a disillusionment that necessarily creates the fertile ground in which "far-right" movements grow, reflects Heideggerian ideas about the limitations of scientific reason, the destructive and alienating potential of technology and the levelling out and hollowing out that results from globalisation and democracy. Thus, Heidegger provides us with an unparalleled level of insight into the modern disenchantment that the "far-right" exploits.

Division Two aimed to dig into the foundations of this malaise, and the response to it, in order to grant us a deeper understanding of both the crisis of the post-war liberal order and the nature of the reaction against it. The first chapter discussed the understanding of "being-as-care" elucidated by Martin Heidegger and attempted to show that in its spatial rooting of being in the context of the things, people and culture that is immediately "at hand", it represents a rejection of the universalist potential of a spatially transcendent being. This dichotomy between the rooted being and the uprooted, universalised being was shown to be equally present in the characters of "Submission" among whom those rooted in their cultural heritage are granted a kind of authenticity that eludes those who attempt to be cosmopolitan citizens of the world. Similarly, this dichotomy plays out in the distinction made by the National Front between the authentic rooted "frenchness" 
of the "Français de souche" and the inauthentic, superficial "frenchness" of the "Français de papier". In light of this, it becomes clear that the argument made by Heidegger for the rootedness of being, be it in culture or merely in the context of objects that are "at hand", has a profound and direct influence on the conception of authentic national appartenance that is traded upon by the "far-right" in France. The second chapter engages similarly with Heidegger's critique of the ideal form, a critique of Platonic metaphysics, and of historicism, particularly that of Hegel. Heidegger's critiques constitute a rejection of two of the necessary conditions of the "progressive" view of history, a fixed point to which we can be said to "progress" and the universal consciousness necessary for that point to be able to reveal itself to us. This rejection of "progressivism" plays out in Houellebecq in an interesting way. He experiments with various different versions of the ideal, or Utopian, form of human existence and demonstrates that, even if they are attainable, the ideal forms would reveal themselves to be ugly precisely as a result of their ideal nature. The "far-right", on the other hand, takes up this opposition to progress in a far more vulgar manner, retreating to what Heidegger might term the flight towards the comfort of tradition. They can thus be said to share Heidegger's scepticism of liberal idealism, but not to represent a response to this that is true to the spirit of "Being and Time". Indeed, it is upon these lines that Division Two concludes, with an exploration of the divergence between Heidegger, as a writer if not as a man, and the politics of the "far-right". It was shown that Heidegger falls prey to a certain ambiguity in his position on the relationship between the individual and the collective in which he is rooted and that Houellebecq, who only sees salvation in the absolute removal of the individual from being-withothers, and the National Front, who propose a comforting return to the certainties of the "they", are unwilling or unable to engage with. Finally, it was shown that Heidegger's stated response to the anxiety caused by alienation from authentic Dasein consists of a kind of opening up of the self 
to the unconcealing of authentic Dasein, and thus a free relation to being and the world, that has nothing whatsoever in connection with the politics of the "far-right". It can thus be concluded that the "far-right" is responding to a profound, and deeply rooted anxiety about the impact of technology, the dominance of scientific reason, the abstraction of the individual and globalisation that is, at its core, rooted in a scepticism about the universalist and progressive view of being and history that is such a fundamental bedrock of the Enlightenment worldview. However, while they have been able to exploit this anxiety effectively, the response of the "far-right" to these anxieties is at every turn vulgar, opportunistic and disappointing. In conclusion, the rise of the "far-right" can clearly be linked to the increasing relevance of the Heideggerian critique of modernity, a critique that seems to be proving to gain in relevance as technology unfolds in history, and this provides us with an explanation for this phenomenon that could be satisfactory in a way that economic and sociological explanations cannot. However, we must temper this by being clear that, while their rise might be explained in this way, the parties of the "far-right" cannot in themselves by understood as Heideggerianism in action. They are simply too vulgar for this to be tenable. Rather, we should understand the "far-right" as a combination of the political ambitions of a few, and the anxieties, fears and uncertainties of many when faced with a conception of "progress" and a political "mainstream" that they find threatening, unsatisfactory and even openly hostile. It is perhaps less the revolt of the malcontents than the reticence of the disenchanted. 


\section{Final Reflections}

In light of the above, I believe that there are a number of key considerations that should result from a serious engagement with this philosophical analysis of the French "far-right". These will follow, and will concern: the new Japanized-man, and the consequences of his rejection of the post-coldwar order; the parallels between the National Front and Donald Trump, which surely necessitate an analysis of this sort in an American context; and finally a reflection on the way in which the analysis presented in this paper brings into doubt the way in which the "far-right" is presented in popular political discourse, including the validity of the term "far-right". Altogether, this will demonstrate that philosophical analyses of "far-right" political movements have the potential to radically change, and greatly improve, our understanding of this epochal phenomenon.

\section{The New Japanized Man}

Perhaps the most important reflection on the "far-right" to come out of this paper must surely be the insight into the objection to mainstream political and social currents that has been evidenced by the Heidegger comparison. As with Heidegger himself, it is easy and tempting to dismiss the bulk of the "far-right" opposition on account of the unsavoury and reactionary aspects of their political engagement. Much as one might dismiss Heidegger as a philosopher due to his association with the Nazi Party196, one might equally be tempted to dismiss entirely "Far-right" scepticism

\footnotetext{
196 Resisting the temptation of the fascinating and richly researched connection between Heidegger and the Nazi Party should in no way be mistaken for an attempt to deny Heidegger's Nazism nor to exonerate or exculpate him in any way. The fact that this connection is debated is interesting and, I believe, speaks to the way in which Heidegger's ideas have profoundly influenced so much of contemporary Western thought. The posthumous publication of Heidegger's "Black Books" and the content of his rectory speech at Freiburg University, among mountains of other evidence, should close the case on this particular debate, and I believe it is only because so many post-modern thinkers recognise their own significant debt to Heidegger, but recoil at acknowledging to themselves that they are so heavily indebted to an unrepentant Nazi and virulent anti-Semite, that the question of Heidegger's Nazism remains open. Emmanuelle Faye and others have explored this question with a level of insight that I can neither match nor add to. Therefore I will not explore Heidegger's Nazism in any great depth in this thesis.
} 
about science and technology, universalism and progress on account of the vulgar bigotry that is often expressed by National Front partisans and advocates. However, in both cases, one should not allow revulsion at the reactionary excesses of the current political embodiment of this form of dissent to prevent us from taking seriously the critique of modernity that they are offering. One might also be tempted to conclude, along the lines of Kojêve, that this political moment will pass and that the "far-right", like the Japanized man, will either destroy itself or be slowly co-opted back into the mainstream. However, when one considers the fact that this tide has already taken the United Kingdom out of the European Union and given Donald Trump four years in the White House it is clearly no longer feasible to see the "far-right" as an irrelevant "tilting at windmills" on the part of a resentful, but ultimately doomed, minority of malcontents. Furthermore, the salience of the Heideggerian comparison suggests that the phenomenon in question may in fact grow in strength, as the liberalism against which it militates unfolds in history, and that, as with the Nazi's, this phenomenon can only be ended by some sort of final confrontation with opposing forces. In fact, the originator of the "End of History" thesis, Francis Fukuyama, seems to arrive at a similar conclusion to that of this paper in his analysis that "Globalization really does seem to produce these internal tensions within democracies that these institutions have some trouble reconciling," he said. "Combined with grievances over immigration and multiculturalism, it created room for the "demagogic populism" that catapulted Trump into the White House."197 While he conceded that this tide might be reversed if Trump or Le Pen fail spectacularly in some way he suggest that he may well have been prescient in his earlier claim that "perhaps this very prospect of centuries of boredom at the end of history will serve to get history started once

197 Tharoor, Ishaan. "The Man Who Declared the 'End of History' Fears for Democracy's Future." Washington Post Online. N.p., 9 Feb. 2017. 
again."198 However one looks at it, liberal democracy is clearly being faced with a challenge that its institutions are struggling to respond to, and which cannot be dismissed as a mere bump in the road to the Universal Homogenized State. The survival or the post-cold-war order will depend upon its ability to adapt itself to assuage the concerns and anxieties of the swelling ranks of the disenchanted. Hillary Clinton's abject and spectacular failure proved to all but the most myoic that demonization, ridicule and moral opprobrium are ineffective responses to this movement, and the time perhaps has come to rise to this serious challenge.

\section{Donald Trump and the Revolt of the Malcontent}

It is impossible to deny at this point that a shadow has been cast over this paper by the political earthquake that took place in the American presidential elections of 2016. Donald Trump's surprise victory seemed highly unlikely as this thesis was being researched and written, but is an event that has undoubtedly had serious consequences for our exploration of the "far-right" as a subject of study. When one considers that the unemployment level in the United States was not particularly low, that the economic situation had improved dramatically since Obama's 2012 victory, that GDP growth is steady and that there has not been a major terrorist attack on U.S soil since 9-11; it might seem implausible that the American public would opt for such a radical break from mainstream politics. This lends credence to the belief that the "far-right", of which Trump is undoubtedly a part, is not an economically explainable phenomenon. Moreover, unless one believes that the voters who delivered the election to Trump, those in the Great Lakes region who had supported Obama previously, have suddenly become racist and xenophobic in the last four years; it is difficult to argue that these sociological claims are any more appropriate in the American case as in the French case described here. Given that we have established these

198 Fukuyama, Francis. "The End of History." Wesjones.com. N.p., n.d. Web. <http://www.wesjones.com/eoh.htm> 
movements as being particularistic, and deeply rooted in national culture, it is unsurprising that the substance of Trump and Le Pen's politics do not seem similar at first glance. However, both clearly appeal to the same sense of disenchantment with "progress", search for cultural identity, anti-elitism and fear. It is therefore likely that a study such as this, but one focusing on finding links between a contemporary American dystopian writer, an anti-liberal philosopher and the Trump movement would provide far greater insight into the Trump phenomenon than the current focus on racism and income inequality. This would seem to be a very worthwhile avenue for further research.

\section{The Question Concerning the "Far-Right"?}

Observant readers will have noticed that throughout this paper the term "far-right" has been placed in quotation marks. This is no coincidence, and reflects an observation that has become fairly clear over the course of this thesis. The term "far-right" suggests that this political movement fits onto the ordinary political spectrum, and that parties like the National Front merely represent a more extreme version of the parties of the mainstream right, a sort of Conservatism on steroids. However, it is clear that a political movement based on the rejection of principals of universalism and progress, and one fueled by scepticism of the promise of technology, science and global interconnectedness, bears little resemblance, and is in fact highly antagonistic towards what they would consider to be the "establishment" Conservatism of a Steven Harper or a George W. Bush. Given the importance placed by philosophy on the proper definition of things, and the centrality of naming things correctly to the political engagement therewith, it would probably be best to refer to this phenomenon as "anti-liberalism" or better yet "anti-progressivism" if one wishes to convey the actual substance of this phenomenon in its 
definition. Even this definition must be tempered somewhat by the realization that in the case of Brexit199 and Trump in particular, the things that people thought they were voting for, and what was actually on offer were often rather different. While not a new phenomenon, the fact that the reasons for the rise of the "far-right" and the actual substance of "far-right" politics are often misaligned confused the picture further.

However, alongside the attempt to denude the chimera of this political phenomenon, it must also fall upon philosophy to question it at a level that goes beyond moral indignation and "de-haut-en-bas" sneering at the vulgarity and parochialism of many "anti-progressive" adherents. The above analysis presents serious challenges both to supporters and opponents of the "anti-progressive" movements. Supporters of parties like the National Front must contend with the lack of genuine alternative being offered by their party, which has been shown to retreat behind vulgar romanticism when faced with the challenge of providing a positive political programme, as well as the need to develop a genuine response to the threat that they perceive in the unfolding of technology in history, a task made all the more difficult by the fact that they seem unaware of the centrality of these fundamental philosophical anxieties to their political appeal. For opponents, the task is equally difficult. In a developed world where robotisation threatens working class jobs, where artificial intelligence is a genuine possibility, where nations

\footnotetext{
199 Although Brexit, the FN and Trump share enough to merit their being mentioned together in this case, it is both lazy and fatuous to simply lump them together as three different manifestations of the same phenomenon. Brexit was at least in part motivated by the resistance to modernity and the disenchantment with progress described in these pages, however this was only one of many reasons why people voted to leave the E.U. Brexit, being a referendum, is different in type to a coherent political movement. While some may have voted to leave for reasons explained by this thesis, others chose to leave for reasons rooted in classical liberal arguments against the anti-free trade aspects of the E.U while others voted for reasons rooted in a socialist rejection of the open internal market. However, Brexit undoubtedly benefited from a general malaise with the status quo and certain elements of the campaigning message were undeniably similar to FN discourse. Without the Farage wing, and their focus on globalisation, anti-elitism and patriotism, Brexit would likely not have happened (since it so nearly failed with it). Therefore, British E.U membership can be claimed as a scalp of this disenchantment without the Brexit movement as a whole being categorized as "far-right".
} 
possess nuclear arsenals capable of killing millions in one stroke and where many primary health issues: depression, obesity, alcoholism and stress appear to be products of progress itself; it is clear that there is something substantial and valid in a position of scepticism towards the idea of progress and the promises of science and technology. It will be my final contention that "antiprogressive" political movements thrive on the fact that they oppose a "progressivism" that has abandoned all Utopian pretentions. The idea of "universal progress" in history has survived the collapse of the communist Utopia of international socialism, the Enlightenment Utopia of the Republic of Reason and the liberal Utopia of a perpetual democratic peace. Thus we are left with constant exhortations to "get with the programme" and be on the "right side of history" by embracing an idea of progress whose ends are, at best, ill-defined and at worst, particularly if one is white and working class, actively threatening. Thus we are left in desperate need of a serious questioning of the ideals of our societies, and a serious consideration of precisely what ends should be pursued in order to genuinely "progress". Questioning is indeed, as Heidegger puts it, "the piety of thought", and this piety is more vital than ever; because should the pious and thoughtful fail, the unscrupulous and unthinking will define the coming age. 


\section{Works Cited}

"A Look at Racist Skinhead Symbols and Tattoos." Southern Poverty Law Center. N.p., n.d. Web. 10 Feb. 2017. https://www.splcenter.org/fighting-hate/intelligence-report/2006/lookracist-skinhead-symbols-and-tattoos

Bell, D. S. "The French National Front." History of European Ideas 18.2. 1994.

Betty, L. "Michel Houellebecq and the Promise of Utopia: A Tale of Progressive Disenchantment." French Forum, vol. 40 no. 2, 2015, pgs. 97-109

Berezin, Mabel. "Revisiting the French National Front: The Ontology of a Political Mood." Journal of Contemporary Ethnography 36.2 (2007): 129-46. Web.

Cochrane, Christopher, and Neil Nevitte. "Scapegoating: Unemployment, Far-Right Parties and Anti-Immigrant Sentiment." Comparative European Politics 12.1 (2014): 1-32. ProQuest. Web. 17 Nov. 2016.

Cole, Alexandra. "Old Right or New Right? The Ideological Positioning of Parties of the Far Right." European Journal of Political Research 44.2 (2005): 203-30. Web. 18 Nov. 201

Davies, Peter. The Extreme Right in France, 1789 to the Present: From De Maistre to Le Pen. London: Routledge, 2002. Print.

Darby, Tom. "Homecomings." The Feast. Toronto: U of Toronto, 1982

Delamaide, Darell. "French Election Shaping up to Be Another Disaster for Establishment Parties; Le Pen Bolstered by Trump and Brexit, Not to Mention Her Weak and Corrupt Opponents." Editorial. Market Watch. N.p., 18 Nov. 2016. Web.

Dopp, Terrence, Zachary Mider, and Helene Fouquet. "France's Le Pen Generates a Stir With Stops at Trump Tower." Bloomberg.com. Bloomberg, 12 Jan. 2017. Web. 16 Jan. 2017.

Dreyfus, Hubert L. "Heidegger on the Connection Between Nihilism, Art, Technology, and Politics." The Cambridge Companion to Heidegger (1993): 289-316.

Duff, Alexander S. Heidegger and Politics the Ontology of Radical Discontent. New York, NY: Cambridge U, 2015. Print

Duff, Alexander S. "Heidegger's Ghosts." American Interest 25 Feb. 2016, CounterLiberalism sec.: n. pag. Print

Dutt, Barkha. "Trump Presidency an Opportunity for Liberal Politics to Re-examine Itself." The Hindustan Times. N.p., 18 Nov. 2016. Web. 
Ellinas, Antonis A. "Playing the Nationalist Card: Mainstream Parties, Mass Media and Far Right Breakthroughs in Western Europe." Order No. 3286114 Princeton University, 2007. Ann Arbor: ProQuest. Web. 17 Nov. 2016.

Faye, Emmanuel, et al. "Nazi Foundations in Heidegger's Work." South Central Review, vol. 23, no. 1, 2006, pgs. 55-66.

Fukuyama, Francis. "The End of History." Wesjones.com. N.p., n.d. Web.

$<$ http://www.wesjones.com/eoh.htm $>$

Galiero, Emmanuel. "Les Propositions De Marine Le Pen Pour Lutter Contre Le Communautarisme." Lefigaro.fr. N.p., 16 Jan. 2015. Web

Goodliffe, Gabriel. (06/01/2012). The Price of Disengagement: Radical Populism in France and Germany. Journal of contemporary European studies. (20)2. p.137 - 160.

Heidegger, Martin. Being and Time. Trans. Joan Stambaugh. Albany: State U of New York, 2010.

Heidegger, M. Science and Reflection. In M. Heidegger, The Question Concerning Technology and Other Essays. New York: Garland Publishing inc. 1977. pgs, 155-182.

Heidegger, M. The Age of the World Picture. In M. Heidegger, The Question Concerning Technology and Other Essays. New York: Garland Publishing inc. 1977. Pgs. 115-153.

Heidegger, M. The Question Concerning Technology. In M. Heidegger, The Question Concerning Technology and Other Essays. New York: Garland Publishing inc. 1977. Pgs 335 .

Hoberman, John. "Kierkegaard's Two Ages and Heidegger's Critique of Modernity," International Kierkegaard Commentary, 1984, pgs. 248-249.

Houellebecq, Michel. Extension Du Domaine De La Lutte. Paris: Falmmarion, 1994.

Houellebecq, Michel. La Carte et le Territoire. Paris: Flammarion, 2010

Houellebecq, Michel. La Possibilite D’une Ile: Roman. Paris: Flammarion, 2005

Houellebecq, Michel. Les Particules Elementaires: Roman. Paris: Flammarion, 1998

Houellebecq, Michel. Platforme. Paris: Flammarion, 2001.

Houellebecq, Michel. Soumission: Roman. Paris: Flammarion, 2015

Hourmant, Francois. "Le FN Capte Les Laissés Pour Compte." Le Courrier De L'Ouest. N.p., 19 Nov. 2016. Web.

Jones, Owen. "If There Is Another Economic Crash, Europe’s Far Right Is Ready for It." Editorial. The Guardian. The Guardian, 11 Feb. 2016. Web. 
Judis, John B. "Us v Them: The Birth of Populism." The Guardian. The Guardian, 13 Oct. 2016. Web.

Kauffmann Grégoire, «Les origines du Front national », Pouvoirs 2/2016 ( $\left.{ }^{\circ} 157\right)$, p. 5-15 URL : www.cairn.info/revue-pouvoirs-2016-2-page-5.htm.

Lebourg Nicolas, «Les dimensions internationales du Front national », Pouvoirs 2/2016 ( ${ }^{\circ}$ 157), p. 105-113. URL : www.cairn.info/revue-pouvoirs-2016-2-page-105.htm.

Le Goff Jean-Pierre, «Le syndrome du Front national. Genèse d'une ascension», Le Débat 4/2011 (nº 166), p. 53-62 URL : www.cairn.info/revue-le-debat-2011-4-page-53.htm.

Le Pen, Jean-Marie (lepenjm). "Je suis Français de souche bretonne. Mes 16 arrière-arrièregrands-parents sont nés en Morbihan. Dois-je m'en excuser auprès de M. Valls ?" 27 February 2015. 9:55 AM. Tweet.

"Les Trois Enfants De Marine Le Pen." Les Trois Enfants De Marine Le Pen. N.p., n.d. Web. 10 Feb. 2017.

Lovejoy, Arthur O. "Reflections on the History of Ideas." Journal of the History of Ideas, vol. 1, no. 1, 1940, pp. 3-23. www.jstor.org/stable/2707007.

Lubbers, Marcel, and Peer Scheepers. "French Front National voting: a micro and macro perspective." Ethnic and Racial Studies 25.1, 2002: 120-149.

Morrey, Douglas. "Science and Religion." Michel Houellebecq: Humanity and Its Aftermath. Oxford: Liverpool UP, 2013. Pg.117

Mudde, Cas. "The single- issue party thesis: Extreme right parties and the immigration issue." West European Politics 22.3, 1999: 182-197.

Nelson, Fraser. "Michael Gove Was (accidentally) Right about Experts." The Spectator [London] 14 Jan. 2017

Nossiter, Adam. "An Unlikely Contender Rises in France as the Antithesis of Trump." The New York Times 18 Nov. 2016: n. pag. Print.

Ockrent, Christine. "Trumpism, the French Way." Washington Post Online. The Washington Post, 19 Nov. 2016. Web.

Pocock, J. G. A. "The History of Political Thought: A Methodological Inquiry." - Political Thought and History: Essays on Theory and Method. Cambridge: Cambridge UP, 2009. 3 20. Print.

Sauga, Michael, Christian Reierman, Alexander Jung, Christoph Pauly, Martin Hesse, Sven Boll, and Armin M-W Wagner. "Inequality, Market Chaos and Angry Voters." Der Spiegel Online International. Der Spiegel, 17 Nov. 2016. Web.

Scruton, Roger. The Aesthetic Gaze. In An Intelligent Person's Guide to Modern Culture. South Bend: St. Augustine's Press, 2000 p.35-46. Print. 
Saull, Richard. "Capitalism, Crisis and the Far-Right in the Neoliberal Era." Journal of International Relations and Development 18.1, 2015: 25-51. ProQuest. Web. 17 Nov. 2016.

Shields, James. "Marine Le Pen and the 'New' FN: A Change of Style or of Substance?" Parliamentary Affairs 66.1, 2013. 179-96. Web.

Strauss, Leo. "German Nihilism" Interpretation. 26:3, 1999: 353-378. Print.

Strauss, Leo. "Political Philosophy and History." What Is Political Philosophy? and Other Studies. Glencoe, IL: Free, 1959. Print.

Tharoor, Ishaan. "The Man Who Declared the 'end of History' Fears for Democracy's Future." The Washington Post. WP Company, 9 Feb. 2017. Web. 10 Feb. 2017. Web.

"The Guardian View on the French Elections: Front National Fails to Gain Power but Its Defeat Is Only Partial." Editorial. The Guardian. The Guardian, 14 Dec. 2014. Web.

Van der Brug, Wouter, and Meindert Fennema. "Causes of voting for the radical right." International Journal of Public Opinion Research 19.4, 2007: 474-487. Web.

Valls, Manuel. La République Mobilisée Contre Le Racisme Et L'anti-semitisme. Asembéle Nationale, Paris. 17 Apr. 2015. Orange.fr. Web.

$<\mathrm{http}$ //actu.orange.fr/politique/videos/francais-depuis-1-000-ans-manuel-valls-repond-ajean-marie-le-pen-VID0000001AxPx.html>.

Veugelers, John. "Social Cleavage and the Revival of Far Right Parties: The Case of France's National Front." Acta Sociologica 40.1. 1997. 31-49. Web.

Waterfield, Bruno. "Jean-Marie Le Pen Repeats Holocaust Comments in European Parliament." The Telegraph. N.p., 25 Mar. 2009. Web.

Whitte, Griff, Emily Rauhala, and Dom Phillips. "Trump's Win May Be Just the Beginning of a Global Populist Wave." Editorial. Washinton Post Online. The Washington Post, 18 Nov. 2016. Web.

Zemmour, Eric. "Grand Débat No 2." Interview by Anais Bouton. Zemmour Et Naulleau. M6. Paris, France, 09 Mar. 2016. Television

Zemmour, Eric. "Immigration: Zemmour Dérapé." Interview by Thierry Ardisson. Salut Les Terriens. Canal+. Paris, France, 06 Mar. 2010. Television

Zemmour, Eric. Interview by Léa Salamé. On N'est Pas Couché. France 2. Paris, France, 04 Oct. 2014. Television

Zemmour, Eric. Le Premier Sexe. Paris: Denoël, 2006. Print.

Zemmour, Eric. Le Suicide Francais. Paris: Albin Michel Litterature, 2014. Print 